Florida International University FIU Digital Commons

\title{
Investigating the Effects of Cognitive Apprenticeship-Based Instructional Coaching on Science Teaching Efficacy Beliefs
}

Teo O.H. Cooper

Florida International University, tohcooper@gmail.com

DOI: $10.25148 /$ etd.FI15032165

Follow this and additional works at: https:// digitalcommons.fiu.edu/etd

Part of the Elementary Education and Teaching Commons, Other Teacher Education and Professional Development Commons, and the Science and Mathematics Education Commons

\section{Recommended Citation}

Cooper, Teo O.H., "Investigating the Effects of Cognitive Apprenticeship-Based Instructional Coaching on Science Teaching Efficacy Beliefs" (2015). FIU Electronic Theses and Dissertations. 1779.

https://digitalcommons.fiu.edu/etd/1779 


\section{FLORIDA INTERNATIONAL UNIVERSITY \\ Miami, Florida}

\section{INVESTIGATING THE EFFECTS OF COGNITIVE APPRENTICESHIP-BASED \\ INSTRUCTIONAL COACHING ON SCIENCE TEACHING EFFICACY BELIEFS}

A dissertation submitted in partial fulfillment of the

requirements for the degree of

DOCTOR OF EDUCATION

in

CURRICULUM \& INSTRUCTION

by

Teo O.H. Cooper 
To: $\quad$ Dean Delia C. Garcia

College of Education

This dissertation, written by Teo O.H. Cooper, and entitled Investigating the Effects of Cognitive Apprenticeship-Based Instructional Coaching on Science Teaching Efficacy Beliefs, having been approved in respect to style and intellectual content, is referred to you for judgment.

We have read this dissertation and recommend that it be approved.

$\begin{array}{r}\text { Mido Chang } \\ \hline \text { Dennis Wiedman } \\ \hline \text { George O’Brien } \\ \hline \text { Eric Brewe, Major Professor }\end{array}$

Date of Defense: March 18, 2015

The dissertation of Teo O.H. Cooper is approved.

Dean Delia C. Garcia College of Education

Dean Lakshmi N. Reddi

University Graduate School

Florida International University, 2015 
(C) Copyright 2015 by Teo O.H. Cooper

All rights reserved. 


\section{DEDICATION}

I dedicate this dissertation to the memory of my professional mentor, Dr. Helen Ellison, Former Associate Vice President for Student Affairs at Florida International University. Her incredible love, advocacy and support tremendously influenced my career and have made my master's and doctoral studies possible. 


\section{ACKNOWLEDGMENTS}

As I write this acknowledgment, I am moved by a deep sense of gratefulness to all who have helped me achieve this milestone. As a first generation college student and the first in my family to obtain a doctorate degree, this accomplishment is momentous and significant on many levels.

I begin by expressing sincerest appreciation to my major professor, Dr. Eric Brewe. Thank you for believing in my ability. Your tough coaching during this process stretched me to produce to my greatest potential in this dissertation. Also, to my hardworking and dedicated committee members: Dr. Mido Chang, Dr. Dennis Wiedman, and Dr. George O’Brien, thank you for your outstanding mentorship, instruction, and guidance. A special thanks to the students of my science methodology class (EDU 363 Fall 2013), and the five committed inservice teachers who served as participants in my studies_-without you this would not be possible.

I am very indebted to my siblings, Tara and Tyrone; my extended, adopted, and church families (especially my adoptive parents); and my special friends and encouraging colleagues for your tangible assistance, kind words, phone calls, email, and messages of love and support. A special thanks to my former professor, and now colleague and mentor, Dr. Thalia Micklewhite, I appreciate your invaluable support in helping me get through this dissertation while working and starting out as a new member of the faculty. I also express great appreciation to Dr. Ruth Sumner (College/University of The Bahamas), Ms. Jennifer Isaacs-Dotson (College/University of The Bahamas), and Ms. Elena Cruz (Florida International University) for the significant roles you played in helping to make this dissertation and my professional goals a reality. Sincerest 
appreciation is also extended to all of the donors and individuals whose financial contributions helped to make my studies possible.

I would be remiss if I failed to express my gratitude for my birth parents, Moses and Annaville Cooper (deceased), who gave me the life that enables me to be the best I could be. Above all, my most sincere appreciation is to my heavenly father, and to my Lord and Savior, Jesus Christ. It is truly your divine favor, strength, and provisions which empowers me to live a purpose-driven life. 


\begin{abstract}
OF THE DISSERTATION
INVESTIGATING THE EFFECTS OF COGNITIVE APPRENTICESHIP-BASED

INSTRUCTIONAL COACHING ON SCIENCE TEACHING EFFICACY BELIEFS
\end{abstract}

by

Teo O.H. Cooper

Florida International University, 2015

Miami, Florida

Professor Eric Brewe, Major Professor

The overall purpose of this collected papers dissertation was to examine the utility of a cognitive apprenticeship-based instructional coaching (CAIC) model for improving the science teaching efficacy beliefs (STEB) of preservice and inservice elementary teachers. Many of these teachers perceive science as a difficult subject and feel inadequately prepared to teach it. However, teacher efficacy beliefs have been noted as the strongest indicator of teacher quality, the variable most highly correlated with student achievement outcomes. The literature is scarce on strong, evidence-based theoretical models for improving STEB.

This dissertation is comprised of two studies. STUDY \#1 was a sequential explanatory mixed-methods study investigating the impact of a reformed CAIC elementary science methods course on the STEB of 26 preservice teachers. Data were collected using the Science Teaching Efficacy Belief Instrument (STEBI-B) and from six post-course interviews. A statistically significant increase in STEB was observed in the quantitative strand. The qualitative data suggested that the preservice teachers perceived 
all of the CAIC methods as influential, but the significance of each method depended on their unique needs and abilities.

STUDY \#2 was a participatory action research case study exploring the utility of a CAIC professional development program for improving the STEB of five Bahamian inservice teachers and their competency in implementing an inquiry-based curriculum. Data were collected from pre- and post-interviews and two focus group interviews. Overall, the inservice teachers perceived the intervention as highly effective. The scaffolding and coaching were the CAIC methods portrayed as most influential in developing their STEB, highlighting the importance of interpersonal relationship aspects in successful instructional coaching programs. The teachers also described the CAIC approach as integral in supporting their learning to implement the new inquiry-based curriculum.

The overall findings hold important implications for science education reform, including its potential to influence how preservice teacher training and inservice teacher professional development in science are perceived and implemented. Additionally, given the noteworthy results obtained over the relatively short durations, CAIC interventions may also provide an effective means of achieving improvements in preservice and inservice teachers’ STEB more expeditiously than traditional approaches. 
TABLE OF CONTENTS

CHAPTER

PAGE

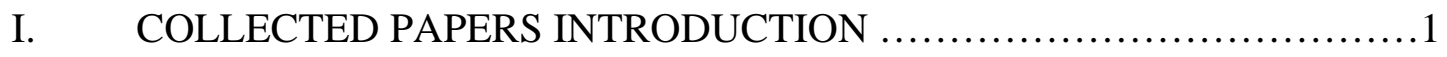

Statement of the Problem ..................................................

Overview of Dissertation ................................................

Statement of Purpose ..................................................11

Research Questions ...................................................13

Methodological Overview ............................................13

Theoretical and Conceptual Overview ..................................14

Self-Efficacy Beliefs ..............................................14

Cognitive Apprenticeship Theory ...................................15

Cognitive Apprenticeship-Based Instructional Coaching ................17

Overview of Collected Papers ............................................18

Significance of Collected Papers Research ................................28

Chapters of the Dissertation ................................................

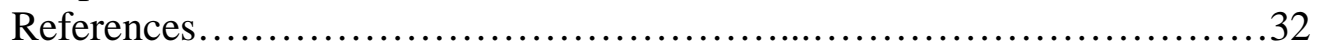

II. STUDY \#1, EXPLANATORY MIXED-METHODS-THE EFFECTS OF A COGNITIVE APPRENTICESHIP-BASED INSTRUCTIONAL COACHING METHODS COURSE ON THE SCIENCE TEACHING EFFICACY BELIEFS OF ELEMENTARY PRESERVICE TEACHERS ...37

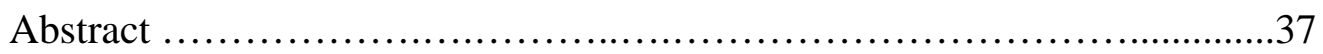

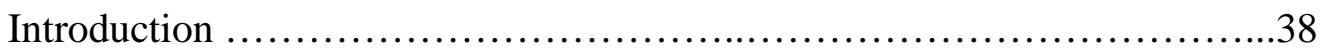

Conceptual Framework ….............................................. 41

Research Purpose and Question ........................................43

Theoretical Framework ...............................................43

Description of Intervention ..........................................44

Methodology ............................................................ 47

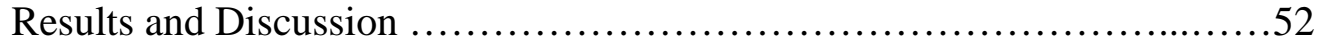

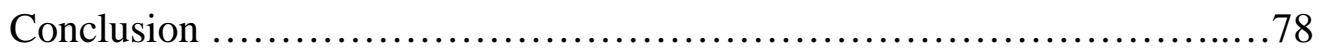

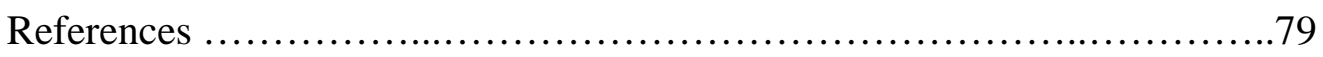

III. STUDY \#2, PARTICIPATORY ACTION RESEARCH CASE STUDYTHE UTILITY OF COGNITIVE APPRENTICESHIP-BASED

INSTRUCTIONAL COACHING FOR IMPROVING SCIENCE

TEACHING EFFICACY BELIEFS AND COMPETENCY IN

IMPLEMENTING AN INQUIRY-BASED CURRICULUM AMONG

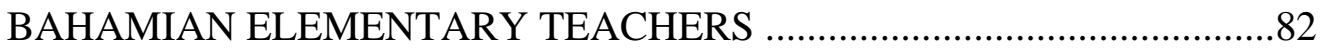

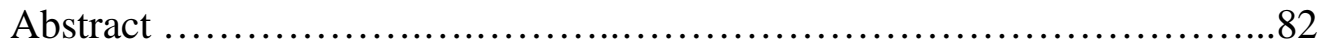

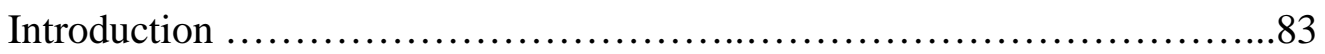

Research Purpose and Question ........................................86

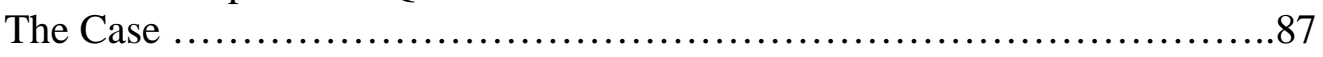

Theoretical and Conceptual Framework ….............................99 
Review of Literature ..............................................92

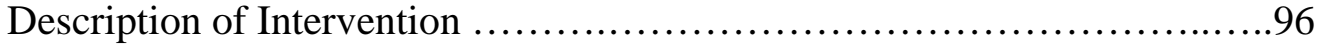

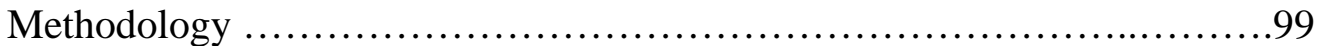

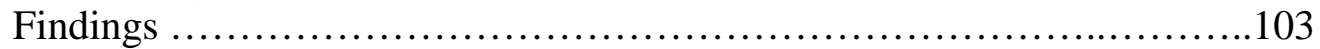

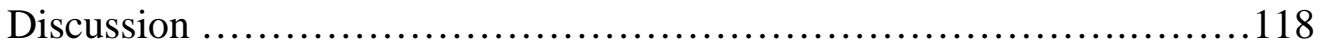

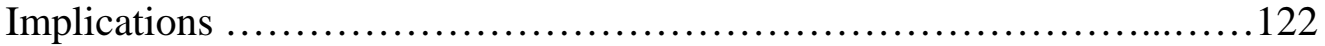

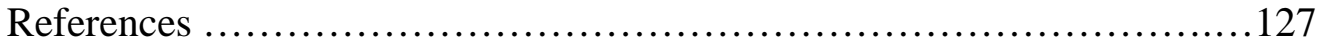

IV. TOWARDS AN EFFECTIVE MODEL FOR IMPROVING SCIENCE TEACHING EFFICACY BELIEFS THROUGH COGNITIVE APPRENTICESHIP-BASED INSTRUCTIONAL COACHING ..............131

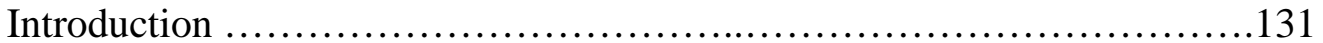

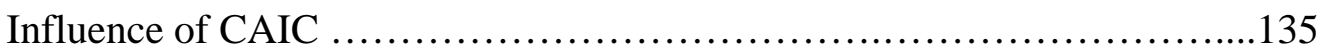

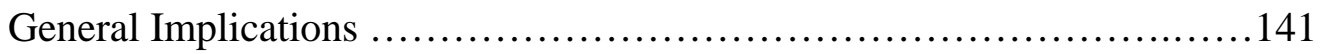

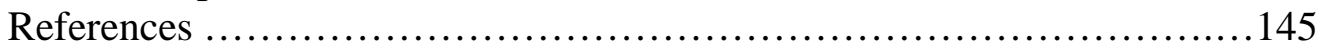

VITA............................................................................ 


\section{LIST OF TABLES}

TABLE

PAGE

Table 1. Collected Papers Studies 1 and 2........................................19

Table 2. Conceptual relationship between aspects of the methods course and theories employed.

Table 3. Reliability Statistics for PSTE and STOE from each administration of the STEBI-B

Table 4. Descriptive statistics of means of PSTE and STOE from the four measure......54

Table 5. Multivariate Test of significance of the difference between group means........54

Table 6. Mauchly's Test for data violation of the Repeated Measures ANOVA Sphericity assumption

Table 7. Tests of Within-Subjects Effects for significance in the difference between mean scores.

Table 8. Tests of Within-Subjects Contrasts for significant geometrical patterns in the Data

Table 9. Tests of Between-Subjects Effects for differences in scores between Participants

Table 10. Paired samples $t$-test of changes in PSTE over the three intervals measured after the baseline

Table 11. Descriptive statistics of means of internship and non-internship student

Table 12. Independent samples $t$-test of difference in internship and non-internship students' means

Table 13. Categories/themes regarding preservice teachers' experiences.................61

Table 14. Categories/themes regarding aspects of methods course......................66

Table 15. Conceptual relationship between aspects of the methods course and theories employed....

Table 16. Findings on influence of CAIC methods on science teaching efficacy Beliefs 
Table 17. Findings on influence of CAIC on inquiry-based curriculum

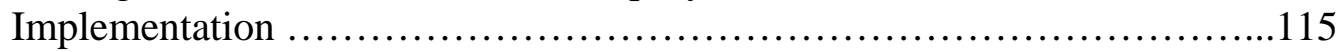




\section{COLLECTED PAPERS INTRODUCTION}

\section{Background to the Problem}

Capacity in science and technology is a key element in economic and social development. Promoting science education at all educational levels, and scientific literacy in society in general, is a fundamental building block to building a country's capacity in science and technology.

- United Nations Educational Scientific Cultural Organization (Science Ed. Programme, n.d., para.1)

Science education reform issues have gained global prominence in recent decades. The narrative above echoes a sense of urgency to promote science education, as heralded by the United Nations Educational Scientific Cultural Organization (UNESCO), the leading international scientific organization. It was John Dewey, the famous American education philosopher, who posited that the goal of education should be to train students to live and work in a progressive society, which is one that is continuously evolving and advancing for the better. To this end, it becomes imperative that governments provide a relevant education for citizens geared specifically towards economic and social advancement, as well as towards meeting national needs. Despite the need for more scientists and engineers globally, there has been a marked decrease in the number of students pursuing careers in the sciences in recent decades. UNESCO indicated that "the steady decline of enrollment of young people in science is cause for concern” (Science Education, para. 1). Consequently, this trend has prompted many countries around the world to channel increasing resources toward improving K-12 science education. 


\section{Science Education and Reform in The Bahamas}

The literature is scarce on developments in science education reform in The Bahamas. Presently, science is offered to Bahamian students in the lower elementary grades (Grades 1-3) as part of an interdisciplinary curriculum along with other social subject areas such as; religious and social studies. However, a pure science curriculum is mandatory for students in the upper elementary grades (Grades 4-6). In junior high school (Grades 7-9), students take a 3-year general or/and health science curriculum that leads into pursuing a mandatory 3-year biology or combined science curriculum in high school (Grades 10-12). Other science subjects such as chemistry and physics, are only available to high school students who choose science as their academic major concentration. Over

the last 5 years, the government invested large sums of money into revising these science curricula at all levels to reflect current trends in science education and to make them more inquiry-based. The new elementary curriculum, The Bahamas Primary Science Curriculum, was revised in 2010 to become fully inquiry-based. However, several issues have surfaced with regards to implementing the new curriculum documents, such as inadequate resources and the lack of appropriate preservice and inservice teacher training to implement them.

Nevertheless, it is apparent that science education has become a greater national priority in The Bahamas in recent years. In 2010, a special committee was convened by the Bahamas Environment Science and Technology (BEST) commission to assess the state of science and technology education in the country and the outcome was a document entitled, Bahamas Roadmap for Science and Technology (2010). This landmark document emphasized the dire national need for greater research capacity in science and 
science education. It also highlighted the need to "expand opportunities for teacher upgrading, with greater emphasis being placed on current trends in S \& T [science and technology] Education. This should include pre-service and in-service training” (Curling et al., 2010, p. 24). As a result, the Department of Education (DOE) began exploring new initiatives to enhance preservice teacher training and inservice teacher professional development in science. For example, in a direct effort to combat present shortcomings in science achievement outcomes at the elementary level, the DOE placed a number of science specialists and coordinators in some local schools within the last five years. Most of the specialist teachers hold degrees in elementary education; however, a few have degrees in secondary science education. The specialists are responsible for teaching the science curriculum to students in the upper grades (Grades 4-6) only. Coordinators, on the other hand, are elementary generalist teachers identified as being strong in science teaching, and are intended to provide instructional support to teachers in the lower grade level (Grades 1-3). This responsibility is in addition to performing their duties as fulltime classroom teachers.

\section{Science Education and Reform in the United States}

In the United States (U.S.), there is substantially more literature on developments in science education. After the 1957 launch of the Sputnik satellite by the former Soviet Union, new curricula were developed, national and state science education standards were established, and a plethora of research and best-practices in student and teacher learning began to emerge as part of the wider science education reform efforts (Pea \& Collins, 2008). Additionally, results from several national and international studies, 
including the Trends in International Mathematics and Science Study (TIMMS) and the National Assessment of Educational Progress (NEAP), suggested numerous deficiencies in K-12 science achievement in the U.S. (Zucker, 1997) and many other countries as well (Loveless, 2013). These studies became further impetuses for a myriad of subsequent science education reform initiatives globally from the late 1990s to the present. In the U.S., several new pieces of legislation mandated states to actively adhere to, and enact new policies and programs to directly address this concern for improving the quality of science education. The National Defense Act (1957), the Elementary and Secondary Education Act (1965), and the No Child Left Behind Act (2001) all pumped large sums of money into strengthening mathematics and science education in U.S. The No Child Left Behind Act (NCLB) of 2001 also ushered in an accountability component to science education reform efforts by mandating all states to implement standardized testing in science (Lord, 2006).

Prior to NCLB, researchers in several studies had identified "teacher quality" as the school characteristic having the highest correlation with student achievement outcomes (Darling-Hammond, 2000; Haycock, 1998; Wright, Horn, \& Sanders, 1997). As a result, NCLB also required school districts to only hire "highly qualified" teachers in math and science. That is, they must have "a degree in their core subject as well as certification” (Lord, 2006, p. 1)—which led to significant changes in science teacher preparation, certification, and professional development. Pea and Collins (2008) identified four waves of science education reforms in the U.S. from the 1950s to the present. The three early reform waves were characterized by a focus on developing curricula (1950s - 1960s), student learning and cognition (1960s - Early 1980s), and 
national and state standards (Late 1980s - 1990s) respectively. The current fourth wave, according to Pea and Collins (2008), focuses on a systemic approach to improving science education. This involves a concentration on the aggregate of variables inherent in K-12 science education as opposed to only focusing on individual components, as was done in the previous reform waves. Systemic science education reform is geared towards coordinating curriculum design, activities, learning tools, assessments, and teacher professional development (Pea \& Collins, 2008). As such, this new paradigm has placed classroom teachers and their instructional practices at the center of the present science education reform movement.

\section{Professional Development and Instructional Coaching}

Increasingly, professional development literature and research continue to emphasize the significant link between teacher quality and persistent student achievement gains (Coble \& Azordegan, 2004; Warren, 2008). Acknowledging that real educational change occurs at the classroom level, policymakers globally are investing more resources into professional development for preservice and inservice teachers as a means of improving instructional practice towards ultimately improving student achievement. Teacher professional development also became a critical focus because inservice teachers during this period were found to be engaging in minimal amounts of professional development. For example in the U.S., "only 9 to $15 \%$ of elementary teachers reported participating in more than 35 hours of professional development in the last three years” (Wicker, 2006, p. 2). Inadequate professional development significantly impedes the ability of educators, particularly in constantly evolving fields like science education, to 
keep up with the latest developments in scientific knowledge and instructional bestpractices.

Seminal researchers Joyce and Showers (1980) had long suggested that traditional models of teacher professional development were largely ineffective. They found that the traditional models, which involved presenting and demonstrating theories during seminars, yielded at most an average of $10 \%$ transferability into practice. However, Joyce and Showers reported that upwards of " $90 \%$ of learners will transfer a new skill into their practice as a result of theory, demonstration, practice, and corrective feedback during the training when it is followed up with job-embedded coaching” (UC Davis, 2013). Consequently, many job-embedded models of professional development began to emerge in the U.S. As part of the 2003-2004 standards for professional development, the National Staff Development Council recommended that the school be the center for individual and collective professional learning. This triggered an influx of innovative professional development initiatives in schools across the U.S. in the early 2000s as key components of this new "systemic reform” agenda promoting school-based professional development. Science instructional coaching as a means of job-embedded professional development for teachers was one such program that emerged during this period.

According to Knight (2009), an instructional coach "partners with teachers to help them incorporate research-based instructional practices into their teaching which help students learn more effectively” (p. 30). Instructional coaching programs have now been widely implemented in school districts throughout the U.S. In 2008, Cornett and Knight noted that "there are currently more than 2,100 full-time coaches in Florida alone" (p. 2). In some school districts coaches work with teachers across disciplines, and in others they 
provide specific instructional support only in the content areas. Some preliminary research on instructional coaching indicated many benefits, including its potential to: provide a link between teachers and administrators (Baker, 2010), improve teacher selfefficacy (Scurry, 2010), improve teacher reflection (Reed, 2006), enhance teachers’ emotional intelligence (Avant, 2012), and foster effective collaboration in communities of practice (Wicker, 2006). However, in other studies, instructional coaching programs were found to have fallen short of their intended goals due to several missteps and important oversights during the process of implementation (Denton \& Hasbrouck, 2009).

\section{Statement of the Problem}

Science education in The Bahamas. Though valiant efforts have been made by the Bahamas Government and the local Department of Education (DOE) to reform science education in the country, student achievement outcomes in science remain at an all-time low. Little is known about the design and delivery of the only elementary preservice teacher science methods course at the primary teacher training institution in The Bahamas. The course had been deemed to be antiquated and irrelevant because, to date, the latest formal revision of the course outline was completed in 1996. Many elementary teachers leave this course feeling insufficiently prepared to teach science effectively, which is also reflected in one of the studies in this dissertation. Hence, research is needed to inform present and future revisions of this course and provide reform and evidence-based approaches to preservice teacher training in science. Many of the science specialists recently introduced in elementary schools themselves feel inadequately prepared to teach science effectively and to implement the new inquiry- 
based curriculum. The coordinators, like the specialists, are full-time classroom teachers and have very little time to assist other teachers outside of a limited number professional days per year. They also do not feel adequately prepared to facilitate teacher learning as they too have little support and training in carrying out their responsibilities.

Many people remain skeptical about the effectiveness of the science specialist intervention and about the potentially adverse long-term implications that it can have on the science teaching efficacy of the other teachers in the upper elementary grades who do not teach science. This is particularly problematic as teachers in Bahamian public schools are civil servants, who are likely to be transferred at any given time to a school where this new innovation may not have been enacted and would therefore be expected then to teach science. Finally, there is a great paucity of quality professional development opportunities for Bahamian elementary teachers, particularly in science. As a result, many have become apathetic towards the professional development workshops offered at their local schools or through the DOE. Research on more efficient means of providing quality job-embedded professional development for Bahamian teachers in science is needed. Therefore, similar instructional coaching interventions as presently employed in the U.S. may provide a framework not only for inservice teacher professional development but potentially for preservice teacher training as well.

Instructional Coaching in the U.S. More than three decades since the Joyce and Showers (1980) findings and more than two decades since instructional coaching became prominent, there remain more questions than answers regarding the effectiveness of instructional coaching. The results of studies attempting to link instructional coaching to 
student achievement were inconclusive (Hearn, 2010; Sumner, 2011). Researchers in some studies reported positive outcomes with regards to improved teacher self-efficacy as a result of instructional coaching (Scurry, 2010), but there is a scarcity of research linking instructional coaching directly to improved teaching practice (Horne, 2012). Consequently, in an era of increasing accountability at all levels, the benefits of instructional coaching programs have come under substantial scrutiny. The inability of instructional coaching programs to deliver on the empirical demands and expectations of policymakers, by even marginally linking instructional coaching to student achievement outcomes or improved teacher practice, has led many schools and school districts to discontinue their coaching programs (Hearn, 2010, Trombly 2012).

Structural and theoretical issues present perhaps the greatest challenge in providing strong empirical evidence of successful instructional coaching programs in the literature. Researchers studying instructional coaching programs are often hampered by the fact that the structures of instructional coaching programs vary significantly in how they are implemented between school districts and even from school to school. In some school districts, one general instructional coach may be assigned to each school, whereas in others, coaches may move between schools or each school may have several content area coaches. Numerous theoretical approaches to coaching also appear in the literature, including cognitive coaching and peer-coaching. These variations make it difficult to compare outcomes, as different approaches will inevitably yield different results, and therefore invalidate any generalizations which can be made about their success or failure (Hearn, 2010). Further, many of those studies failed to provide adequate information about the theoretical model of coaching used to allow for cross-validation. 
Many studies on the impact of coaching have also failed to take into account the nuances of the local context in which it is being implemented. It is not judicious to evaluate the success or effectiveness of instructional coaching or any reform innovation divorced from its context of implementation. Hence, the role of accountability measures in any reform initiative in schools must be juxtaposed with the nuances of its local context if any valid conclusions about the reform's merit can be asserted (Trombly, 2012). Schools and school districts infamously initiate many promising programs annually, which are often prematurely discontinued when they are unable to produce significant results in the short-term. Consequently, many school districts go through program after program, leading teachers to become cynical when future initiatives are introduced. The reality is that school reform and change take time. Ideally, new initiatives should be given time to be assimilated, validated, and refined before they are widely implemented—which most often does not happen.

Denton and Hasbrouck (2009) reported that, “unfortunately, the rush to implement coaching before strong theoretical models, or even well-defined job descriptions, were in place has caused a good deal of confusion related to the role and focus of coaching” (p. 155). Very little is known about instructional coaches, what they do, and how they do it. To this end, more robust empirical studies are needed to identify strong theoretical models which provide more effective and relevant approaches to implementing and exploiting the potential of instructional coaching as a useful tool in preservice teacher learning and inservice teacher professional development. 


\section{Overview of Dissertation}

Statement of Purpose. The purpose of this collected papers dissertation comprised of two scholarly papers was to examine the utility of instructional coaching interventions developed and implemented using Cognitive Apprenticeship (Collins, Brown, \& Newman, 1989) as a theoretical model to improve the science teaching efficacy beliefs of preservice and inservice elementary teachers. In so doing, it contributes to the literature on improving preservice and inservice teacher quality outcomes towards ultimately improving student achievement results in schools.

An essential goal of instructional coaching in science is to improve teaching efficacy relative to implementing curricula and pedagogical best-practices (Knight, 2009). Teaching efficacy refers to the ability of teachers to effectively implement curricula and instructional best-practices. It has been cited by many researchers as the teacher characteristic that most positively correlates with student achievement outcomes (Ashton, 1984; Scharmann \& Hampton, 1995). According to Bandura (1986), an individual's efficacy belief is the greatest predictor of personal effectiveness. Thus, teachers with greater confidence in their ability to be effective are the most likely to succeed in the classroom. The concept of science teaching efficacy beliefs is derived from Bandura’s (1986) construct of self-efficacy beliefs and refers to an individual's selfperceived ability to teach science effectively. Therefore, research focused on developing strong interventions to positively influence science teaching efficacy beliefs towards increasing science teacher efficacy at all levels is both desirable and imperative.

These collected papers also considered and sought to address many of the empirical and theoretical issues identified in the literature with implementing coaching 
studies and interventions. First, these studies did not merely focus on the relationship between instructional coaching and the broad construct of self-efficacy beliefs. Rather, they were focused on instructional coaching and teaching efficacy beliefs specifically, which is the variable most significantly tied to teachers' practice outcomes. Second, in addition to looking at teacher efficacy beliefs, the second study in this dissertation also looked at the potential influence of instructional coaching on teachers' competency in implementing inquiry-based curricula, which is the most important function of teacher practice in reform-based science classrooms. Therefore, the studies in this dissertation attempted to form empirical links between instructional coaching practices and both the teaching efficacy beliefs and teacher classroom practice outcomes of preservice and inservice teachers of science.

Third, this dissertation is also significant because the studies were centered on coaching through one explicit theoretical model, cognitive apprenticeship-based instructional coaching (CAIC), in the science content area. The model is uniquely built on a set of coaching methods which can be utilized by content area coaches who work both within and between schools and also by college science methods instructors who may want to integrate instructional coaching in the training of preservice teachers. All aspects of the coaching interventions are clearly outlined in the studies so that there is no ambiguity about how they were implemented. Fourth, pertinent background information was provided in both studies to help readers understand the nuances of the local contexts of implementation, so they were able to accurately make judgments about the relevance of the findings to their unique settings. Finally, because of the demand for more interventions with potential to produce results over the short-term, the studies in this 
dissertation were undertaken over relatively short durations to determine what might be achieved within these timeframes.

Research Questions. The three guiding research questions of this dissertation were:

1. Is there a change in the science teaching efficacy beliefs of Bahamian preservice elementary teachers who participate in a methods course delivered using a cognitive apprenticeship-based instructional coaching approach?

2. From their perspectives, how do Bahamian preservice elementary teachers describe their experiences in a methods course delivered using cognitive apprenticeship-based instructional coaching and the effects of the cognitive apprenticeship-based instructional coaching methods on their science teaching efficacy beliefs?

3. From the perspectives of Bahamian inservice elementary teachers, how did participating in a cognitive apprenticeship-based instructional coaching program influence their science teaching efficacy beliefs and ability to implement inquirybased curricula?

Methodological Overview. Overall, this dissertation employed a mixed methods research design (Tashakkori \& Teddlie, 2003). According to Newman, Newman, and Newman (2010), “mixed methodology is an integrated approach that has increased in use and desirability over the past twenty years” (p. 192). Specifically, the overall dissertation employed a convergent parallel mixed methods design, where "the researcher uses concurrent timing to implement the quantitative and qualitative strands during the same phase of the research process, prioritizes the methods equally, and keeps the strands 
independent during analysis and then mixes the results during the overall interpretation” (Creswell \& Plano, 2007, pp. 70-71). Using this design, the researcher was informed through the collection of both qualitative and quantitative data, and meta-inferences were made by comparing the findings of the qualitative and quantitative components both papers in this dissertation (Newman et al., 2010).

Moreover, mixed methods became the optimal choice because of the purpose of this dissertation and the nature of the research questions posed (Newman et al., 2010). The first question warranted quantitative methods of inquiry because the researcher intended to measure growth over time due to the intervention. However, to answer the remaining two questions, qualitative tools were desirable so participants were able to adequately describe their experiences with the cognitive apprenticeship-based instructional coaching interventions.

\section{Theoretical and Conceptual Overview}

In this section, I broadly summarize the concept of self-efficacy beliefs and cognitive apprenticeship theory. Then, I propose and discuss how the instructional coaching using cognitive apprenticeship as a theoretical model can potentially increase science teaching efficacy beliefs.

Self-Efficacy Beliefs. Alfred Bandura proposed social cognitive theory with the publication of Social Foundations of Thought and Action: A Social Cognitive Theory in 1986. As an advancement of his earlier work on Social Learning Theory, this new paradigm postulated, "that learning occurs in a social context with a dynamic and reciprocal interaction of the person, environment, and behavior” (Boston University 
School of Public Health, 2013, para. 1). That is, learning and cognition transpires actively through the complex interplay of personal, environmental, and behavioral factors. At the heart of Bandura's theory is the concept of self-efficacy beliefs, that is, “one’s belief in one’s own ability to successfully perform a specific task” (Lakshmanan, Heath, Perlmutter, \& Elder, 2010, p. 534). Hence, the degree to which individuals are inclined to engage in specific tasks is largely determined by their beliefs about their ability to complete that task successfully (i.e. self-efficacy beliefs). The construct, science teaching efficacy beliefs, was derived from self-efficacy belief and refers specifically to teachers' beliefs about their ability to teach a given content area effectively.

In his social cognitive theory, Bandura (1977) theorized that there are four sources of self-efficacy beliefs development (and therefore, science teaching efficacy beliefs as well): mastery experience, vicarious experiences, social and verbal persuasion, and the individual's physical and emotional well-being. Mastery experiences, he noted, were the most influential on developing self-efficacy beliefs. A number of education researchers have documented a highly significant positive relationship between teacher self-efficacy beliefs and student achievement outcomes (Mahmoee \& Pirkamali, 2013). As a result, many preservice teachers’ science methods courses and inservice teachers’ professional development initiatives are being developed with greater emphasis on positively influencing teaching efficacy beliefs.

Cognitive Apprenticeship Theory. The development of the interventions used in these collected papers were guided by the methods of cognitive apprenticeship theory (Collins, Brown, \& Newman, 1989). Cognitive apprenticeship theory provides a 
framework for teaching the pertinent thinking and problem-solving skills needed for mastery at a given task. The task in this case is teaching science effectively. Also, "apprenticeship embeds the learning of skills and knowledge in their social and functional context” (Collins et al., 1989, p. 454). Therefore, unlike many traditional approaches to teacher learning and professional development, these interventions engage preservice and inservice teachers in learning contextually relevant thinking, reasoning, and instructional decision-making skills involved in science teaching, rather than simply learning how to transmit science as a generic product.

According to Collins et al. (1989), "cognitive apprenticeship refers to the focus on learning-through-guided-experience, on cognitive and metacognitive, rather than physical skills and processes” (p. 457). The methods of cognitive apprenticeship theory are modeling, coaching, scaffolding, articulation and reflection, and exploration. Collins (2006) defined these methods as follows:

Modeling involves an expert performing a task so that the students can observe and build a conceptual model of the processes that are required to accomplish it. Coaching consists of observing students while they carry out a task and offering hints, challenges, scaffolding, feedback, modeling, reminders, and new tasks aimed at bringing their performance closer to expert performance. Scaffolding refers to support the teacher provides to help students carry out tasks. Articulation includes any method of getting students to explicitly state their knowledge, reasoning, or problem-solving processes in a domain. Reflection involves enabling student to compare their own problem solving processes with those of an expert, another students, and ultimately, an internal cognitive model of expertise. 
Exploration involves guiding students to a mode of problem solving on their own. (pp. 50-51)

Finally, cognitive apprenticeship learning often occurs within authentic Communities of Practice (Wenger, 1998). That is, it involves collaborative learning groups. The preservice teachers in the first study in this dissertation worked in cooperative learning groups throughout the semester, whereas the inservice teachers in the second study worked together with each other and the instructional coach as a professional learning community.

\section{Cognitive Apprenticeship-Based Instructional Coaching. Cognitive} apprenticeship theory (Collins, Brown \& Newman, 1989) provided a proficient model of delivering instructional coaching for the preservice teacher learning and inservice teacher professional development in this dissertation, which sought to positively influence science teaching efficacy beliefs. The cognitive apprenticeship-based instructional coaching approach is designed to teach the pertinent thinking and problem-solving skills needed for mastery in effective science teaching. This specific theory was applied to teacher learning and professional development in this dissertation because of its potential to foster the level of metacognition and self-reflection preservice and inservice teachers need to make keen instructional decisions about implementing new reform-based curricula, innovations, and practices.

Conceptually, the cognitive apprenticeship-based instructional coaching model is worthy of exploration for its utility in enhancing science teaching efficacy beliefs because it can be tailored to target each of Bandura's (1977) four main ways of increasing science 
teaching efficacy beliefs. The essence of instructional coaching using the cognitive apprenticeship (Collins et al., 1989) model involves engaging preservice and inservice teachers, as apprentices, in mastery learning experiences through guided practice. This is accomplished through a process involving modeling, coaching, scaffolding, and eventually fading of scaffolds as they gain mastery of tasks. This theoretical model of instructional coaching also encourages articulation of cognitive processes and reflection by the participants. This enables the instructional coaches, as the experts, to provide the appropriate support needed to directly improve science teaching efficacy beliefs and empower teachers to succeed in evidence-based science teaching and learning.

Cognitive apprenticeship-based instructional coaching takes place within communities of practice via cooperative learning groups and professional learning communities. This constant interaction provides vicarious experiences for participants where they can learn from each other and from the instructional coach through direct observation. This approach to instructional coaching also inherently creates a supportive and encouraging learning environment that is conducive to fostering science teaching efficacy beliefs development through social and verbal persuasion. Additionally, as for the preservice and inservice teachers' social and emotional well-being (the fourth element), collective engagement has been shown to reduce anxiety and maintain motivation (Ashton, 1984).

\section{Overview of Collected Papers}

This dissertation is written in the collected papers format, comprising of two scholarly papers investigating the utility of cognitive apprenticeship-based instructional 
coaching as a means of increasing the science teaching efficacy beliefs (STEB) of elementary preservice and inservice teachers. Table 1 illustrates the running titles, methods, and publication outlets for each article. It is followed by a detailed description of each study.

Table 1

Collected Papers Studies 1 and 2

\begin{tabular}{|c|c|c|}
\hline Running Title & Method & Publication Outlet \\
\hline $\begin{array}{l}\text { STUDY \#1: The effects of a } \\
\text { Cognitive Apprenticeship- } \\
\text { based instructional coaching } \\
\text { methods course on the } \\
\text { science teaching efficacy } \\
\text { beliefs of elementary } \\
\text { preservice teachers }\end{array}$ & $\begin{array}{l}\text { Sequential explanatory } \\
\text { mixed methods (Tashakkori } \\
\text { \& Teddlie, 2003) }\end{array}$ & $\begin{array}{l}\text { Journal of Science Teacher } \\
\text { Education } \\
\text { To be submitted for review } \\
\text { after this dissertation is } \\
\text { published. }\end{array}$ \\
\hline $\begin{array}{l}\text { STUDY \#2: The utility of } \\
\text { Cognitive Apprenticeship- } \\
\text { based instructional coaching } \\
\text { for improving science } \\
\text { teaching efficacy beliefs and } \\
\text { competency in } \\
\text { implementing an inquiry- } \\
\text { based curriculum among } \\
\text { Bahamian elementary } \\
\text { teachers }\end{array}$ & $\begin{array}{l}\text { Participatory action } \\
\text { research case study } \\
\text { (Merriam, 2002) }\end{array}$ & $\begin{array}{l}\text { Journal of Research in } \\
\text { Science Teaching } \\
\text { Submitted: March 21, } 2015\end{array}$ \\
\hline
\end{tabular}

\section{Study \#1: Sequential Explanatory Mixed-Methods}

Introduction. Elementary preservice teacher learning in science became a critical focus of science education reform in recent decades. Traditional methods of teacher training are being abandoned in favor of newer strategies focused on increasing science teaching efficacy beliefs among elementary preservice teachers towards ultimately raising student achievement outcomes in science. According to Bandura (1977), mastery experience is the most significant way of influencing efficacy beliefs. Instructional coaching (Knight, 2009) is one emergent method of supporting in-service teachers as 
they engage in mastery experiences in implementing new evidence-based curricula and practices in schools. Numerous coaching approaches have been engaged as measures to facilitate inservice teacher professional development. However, a review of teacher training literature did not provide evidence of studies attempting to employ an instructional coaching approach to facilitating preservice teachers' learning to use evidence-based curricula, best-practices, and innovation to effectively teach science.

Purpose and Question. The purpose of this sequential explanatory mixed methods (Tashakkori \& Teddlie, 2003) study was to investigate the utility of a methods course designed and implemented using a cognitive apprenticeship theory-based (Collins, Brown, \& Newman, 1989) instructional coaching approach for improving the science teaching efficacy beliefs of Bahamian elementary preservice teachers. The study was guided by the following research questions:

1. Is there a change in the science teaching efficacy beliefs of Bahamian preservice elementary teachers who participate in a methods course delivered using a cognitive apprenticeship-based instructional coaching approach?

2. From their perspectives, how do Bahamian preservice elementary teachers describe their experiences in a methods course delivered using cognitive apprenticeship-based instructional coaching and the effects of the cognitive apprenticeship-based instructional coaching methods on their science teaching efficacy beliefs? 
Description of Intervention. The study involved 26 preservice teachers enrolled in a 14-week methods course on teaching science in the elementary school. During the semester, the researcher, as the course instructor, assumed the role of the instructorcoach. This mentoring approach provided a framework for supporting the preservice teachers as they learned reform-based practices in science education, in instructional decision-making skills, and the utilization of evidence-based tools to implement an inquiry-based curriculum. The instructor-coach modeled curriculum implementation through a 6-week, 1-hour Unit and Lesson Planning Workshop integrated within the class time.

Additionally, the instructor as coach modeled three lessons simultaneously making expert thinking and instructional decision-making visible during each aspect of the lessons' development. During the semester, preservice teachers were also engaged in authentic classroom cooperative learning activities called, skills, attitudes, and knowledge (SAK) presentations, designed as scaffolds for students. Further, as part of the methods course, each preservice teacher was required to deliver an in-class microteaching (or practice teaching) lesson at mid-semester to facilitate feedback from the instructor-coach. Their culminating task was a 5-week field teaching experience scheduled toward the end of the semester.

Method. The study employed a sequential explanatory mixed methods design (Tashakkori \& Teddlie, 2003) which involved independent quantitative and qualitative strands. The quantitative strand addressed the first research question using a preexperimental, one-group pre-test post-test research design. These pre-experimental designs lack a control group "are used quite frequently in field research" (Shadish, Cook, 
\& Campbell, 2002, p.104), especially when attempting to establish the utility of an intervention (Stock, 1999). "Single subject designs involve repeated, systematic measurement of a dependent variable before, during, and after the manipulation of an independent variable” (Stock, 1999, para. 3). The one-group pretest-posttest design employing repeated measures statistical analysis while controlling for plausible threats to internal validity to the greatest extent possible, followed by a series of paired samples $t$ tests, was determined to be adequate for this investigative study exploring the utility of this novel intervention.

Quantitative data were collected by administering the revised Science Teacher Efficacy Belief Instrument - Form B (STEBI-B) by Enoch and Riggs (2002) at equal intervals throughout and after the course. Reliability estimates of the instruments for this population were determined by calculating the alpha coefficients after each administration. Composite variables for personal science teaching efficacy (PSTE) and science teaching outcome expectancy (STOE) were calculated for each measure and analyzed using repeated measures analysis of variance (ANOVA) statistics to determine whether the variance in the four means were statistically significant. Finally, a series of paired samples $t$-tests were employed to determine if the differences, if any, in the means for PSTE between each administration periods were statistically significant.

The qualitative strand addressed the second research question. Data were collected through document analysis of the preservice teachers' end of year portfolio reflections and from six preservice teachers purposively selected to participate in a 50-60 minute post-course individual interview. The interviews were loosely guided by a set of open-ended questions asking about their experience during the methods course and how 
the cognitive apprenticeship-based instructional coaching methods used by the instructorcoach contributed to any changes in their PSTE beliefs. The qualitative analysis employed a number of manual coding procedures with the aide of NVivo 10. In first coding cycle, initial coding was used simultaneously with process coding (Saldana 2009). During the second coding cycle, focused coding was used to meaningfully categorize the codes, and then detailed memos were also written to ascertain the narratives embedded in each category. Finally, the data and memos in each category were analyzed inductively with a priori codes, for references pertaining to the preservice teachers' experiences in the course and their perceptions of the effects of the cognitive apprenticeship-based methods (coaching, modeling, scaffolding, articulation and reflection, and exploration) on their science teaching efficacy beliefs.

Findings. The quantitative findings showed a continuous statistically significant linear increase between the three measures of PSTE beliefs of the Bahamian preservice teachers from the baseline measure to the end of the course. However, a slight decrease in their PSTE beliefs was observed in the final measure but was determined as not statistically significant. The qualitative findings suggested that the preservice teachers' descriptions of their experience in the methods course were centered on discussing how the methods course influenced their attitudes and beliefs about science and science teaching and how they perceived they grew in areas such as self-confidence and teaching abilities. These findings also suggested that generally the preservice teachers perceived that all of the cognitive apprenticeship-based instructional coaching methods positively 
influenced their PSTE, but respective individuals valued them differently depending on their unique needs and perceptions of their own levels of science teaching efficacy.

Publication Formatting and Submission. This journal article will be submitted to the Journal of Science Teacher Education (JSTE), the lead publication of Association for Science Teacher Education. This journal was selected because of its keen emphasis on publishing quality empirical research on science teacher preparation. The Journal of Science Teacher Education follows the American Psychological Association (APA) guidelines. However, it required that in-text citations should only include the name and year. Therefore direct quotations in the article do not specify page numbers. This article will be altered to fit the journal's 25-page requirements and submitted for consideration shortly after this dissertation is published.

\section{Study \#2: Participatory Action Research Case Study}

Introduction. Despite the numerous advances in science education reform, "both pre-service and inservice teachers perceive science as a difficult subject and feel themselves inadequately prepared to teach science in elementary schools” (Yilmaz \& Huyuguzel Cavas, 2008, p. 45). In The Bahamas, a national commission was convened to look at the state of science education and recommended that greater emphasis be placed on professional development in science for inservice teachers (Curling et al., 2010). A similar call was also made in the United States by the National Staff Development Council (2001), and resulted in job-embedded professional development becoming a key focus of the current "systemic" science education reform movement. Instructional coaching became one widely implemented approach to providing job-embedded support 
to teachers in U.S. schools as they implement evidence-based curricula and practices in schools in the areas of reading, mathematics, and science predominantly. Many researchers have reported instructional coaching as promising, and therefore it may provide a viable option for meeting the professional development needs in The Bahamas as well. However, though coaching in principle has proven to be a very effective means of professional development (Joyce \& Showers, 1980), the rush to implement instructional coaching professional development programs without strong theoretical models has caused them to fall short of their intended goal of influencing teaching efficacy beliefs towards ultimately increasing student achievement outcomes (Denton \& Hasbrouck, 2009).

Purpose and Question. The purpose of this participatory action research case study (Merriam, 2002) was to investigate the utility of a cognitive apprenticeship-based (Collins, Brown, \& Newman, 1989) instructional coaching professional development program for improving science teaching efficacy beliefs of Bahamian inservice elementary teachers and their competency in implementing inquiry-based science curricula. The study was guided by the following research question:

1. From the perspectives of Bahamian inservice elementary teachers, how did participating in a cognitive apprenticeship-based instructional coaching program influence the development of their science teaching efficacy beliefs and competency in implementing inquiry-based curricula?

Description of Intervention. This study involved five Bahamian inservice teachers mentored by the researcher, who provided instructional coaching for a period of 
10 weeks. The teachers and the instructional coach worked together in a professional learning community meeting for an hour and a half bi-weekly. The coach prescribed a number of problem-based learning tasks (called SAK Activities) designed to teach evidence-based practices in science curriculum implementation and instruction. Through modeling and guided practice, the instructor-coach facilitated the participants learning to use evidence-based tools for developing unit/lesson plans to implement the new inquirybased Bahamian elementary science curriculum. In addition to modeling science unit/lesson plan development, the instructional coach modeled the delivery of two lessons for the teachers, simultaneously making his thinking and instructional decision-making visible. These model lessons were followed by a reflective discussion of each lesson. The participating teachers were also required to demonstrate a 30-minute microteaching lesson within their community of practice and facilitate a time for self-reflection and feedback from the other teachers and the instructional coach. Mandatory coaching sessions with the instructional coach were facilitated after each microteaching lesson and throughout the duration of the study as needed or requested. The participating inservice teachers taught a 3-week inquiry-based science unit plan within their respective classrooms, which was developed in collaboration with the instructional coach.

Method. This study employed a qualitative participatory action research case study (Merriam, 2002) design. The researcher and participants worked collaboratively to define the problem and to examine how the cognitive apprenticeship-based instructional coaching program might influence the science teaching efficacy beliefs (STEB) and competency in implementing the new Bahamian elementary inquiry-based science 
curriculum. The primary data sources were two 30-45 minute open-ended individual interviews with each inservice teacher and two focus group interviews with all participants. Interviews were conducted at the beginning and end of the intervention, and the two focus group sessions were facilitated mid- and post-intervention. Coding methods used for analysis included, in vivo, process, emotion, values, and focused coding (Saldana, 2013), because of the nature of the research question, which "suggest[ed] the exploration of personal, interpretive meanings found within the data” (Saldana, 2013, p. 61). The data were then themed using the cognitive apprenticeship methods (coaching, modeling, scaffolding, articulation and reflection, and exploration), and the term “curriculum implementation” as a priori codes. Finally, the data were analyzed inductively to derive narratives about how the inservice teacher perceived that the cognitive apprenticeship-based methods influenced their STEB, and curriculum implementation competencies. All qualitative data were stored, managed, and manually coded using NVivo 10 software.

Findings. The findings of the study suggested that the inservice teachers differed in their perceptions of how the cognitive apprenticeship-based instructional coaching (CAIC) influenced their STEB. The findings suggested that coaching and scaffolding were possibly the most influential of the CAIC methods. This was most likely the result because they both provided many opportunities for closely relating with their colleagues and the instructional coach. Modeling and exploration were referred to the least, however, at least one inservice teacher considered the modeling as the most beneficial contributor to her growth in STEB. The findings also suggested that the inservice 
teachers perceived that the CAIC program had a significantly positive influence on their confidence in their abilities to implement the new inquiry-based curricula effectively.

Publication Formatting and Submission. This article was submitted to the Journal of Research in Science Teaching (JRST) published by the National Association of Research in Science Teaching. This journal was selected because of its history of publishing scholarly reports using a wide variety of methodological approaches including qualitative case study approaches. Submissions to the Journal of Research in Science Teaching requires that all manuscripts are formatted in accordance with the American Psychological Association (APA) sixth edition manual with a few modifications.

References are not required to be double-spaced (as reflected in this dissertation), tables can be 10 point font, and no aspect of the references should be italicized. This article was submitted on March 21, 2015 and is presently under review.

\section{Significance of Collected Papers Research}

The findings of these collected papers have significant implications for teacher learning and professional development and will contribute to the scarcity of empirical literature on instructional coaching. More significantly, they meaningfully contribute to the limited literature on science coaching as "literature on science coaching is sparse" (DeChenne et al., 2012, p. 6). The need for this project is evidenced by priority given to teacher learning and professional development in The Bahamas and the substantial investments in instructional coaching in the United States despite the paucity of strong evidence supporting it. 
The significance of this dissertation to the advancement of science education and professional development in the Bahamas is supported by several important initiatives recently undertaken. The main teacher training institution in that country recently initiated a process to revise the only elementary science methods course for preservice teachers as part of the School of Education's current bachelor program review initiative. This is especially important because this methods course has not been revised since 1996, and the outcomes of this dissertation can have major implications for how this science methods course is designed and implemented in the future. In addition to the special committee formed by the BEST Commission to look at advancing science education in The Bahamas mentioned earlier, the current Prime Minister of The Bahamas recently created the Ministry of Education, Science, and Technology as a symbol of the government’s commitment to improving science education nationally (“Cabinet Appointments,” 2012).

In addition, the current Bahamian Minister of Education, the Honorable Jerome Fitzgerald, in his 2013 budget address, emphasized the government’s commitment to increased teacher professional development. He said "we must commit to equipping them [new teachers] with the skills and training they need to excel. After that is done, then we must give experienced teachers high quality professional development to maintain and enhance their skills” (Fitzgerald, 2013). In this address, the Minister further announced the establishment of a professional development institute in the not too distant future, citing the need to address the national education system's deficiency in the area of teacher professional development. Also, in the 2011-2013 budget year, the Bahamas Department of Education increased its investment in inservice teacher professional 
development by approximately 10\% over previous years (Ministry of Finance, 2012). Hence, this timely study is projected to make a significant contribution to the Bahamian government's goal of advancing teacher learning and professional development for preservice and inservice teachers of science.

In the United States, although relatively few studies have been conducted to date, the number of coaching programs and monies spent on coaching initiatives continues to increase annually. "States, districts, and schools have made huge investments in time, personnel, and resources in this new paradigm of school-based professional development known as coaching” (Wicker, 2006, p. 14). Hence, there is a need for additional accountability measures for the investment of public funds. In the 2006 fiscal year, nearly \$6.5 million was appropriated to Comprehensive School Reform (CSR) programs which included funding for coaching programs (Warren, 2008, p. 2). Additionally, in 2009, Montana State University received a \$3.5 million grant from the National Science Foundation to study instructional coaching in mathematics for elementary teachers. Other universities and colleges have also received federal and private grants to study instructional coaching. Over the past several years, a large number of coaching institutes, centers, and coalitions have been organized by universities as well as private and nonprofit organizations around the country.

However, "although coaches have become commonplace in schools, very little is known about what they do and how they do it” (Warren, 2008, p. 2). According to Simons (2006), "further studies of instructional coaching programs are necessary so educators can gain a better understanding of the instructional coaching process” (p. 6). To this end, this study provides much-needed information about a potentially viable 
theoretical approach to instructional coaching. The findings might simultaneously provide an avenue for greater accountability and yields from substantial resources invested in instructional coaching programs.

\section{Chapters of the Dissertation}

This dissertation followed the guidelines for the collected papers format as prescribed by the College of Education at Florida International University. It comprises of introductory and concluding chapters written solely for the dissertation and the papers outlined above as additional chapters. To this end, the dissertation chapters are as follows:

Chapter 1: Introduction, related literature review and research rationale Chapter 2: Sequential explanatory mixed-methods study of cognitive apprenticeshipbased instructional coaching and preservice teacher learning.

Chapter 3: Participatory action research case study of cognitive apprenticeship-based instructional coaching and inservice teacher professional development.

Chapter 4: Conclusion, implications, and suggestions for further research. 


\section{References}

Ashton, P. (1984). Teacher efficacy: A motivational paradigm for effective teacher education. Journal of Teacher Education, 35(5), 28-32.

Avant, R. C. (2012). Instructional coaching and emotional intelligence (Doctoral Dissertation). Available from ProQuest Dissertations and Theses database. (UMI No. 1019055530)

Baker, G. W. (2010). Instructional coaching in U.S. urban school districts: The principal perspective on how coaches are supervised (Doctoral Dissertation). Available from ProQuest Dissertations and Theses database. (UMI No. 857923369)

Bandura, A. (1977) Self-efficacy: Toward a unifying theory of behavioral change. Psychological Review, 84, 191-215.

Bandura, A. (1986). Social foundations of thought and action: A social cognitive theory. Englewood Cliffs, NJ: Prentice- Hall.

Bencze, L., \& Hodson, D. (1999), Changing practice by changing practice: Toward more authentic science and science curriculum development. Journal of Research in Science Teaching, 36, 521-539.

Boston University School of Public Health. The social cognitive theory. Retrieved from http://sph.bu.edu/otlt/MPH-Modules/SB/SB721-Models/SB721-Models5.html

Cabinet appointments announced. (2012, May 10). The Nassau Guardian. Retrieved from http://www.thenassauguardian.com/index.php?option=com_content\&view=article \&id=30840:cabinet-appointments-announced-\&catid=3:news\&Itemid=27

Coble C. R, \& Azordegan J. M. (2004). The challenges and opportunities of the No Child Left behind Act: Seven strategies for teacher educators. Action in Teacher Education, 26(2), 2-14.

Collins, A. (2006). Cognitive apprenticeship. In R. K. Sawyer (Ed.) Cambridge handbook of the learning sciences (pp. 47-60). Cambridge UK: Cambridge University Press.

Collins, A., Brown, J. S., \& Newman, S. E. (1989). Cognitive apprenticeship: Teaching the crafts of reading, writing, and mathematics. In L. B. Resnick (Ed.), Knowing, learning, and instruction: Essays in honor of Robert Glaser (pp. 453-494). Hillsdale, NJ: Lawrence Erlbaum Associates.

Cornett, J., \& Knight, J. (2008). Research on Coaching. In J. Knight (Ed.) Coaching: Approaches and perspectives. Thousand Oaks, CA: Corwin. 
Curling, L., St. Cyr. K., Moss, S., Moultrie, S., Vanderpool, J., \& Wilchcombe, N. (2010). Bahamas roadmap for science and technology. Bahamas Environment, Science, and Technology Commission. Retrieved from: http://www.best.bs/Documents/Road_Map_new_10.01.06.pdf.

DeChenne, S. E., Nugent, G., Kunz, G.M., Luo, L., Berry, B., Craven, K. (2012). A case study of coaching in science, technology, engineering, and math professional development. National Center for Research of Rural Education. Retrieved from: http://r2ed.unl.edu/workingpapers/2014/2014_7_DeChenne_Nugent_Kunz_Luo_ Berry_Craven_Riggs.pdf.

Denton, C. A., \& Hasbrouck, J. (2009). A description of instructional coaching and its relationship to consultation. Journal of Educational and Psychological Consultation, 19(2), 150-175.

Fitzgerald, J. (2013). Fitzgerald: This budget is about the future. Progressive Liberal Party. Retrieved on October 14, 2013 from: http://myplp.org/2013/06/13/fitzgerald-this-budget-is-about-the-future.

Haycock, K. (1998). Good teaching matters: How well-qualified researchers can close the gap. Thinking K-16, 3(2), 1-14.

Hearn, R. M. (2010). An evaluation of instructional coaching at selected high schools in north Louisiana and its effect on student achievement, organizational climate, and teacher efficacy (Doctoral Dissertation). Available from ProQuest Dissertations and Theses database. (UMI No. 518761207).

Horne, J. B. (2012). Instructional coaching: Teachers' perceptions of practice and effectiveness (Doctoral Dissertation). Available from ProQuest Dissertations and Theses database. (UMI No. 1070964026).

Joyce B. \& Showers B. (1980). Improving inservice training: The messages of research. Educational Leadership, 37(5), 379-385.

Knight, J. (2009). Coaching: Approaches and perspectives. Thousand Oaks, CA: Corwin Press.

Lakshmanan, A., Heath, B. P., Perlmutter, A. and Elder, M. (2011). The impact of science content and professional learning communities on science teaching efficacy and standards-based instruction. Journal of Research in Science Teaching, 48, 534-551. doi: 10.1002/tea.20404.

Lord, M. (2006). No Child Left Behind and science education. Education Writers Association. Retrieved from: http://www.ewa.org/docs/scienceeducation2006.pdf. 
Loveless, T. (2013). The latest TIMMS and PIRLS scores. 2013 Brown Center Report on American Education. Retrieved on October 31, 2013 from: http://www.brookings.edu/research/reports/2013/03/18-timss-pirls-scores-loveless

Mahmoee, H.M., \& Pirkamali, M.A. (2013). Teacher self-efficacy and students' achievement: A theoretical overview. The Social Sciences, 8, 196-202.

Ministry of Finance. (2012). Estimates of expenditure on revenue account 2012/2013. Government of The Commonwealth of The Bahamas. Retrieved from: http://www.thebahamasweekly.com/uploads/10/Budget_2012_2013.pdf.

National Staff Development Council. (2001). Standards for Staff Development (Revised). Oxford, OH: NSDC.

Pea, R. D. \& Collins, A. (2008). Learning how to do science education: Four waves of reform. In Y. Kali, M. Linn, \& E. Roseman (Eds.) Designing coherent science education: Implications for curriculum, instruction, and policy (pp. 3-12). New York: Teachers College Press.

Reed, L. A. (2006). Case study of the implementation of cognitive coaching by an instructional coach in a title I elementary school (Doctoral Dissertation). Available from ProQuest Dissertations and Theses database. (UMI No. 304932087)

Scharmann, L. C., \& Hampton, C. M. (1995). Cooperative learning and preservice elementary teacher science self-efficacy. Journal of Science Teacher Education, 6(3), 125-133.

Scurry, S. N. (2010). Perceptions of instructional coaches in the elementary school setting and their impact on teacher self-efficacy (Doctoral Dissertation). Available from ProQuest Dissertations and Theses database. (UMI No. 829500183)

Shadish, W. R., Cook, T. D., \& Campbell, D. T. (2002). Experimental and quasiexperimental designs for generalized causal inference. Boston, MA: Houghton Mifflin.

Simons, M. H. (2006). The influence of instructional coaches on improving teaching and student performance (Doctoral Dissertation). Available from ProQuest Dissertations and Theses database. (UMI No. 305311885)

Stock, J. (1999). Introduction to single subjects design. Retrieved on November 2, 1014 from: https://www.msu.edu/user/sw/ssd/issd02.htm 
Sumner, K. Y. (2011). An explanatory mixed-methods study of instructional coaching practices and their relationship to student achievement (Doctoral Dissertation). Available from ProQuest Dissertations and Theses database. (UMI No. 863207532)

Tashakkori, A., \& Teddlie, C. (Eds.). (2003). Handbook of mixed methods in social and behavioral research. Thousand Oaks, CA: Sage.

Trombly, C. E. (2012). Comfort with complexity: An examination of instructional coaching in three suburban school districts in massachusetts (Doctoral Dissertation). Available from ProQuest Dissertations and Theses database. (UMI No. 1038140070)

UC Davis Children's Hospital. (2013, February 11). Instructional coaching: An effective way to train. Retrieved October 13, 2013 from: http://pcit.ucdavis.edu/coachingblog

United Nations Educational Scientific Cultural Organization. Science education. Retrieved on October 14, 2013 from: http://www.unesco.org/new/en/naturalsciences/special-themes/science-education

United Nations Educational Scientific Cultural Organization. Science education programme. Retrieved on October 14, 2013 from: http://www.unesco.org/new/en/natural-sciences/special-themes/scienceeducation/about-the-programme

Warren, J. M. (2008). When implementing policy gets messy: An analysis of a districtwide coaching initiative (Doctoral Dissertation). Available from ProQuest Dissertations and Theses database. (UMI No. 304492404)

Wenger, E. (1998). Communities of practice: learning, meaning, and identity. Cambridge University Press.

Wicker, R. K. (2006). Do science coaches promote inquiry-based instruction in the elementary science classroom? (Doctoral Dissertation). Available from ProQuest Dissertations and Theses database. (UMI No. 305358649)

Wright, S. P., Horn, S. P., \& Sanders, W. L. (1997). Teacher and classroom context effects on student achievement: Implications for teacher evaluation. Journal of Personnel Evaluation in Education, 11(3), 57-67.

Yilmaz, H., \& Huyuguzel Cavas, P. (2008). The effects of the teaching practice on preservice elementary teachers' science teaching efficacy and classroom management beliefs. Eurasia Journal of Mathematics, Science \& Technology Education, 4(1), 45-54. 
Zucker, A. (1997). Reflection on state efforts to improve mathematics and science education in light of findings from TIMMS. Retrieved on October 31, 2013 from: http://govinfo.library.unt.edu/negp/reports/zucker.htm 
CHAPTER II

\title{
STUDY \#1, EXPLANATORY MIXED-METHODS-THE EFFECTS OF A COGNITIVE APPRENTICESHIP-BASED INSTRUCTIONAL COACHING METHODS COURSE ON THE SCIENCE TEACHING EFFICACY BELIEFS OF ELEMENTARY PRESERVICE TEACHERS
}

\begin{abstract}
This sequential explanatory mixed-methods study investigated the effectiveness of a reformed methods course grounded in cognitive apprenticeship theory-based instructional coaching for improving personal science teaching efficacy beliefs of elementary preservice teachers. In the quantitative strand, twenty-six elementary preservice teachers responded to the science teaching efficacy beliefs instrument (STEBIB), an instrument with two sub-scale measures, i.e., Personal Science Teaching Efficacy (PSTE) and Science Teaching Outcome Expectancy (STOE). Semi-structured interviews and document analyses of the preservice teachers' end of year reflections were conducted in the qualitative strand to ascertain how they experienced the methods course and to determine the influence of the methods course on their personal science teaching efficacy beliefs. The quantitative findings showed a continuous statistically significant linear increase between the first three measures of PSTE which included the baseline measure until the end of the course. However, a slight decrease in their PSTE was observed in the final post-course measure which is a commonly observed long-term effect after many educational interventions. A $t$-test determined that the decline was not statistically significant, indicating that teaching internship had no significant effect on the preservice teachers' science teaching efficacy beliefs. The qualitative findings confirmed that the preservice teachers perceived that their learning experience in the cognitive
\end{abstract}


apprenticeship-based instructional coaching (CAIC) methods course was unique when compared to other teaching methods courses taken. They also perceived that the CAIC methods used by the instructor-coach played a significant role in the continued growth of their PSTE during the course. However, it appeared that the degree of influence of the respective CAIC methods were contingent upon the individual preservice teachers' needs and self-perceptions of their own competencies.

\section{Introduction}

The twenty-first century ushered in an era of systemic reform and accountability in K-12 science education globally. Policymakers, researchers, and practitioners around the world began seeking innovative ways to improve the quality of science classroom instruction towards attaining higher student achievement outcomes. Elementary science education is one of the areas receiving significant attention because students' experiences during these formative years have shown to be the foundation for future science love and learning. However, "both preservice and inservice teachers perceive science as a difficult subject and feel themselves inadequately prepared to teach science in elementary schools” (Yilmaz \& Huyuguzel Cavas, 2008). This issue is especially problematic as numerous studies have consistently supported teacher quality as the most important inschool factor influencing student achievement outcomes (Darling-Hammond, 2000; Haycock, 1998; Wright, Horn, \& Sanders, 1997).

Teacher's efficacy beliefs have been shown to be indicative of teacher quality (Holzberger, Phillip, \& Kunter, 2013). The construct, teaching efficacy beliefs, derived from Bandura’s (1986) concept of self-efficacy beliefs, refers to teachers' self- 
perceptions of their personal teaching abilities. Many studies have reported positive correlations between teaching efficacy beliefs and important variables like teacher motivation (Aydin \& Boz, 2010; Yilmaz \& Huyuguzel Cavas, 2008), teacher persistence (Cantrell, Young, \& Moore, 2003), and teacher pedagogical innovation (Allinder, 1994). Science teaching efficacy beliefs (STEB), then, refers to teachers' self-perceptions about their ability to teach science effectively. Increasing numbers of studies have focused on influencing STEB towards ultimately improving teacher quality at both the preservice and inservice levels.

Cantrell et al. (2003) suggested that "a specific measure of science teaching efficacy beliefs may predict future science teaching success of preservice science teachers.” Therefore, it is imperative that science educators pursue effective interventions to enhance preservice teachers' perception of their abilities to teach science equally as effectively as they do other subjects. Scharmann and Hampton (1995) suggested that "one goal of undergraduate science education programs should be the development of positive attitudes towards science and science teaching.” Additionally, Bleicher and Lindgren (2005) expressed "strong agreement with the growing body of literature that science teaching efficacy should be explicitly addressed in teacher education programs.”

Science methods courses offer an ideal time to focus on developing preservice teachers' science teaching efficacy beliefs because their experience at this level is least affected by school climate and other factors which may adversely influence their confidence (Cantrell, Young, \& Moore, 2003). Therefore, keen focus should be given specifically to developing STEB in the design and implementation of elementary science methods courses. Some teacher educators believe that preservice teachers may most 
effectively develop STEB during their final teaching internships. However, Yilmaz and Huyuguzel Cavas (2008) found that "teaching experience did not affect preservice elementary teachers’ science teaching efficacy beliefs,” which suggests that waiting until final teaching internships to focus on developing STEB might in fact be too late.

Elementary preservice teachers come to methods courses with a wide range of STEB (Cantrell, Young, \& Moore, 2003). Therefore, “science methods instructors should not leave self-efficacy development to chance” (Scharmann and Hampton, 1995). “Elementary teachers’ attitudes and beliefs about teaching and learning and the pedagogical knowledge garnered from classes and fieldwork play a critical role in shaping their patterns of instructional behavior” (Yilmaz \& Huyuguzel Cavas, 2008). Therefore, well designed and sequenced methods courses focused on enhancing STEB are central to the future success of preservice elementary teachers in teaching science. This means that due consideration must not only be given to the "what" but also to the "how" in the training of elementary preservice science teachers. Developing STEB must be approached differently from simply increasing content knowledge and skills, and therefore may require science methods instructors to step outside of traditional teaching roles to embrace a more mentoring approach to science preservice teacher learning.

Over the last several decades, the literature has been replete with numerous approaches to inservice teacher learning through mentoring. Instructional coaching is one such approach. According to Knight (2009), an instructional coach “partners with teachers to help them incorporate research-based instructional practices into their teaching.” Preservice teachers learn to use and incorporate pedagogical practices during their undergraduate teaching methods courses. However, there is little evidence of 
attempts to apply instructional coaching (Knight, 2009) practices into the design and delivery of preservice teacher methods course. Instructional coaching emphasizes learning through mentoring relationships, where trust and shared values develop as the foundation of a supportive learning environment in which teacher efficacy beliefs can be nurtured. Therefore, incorporating instructional coaching as an integral component of science methods courses may add significant value to the learning process.

According to Denton and Hasbrouck (2009), however, though instructional coaching interventions have been widely implemented in K-12 schools throughout the U.S., "the rush to implement coaching before strong theoretical models, or even welldefined job descriptions, were in place has caused a good deal of confusion related to the role and focus of coaching.” As a result, there remains more questions than answers regarding the effectiveness of these interventions. Thus, it is imperative that a strong theoretical model is clearly identified with any attempt to effectively transfer instructional coaching practices into preservice teacher learning.

\section{Conceptual Framework}

Cognitive apprenticeship theory (Collins, Brown, \& Newman, 1989) can potentially provide a strong theoretical model for the design and implementation of a mentoring-based science methods course for preservice elementary teachers. "Cognitive apprenticeship,” according to Collins, Brown and Newman (1989), “refers to the focus on learning-through-guided-experience, on cognitive and metacognitive, rather than physical skills and processes.” It is designed to teach the pertinent thinking and problem-solving skills needed for mastery in a given field using six methods: modeling, coaching, 
scaffolding, articulation, reflection, and exploration. Collins (2006) defined these methods as follows:

Modeling involves an expert performing a task so that the students can observe and build a conceptual model of the processes that are required to accomplish it. Coaching consists of observing students while they carry out a task and offering hints, challenges, scaffolding, feedback, modeling, reminders, and new tasks aimed at bringing their performance closer to expert performance. Scaffolding refers to support the teacher provides to help students carry out tasks. Articulation includes any method of getting students to explicitly state their knowledge, reasoning, or problem-solving processes in a domain. Reflection involves enabling students to compare their own problem solving processes with those of an expert, another student, and ultimately, an internal cognitive model of expertise. Exploration involves guiding students to a mode of problem solving on their own.

The implementation of these methods of cognitive apprenticeship are required to be situated in the local context of instruction, because "apprenticeship embeds the learning of skills and knowledge in their social and functional context” (Collins et al., 1989).

Ultimately, "the focus of the expert/novice interaction in a cognitive apprenticeship is on developing cognitive skills of reflection through discourse and application of knowledge” (Borman \& Feger, 2006). Therefore, such an approach to preservice teacher learning can foster the development of the level of metacognitive skills and awareness, self-reflection, and self-correction preservice teachers need to make sound instructional decisions about curriculum implementation and practices. In 
summary, a methods course employing cognitive apprenticeship-based instructional coaching involves engaging preservice teachers, as apprentices, in mastery learning experiences through guided practice within a local context of instruction.

\section{Research Purpose and Questions}

The purpose of this study is to investigate the utility of a reformed science methods course designed and implemented using a cognitive apprenticeship-based instructional coaching approach to improve the science teaching efficacy beliefs of preservice elementary teachers. The two guiding research questions are:

1. Is there a change in the science teaching efficacy beliefs of Bahamian preservice elementary teachers who participate in a methods course delivered using a cognitive apprenticeship-based instructional coaching approach?'

2. From their perspectives, how do Bahamian preservice elementary teachers describe their experiences in a methods course delivered using cognitive apprenticeship-based instructional coaching and the effects of the cognitive apprenticeship-based instructional coaching methods on their science teaching efficacy beliefs?

\section{Theoretical Framework}

Bandura's (1986) theory of self-efficacy provides the theoretical underpinnings

for this study. Bandura developed the concept of self-efficacy beliefs as part of his Social Cognitive Theory (Bandura, 1977). It refers to “one’s belief in one’s own ability to successfully perform a specific task” (Lakshmanan, Heath, Perlmutter, \& Elder, 2010). 
Hence, the degree to which individuals are inclined to engage in specific tasks is largely determined by their beliefs about their ability to complete that task successfully (i.e. selfefficacy). The construct, science teaching efficacy beliefs, was developed from Bandura's self-efficacy construct and refers to teachers' self-perceived ability to effectively teach science. Bandura (1986) posited that there are four main ways of increasing self-efficacy beliefs (and as such, science teaching efficacy beliefs as well): mastery experience, vicarious experiences, social and verbal persuasion, and through the individual's physical and emotional well-being. He determined that mastery experiences were the most influential. The learning tasks in the reformed course under study were designed to enhance the science teaching efficacy beliefs of Bahamian preservice elementary teachers by specifically targeting each of Bandura's (1986) four sources of self-efficacy development (Table 1).

\section{Description of Intervention}

The study involved a 14-week methods course on teaching science in the elementary school at a leading teacher training institution in The Bahamas. This is the only science methods course in the four-year Bachelor of Education program for preservice elementary teachers. It is taken in the fourth year, prior to the preservice teachers' final school-based teaching internship. During the semester, the researcher, as the course instructor, assumed the role of instructor-coach; mentoring students as they learn to implement reform-based curricula and best-practices in science, and in making instructional decisions. The aspects of the intervention were as follows: (i) the instructor as coach modeled curriculum implementation through a 6-week, 1-hour unit and lesson 
planning workshop. These workshops were integrated within the class time and were designed to teach preservice teachers how to implement the elementary science curriculum using Backwards Design (Wiggin \& McTighe, 1998) and the 5E Learning Cycle. Backwards design is an evidence-based process of instructional planning which begins with the established learning goals of the curriculum, and proceeds backwards with selecting appropriate assessments before selecting the relevant learning activities to meet those goals. The 5E Learning Cycle Teaching Model (Settlage \& Southerland, 2012), a modification of Karplus and Thier’s (1967) learning cycle, was developed by Rodger W. Bybee (1997) of the Biological Sciences Curriculum Study (BSCS) project. It is a systematic experiential model for delivering inquiry-based lessons in a series of five phases: engage, explore, explain, extend, and evaluate. (ii) The instructor-coach also modeled the delivery of three 5E lessons, simultaneously making expert thinking and instructional decision-making visible during each aspect of the lessons' development.

(iii) During the semester, preservice teachers were also engaged in a number of presentations led by the instructor-coach which were each accompanied by a relevant cooperative group task. These presentations/activities were called skills, attitudes, and knowledge (SAK) Presentations. They served as scaffolds to help students develop science teaching skills, attitudes, and knowledge—as determined necessary based on weaknesses and challenges observed by the instructor-coach during the course. (iv) As part of the methods course, each preservice teacher delivered an in-class microteaching lesson at mid-semester. This was the major scaffold designed to support their readiness for field experience, and to facilitate one-on-one coaching feedback from the instructor- 
coach. (v) The preservice teachers' culminating task was a 5-week school-based field teaching experience during the final weeks of the semester under the supervision of the instructor-coach and a cooperating teacher. The first week was for observation and interviewing students, and they were required to teach four science lessons in schools over the remaining four weeks. The textbook used during the course was Teaching Science to Every Child: Using Culture as a Starting Point (2012) by John Settlage and Sherry Southerland. The chapters most pertinent to the science instructional process (1-5, 8, 9 \& 11) were presented and discussed throughout the course. Table 1 illustrates the conceptual relationship between the CAIC methods, the learning experiences, and the sources of self-efficacy targeted.

Table 2

Conceptual relationship between aspects of the methods course and theories employed

\begin{tabular}{|c|c|c|}
\hline $\begin{array}{l}\text { Methods of CAIC } \\
\text { (Collins, 2006) Used }\end{array}$ & $\begin{array}{l}\text { Elements of the Cognitive } \\
\text { Apprenticeship-Based } \\
\text { Instructional Coaching } \\
\text { Science Methods Course }\end{array}$ & $\begin{array}{l}\text { Source of Self Efficacy } \\
\text { (Bandura, 1986) Targeted }\end{array}$ \\
\hline Scaffolding & $\begin{array}{l}\text { - Skills, Attitudes, and } \\
\text { Knowledge (S.A.K) } \\
\text { Activities } \\
\text { - Microteaching Lesson }\end{array}$ & $\begin{array}{l}\text { Mastery Experiences } \\
\text { Social and Verbal } \\
\text { Persuasion }\end{array}$ \\
\hline Modeling & $\begin{array}{l}\text { - Model Lessons and } \\
\text { Unit/Lesson Plan } \\
\text { Development by Instructor as } \\
\text { Coach }\end{array}$ & Vicarious Experiences \\
\hline Coaching & $\begin{array}{l}\text { - Corrective Feedback } \\
\text { (Unit/Lesson Planning, and } \\
\text { after Microteaching) }\end{array}$ & $\begin{array}{l}\text { Social and Verbal } \\
\text { Persuasion }\end{array}$ \\
\hline Reflection and & - One-on-one Sessions with & Physical and Emotional \\
\hline Articulation & $\begin{array}{l}\text { Instructor-coach (After } \\
\text { microteachings and field } \\
\text { observations) }\end{array}$ & Well-Being \\
\hline $\begin{array}{l}\text { Exploration with } \\
\text { Mentoring }\end{array}$ & $\begin{array}{l}\text { - 4-Week Field Experience } \\
\text { with Mentorship }\end{array}$ & Mastery Experiences \\
\hline
\end{tabular}




\section{Methodology}

\section{Description of Setting and Participants}

The study took place at a small liberal arts college in The Bahamas, which is also a leading teacher training institution in the country. Elementary education in The Bahamas is formally referred as "primary education" and comprises of grades 1-6. The elementary science methods course, required for all elementary education majors, is usually taken in the final semester of their junior year or in the first semester of their senior year, just before final teaching internship. Preceding this course are two prerequisite general science courses designed to provide basic competencies in life, physical, and earth and space sciences. Therefore, all of the preservice teachers in the study shared similar experiences related to science knowledge, skills and preservice training. Twenty-six preservice teachers initially enrolled at the beginning of the semester with ages ranging from early 20 s to early 40s. One participant dropped out of the methods course around week 7. The duration of the course was 14 weeks, meeting once or twice per week for a total of four hours weekly.

\section{Description of Research Design}

This study employed a sequential explanatory mixed-methods research design (Tashakkori \& Teddlie, 2003), i.e., the study has independent quantitative and qualitative strands. In this design, the quantitative data collection and analysis occur first, followed by the collection and analysis of qualitative data to elaborate on the results of the quantitative section. Therefore, the conclusions regarding the utility of the cognitive apprenticeship-based instructional coaching methods course were derived from the 
analysis of both strands. The quantitative strand addressed the first research question using a pre-experimental, one group pretest-posttest design. This type of design lacking a control group is “used frequently in field research” (Shadish, Cook, \& Campbell, 2002), and when establishing the utility of interventions (Stock, 1999). "Single subject designs involve repeated, systematic measurement of a dependent variable before, during, and after the manipulation of an independent variable” (Stock, 1999). Participants in these designs are used as their own controls and are repeatedly measured for changes over time. These designs have minimal internal validity and no external validity (Campbell \& Stanley, 1963).

According to Shadish et al. (2002), "designs without control groups can yield strong causal inferences only by reducing the plausibility of alternative explanations for the treatment effect.” The major threats to internal validity inherent in using the one group pretest-posttest design in this study are history and maturation effects. One way that social scientists in field settings may be able to construct more confident causal knowledge using this design is by shortening the intervals between the pretests and posttests (Shadish et al., 2002). To this end, the study was conducted over a short one semester (14 weeks) duration. Also, in addition to the pre- and post-course measures, two additional measures were taken in seven week intervals to reduce the likelihood of any observed changes being due to a history effect. Another method of improving the onegroup pretest-posttest design is by adding another non-equivalent dependent variablewhere "measures A and B assess similar constructs" (Shadish et al., 2002). The intervention is focused on Measure A, whereas Measure B is also expected to respond to the threats to internal validity of concern in the same way. Therefore, any observed 
difference in measure A and B would unlikely be due to maturation effects alone. The intervention in this study was focused on measuring Personal Science Teaching Efficacy beliefs (PSTE); however, a sufficiently similar construct, Science Teaching Outcome Expectancy (STOE), was also measured simultaneously.

The qualitative strand addresses the second research question. This phase employed the basic interpretive qualitative research design (Merriam, 2002) in which "the overall purpose is to understand how people make sense of their lives and their experiences” (Merriam, 2002). This method is best suited for the qualitative strand of this study because the intent was to describe the preservice teachers' perspectives of their learning experience during the methods course. Therefore, this method of qualitative research was optimized in this study for its potential to provide deep description of their experience, which may not have been adequately understood from the quantitative data alone. In basic interpretive qualitative research, "data are collected through interviews, observations, or document analysis. What questions are asked, what is observed, and what documents are deemed relevant will depend on the disciplinary theoretical framework of the study” (Merriam, 2002). The findings of interpretive qualitative research has no internal validity. Generalizability is only limited to the unique context in which the study was implemented and those determined to be similar by the readers (Merriam, 2002). 


\section{Data Collection}

For the quantitative strand, data for the variables PSTE and STOE were collected using the revised Science Teacher Efficacy Belief Instrument - Form B (STEBI-B) by Enoch and Riggs (2002). It was administered at equal intervals at the beginning of the course, at week 7 after their microteachings, at week 14 after their field experiences, and a post-course measure was taken seven weeks after the course. The instrument contains 23 items and is divided into two sub-scales: 13 items measuring PSTE and 10 items measuring STOE. Developers published the reliability alpha coefficients of 0.90 and 0.76 for the two subscales - personal science teaching efficacy and outcome expectancyrespectively (Enochs \& Riggs, 1990). However, the instrument was revalidated in this study by calculating the Cronbach's alpha reliability coefficient at each administration of the instrument to this population. Participants’ demographic information was also collected. Qualitative data were collected through document analysis of the end-of-course reflections in the preservice teachers' final portfolio and from 50-60 minute individual interviews with six preservice teachers purposively selected to represent a range of ability levels. The preservice teachers' final course grades were used as the sole sampling criteria, as they were selected to reflect the range effectiveness and overall levels of mastery as measured by the final achievement outcomes. During the interviews, participants were asked a number of open-ended questions about their experience during the course, and which aspects of the course they perceived contributed significantly to any changes in their personal science teaching efficacy belief. 


\section{Data Analysis}

The quantitative data from the STEBI-B was coded on a 5-point Likert scale with strongly agree being “ 5 ”, and strongly disagree being “ 1 ”. The ten negatively worded items from the instrument were reversed coded. Numerical data were analyzed using General Linear Model repeated measures analysis of variance in SPSS 21. For this purpose, composite variables for PSTE and STOE were calculated for each time period. Second, a series of paired samples $t$-tests were used to determine whether the differences between the resulting means of each time period were statistically significant. Finally, another paired samples $t$-tests was employed to determine if there was a difference between the post-course measure of PSTE of preservice teacher currently on teaching internship and those who are not.

The qualitative analysis employed a variety of manual coding procedures using NVivo 10. In basic interpretive qualitative research, "the analysis of the data involves identifying recurring patterns (presented as categories, factors, variables, themes) that cut through the data” (Merriam, 2002). In the first coding cycle initial coding was utilized first. "Initial coding is breaking down qualitative data into discreet parts, closely examining them, and comparing them for similarities and differences” (Saldana, 2009). According to Saldana (2009), initial coding can employ other coding methods in order to do this effectively. As such, initial coding employed in vivo and process coding (Saldana, 2009) in this study to break down the data meaningfully while comparing for similarities and differences. In in vivo coding, "a code refers to a word or short phrase from the actual language found in the qualitative data record” (Saldana, 2009). This type of coding was used to ascertain the exact language used by the participants as they describe their 
experience. "Process coding uses gerunds ("ing” words) exclusively to connote action in the data" (Saldana 2009). Therefore, this type of coding was employed to identify the significant on-going actions and interactions of the preservice teachers encroached in their descriptions of their experiences in instructional coaching-based methods course. The second cycle coding involved focused coding. During the second coding cycle, focused coding was employed to meaningfully categorize the codes and then detailed memos were also written to ascertain the narratives embedded within each category. Finally, the data and memos in each category were analyzed inductively for references pertaining to the preservice teachers' experiences in the course and their perceptions of the influence of the respective cognitive apprenticeship-based instructional coaching methods on their PSTE development.

In the end, results of both strands were discussed with a view to making inferences and ultimately a conclusion regarding the utility of the intervention for improving the PSTE of Bahamian elementary preservice teachers.

\section{Results and Discussion}

In this section, the results of the quantitative strand are presented and then discussed, whereas the results of the qualitative section which follow are presented and discussed simultaneously. 


\section{Quantitative Results}

Research Question \#1: Is there a change in the science teaching efficacy beliefs of Bahamian preservice elementary teachers who participate in a methods course delivered using a cognitive apprenticeship-based instructional coaching approach?

The numbers of STEBI-B instruments returned were 25, 26, 25 and 21 respectively. This is because one preservice teacher joined the class in the second week, another dropped around week 7, and only 21 post-course instruments were returned. Additionally, it became necessary to delete item 13 from the STOE subscale because it caused a great deal of confusion for preservice teachers due to ambiguity in the wording of this item. It caused initial reliability estimate of the subscale to be very low (.597), which increased substantially when the item was removed (.690). Hence, 9 items out of the 10 items in the STOE subscale were used in the statistical analyses.

Table 3

Reliability Statistics for PSTE and STOE from each administration of the STEBI-B

\begin{tabular}{llllll}
\hline Measure & $\begin{array}{l}\text { Cronbach's } \\
\text { Alpha }\end{array}$ & $\begin{array}{l}\text { Number of } \\
\text { Items }\end{array}$ & Measure & $\begin{array}{l}\text { Cronbach's } \\
\text { Alpha }\end{array}$ & $\begin{array}{l}\text { Number of } \\
\text { Items }\end{array}$ \\
\hline PSTE 1 & .706 & 13 & STOE 1 & .690 & 9 \\
PSTE 2 & .800 & 13 & STOE 2 & .730 & 9 \\
PSTE 3 & .754 & 13 & STOE 3 & .683 & 9 \\
PSTE 4 & .784 & 13 & STOE 4 & .724 & 9 \\
\hline
\end{tabular}

The Cronbach’s alpha coefficient for the STEBI-B subscale measuring PSTE beliefs all had good reliability scores of .706, .800, .754 and .784 respectively. The Cronbach's alpha coefficient for the STEBI-B subscale measuring STOE beliefs did not all have good reliability scores as 2 fell below .70, but they were deemed acceptable at 
$.690, .730, .683$, and .744 respectively. Thus, overall the STEBI-B instrument had good reliability for use with this population of Bahamian preservice teachers under study.

Table 4

Descriptive statistics of means of PSTE and STOE from the four measures

\begin{tabular}{lllllll}
\hline $\begin{array}{l}\text { Dependent } \\
\text { Variable }\end{array}$ & Means & $\begin{array}{l}\text { Standard } \\
\text { Deviation }\end{array}$ & $\begin{array}{l}\text { Dependent } \\
\text { Variable }\end{array}$ & Means & $\begin{array}{l}\text { Standard } \\
\text { Deviation }\end{array}$ & $\begin{array}{l}\text { Number } \\
\text { of Items }\end{array}$ \\
\hline PSTE 1 & 3.55 & .420 & STOE1 & 3.33 & .502 & 21 \\
PSTE 2 & 4.01 & .406 & STOE2 & 3.73 & .554 & 21 \\
PSTE 3 & 4.42 & .295 & STOE3 & 4.06 & .476 & 21 \\
PSTE 4 & 4.37 & .437 & STOE4 & 3.90 & .508 & 21 \\
\hline
\end{tabular}

Table 5

Multivariate Test of significance of the difference between group means

\begin{tabular}{llllll}
\hline Effect & Value & F & Hypothesis df & Error df & Sig. \\
\hline PSTE Wilks' Lambda & .204 & $23.416^{\mathrm{b}}$ & 3.00 & 18.0 & .000 \\
STOE Wilks' Lambda & .419 & $8.309^{\mathrm{b}}$ & 3.00 & 18.0 & .001 \\
\hline
\end{tabular}

The Wilks' Lambda perspective of the multivariate test yielded significant results (PSTE: $\mathrm{F}=23.416, \mathrm{p}<.001$ and STOE: $\mathrm{F}=8.8309$, $\mathrm{Sig}=.001$ ). Therefore, we reject the null hypothesis at .05 alpha levels and conclude that there is a significant difference between the four group means for both the levels of PSTE and STOE.

Table 6

Mauchly's Test for data violation of the Repeated Measures ANOVA sphericity assumption

\begin{tabular}{lllll}
\hline $\begin{array}{l}\text { Within Subjects } \\
\text { Effect }\end{array}$ & Mauchly's W & Approx. Chi-Square & Df & Sig. \\
\hline PSTE & .656 & 7.899 & 5 & .162 \\
STOE & .780 & 4.644 & 5 & .461 \\
\hline
\end{tabular}

According to Mauchly’s Test of Sphericity, for PSTE, W = .656 (Sig=.162) and for STOE, $\mathrm{W}=.780$ (Sig=.461); indicating failure to reject the null hypothesis which 
states that variances in the differences between levels are not different. Therefore, in both cases the sphericity assumption is not violated.

Table 7

Tests of Within-Subjects Effects for significance in the difference between mean scores

\begin{tabular}{lllllll}
\hline Source & & $\begin{array}{l}\text { Type III Sum } \\
\text { of Squares }\end{array}$ & df & \multicolumn{2}{c}{ Mean SquareF } & Sig. \\
\hline PSTE & Sphericity Assumed 10.107 & 3 & 3.369 & 39.017 & .000 \\
STOE & Sphericity Assumed & 6.178 & 3 & 2.059 & 11.553 & .000 \\
\hline
\end{tabular}

Because both PSTE and STOE do not violate the sphericity assumption, the results will be interpreted using the values with Sphericity Assumed. Subsequently, the mean scores for PSTE and STOE were also statistically significantly different (PSTE: $F=39.017, p<.05$ and STOE: $F=11.553, p<.05)$. In other words, both scores had significant changes over four time periods. This means that the mean scores of both the preservice teachers’ PSTE and STOE changed significantly over the four periods of measurements.

Table 8 Tests of Within-Subjects Contrasts for significant geometrical patterns in the data

\begin{tabular}{lllllll}
\hline Source & & $\begin{array}{l}\text { Type III Sum of df } \\
\text { Squares }\end{array}$ & $\begin{array}{l}\text { Mean } \\
\text { Square }\end{array}$ & F & Sig. \\
\hline \multirow{3}{*}{ PSTE } & Linear & 8.617 & 1 & 8.617 & 60.956 & .000 \\
& Quadratic & 1.330 & 1 & 1.330 & 17.532 & .000 \\
& Cubic & .159 & 1 & .159 & 3.807 & .065 \\
\multirow{3}{*}{ STOE } & Linear & 4.312 & 1 & 4.312 & 19.023 & .000 \\
& Quadratic & 1.683 & 1 & 1.683 & 9.668 & .006 \\
& Cubic & .183 & 1 & .183 & 1.368 & .256 \\
\hline
\end{tabular}

The result of the Tests of Within-Subjects Contrasts indicate both Linear and Quadratic patterns are significant for both PSTE and STOE. That is, either Linear or Quadratic pattern can be adopted for the growth pattern of the data. However, when both linear and quadratic patterns are significant the parsimonious one is preferred and also 
given the small sample size, the quadratic pattern cannot be satisfactorily applied.

Therefore, a linear growth pattern is interpreted as more acceptable in this case.

Table 9

Tests of Between-Subjects Effects for differences in scores between participants

\begin{tabular}{lllllll}
\hline & Source & $\begin{array}{l}\text { Type III Sum of df } \\
\text { Squares }\end{array}$ & Mean SquareF & Sig. \\
\hline PSTE & Intercept & 1404.617 & 1 & 1404.617 & 3899.924 & .000 \\
& Error & 7.203 & 20 & .360 & & \\
STOE & Intercept & 1186.255 & 1 & 1186.255 & 2333.415 & .000 \\
& Error & 10.168 & 20 & .508 & & \\
\hline
\end{tabular}

The analysis showed a statistically significant difference in variance of the means among participants at each of the four measures of PSTE as well as the four measures of STOE. This indicates that preservice teachers' levels of PSTE and STOE were significantly different from each other at the baseline measure and that the changes in PSTE and STOE also continued to vary significantly between them at each subsequent measure taken throughout the study.

Table 10

Paired samples t-test of changes in PSTE over the three intervals measured after the baseline

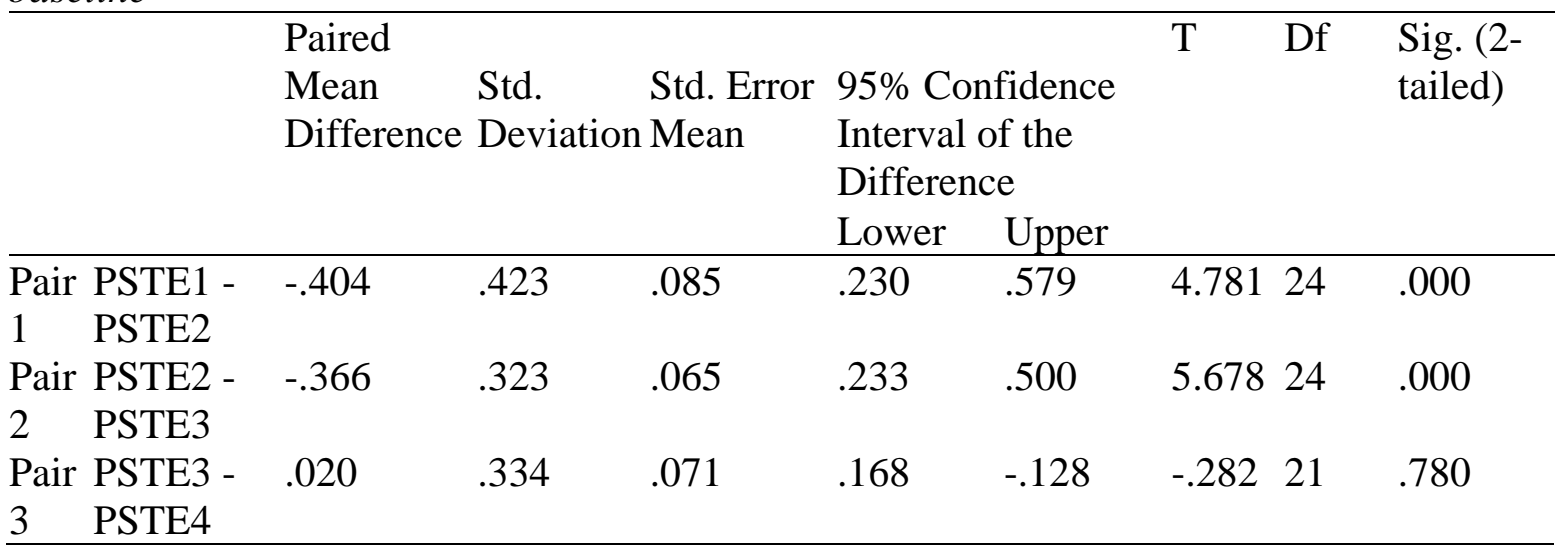


The first paired samples $t$-tests showed that the calculated $t$-value comparing the mean of the baseline PSTE measure (3.55) with the PSTE mean after the microteachings (4.01) is $4.781, \mathrm{p}<.05$. Therefore, we reject the null hypothesis that there is no statistically significant difference between those two means. The second paired samples $t$-tests showed that the calculated $t$-value comparing the mean of the PSTE measure after the microteaching (4.01) with the PSTE mean after the field experience (4.42) is 5.678, $\mathrm{p}<.05$. Therefore, we also reject the null hypothesis here which states there is no statistically significant difference between the two means. The final paired samples $t$-tests showed that the calculated $t$-value comparing the mean of the PSTE measure after the field experience (4.42) with the post-course PSTE measure (4.37) is -.282, $\mathrm{p}<.05$. Therefore, in this case we fail to reject the null hypothesis. This indicates that the decline in mean of the PSTE observed from the end of the field experience to the post-course measure is not statistically significant.

Table 11

Descriptive statistics of means of internship and non-internship students

\begin{tabular}{|c|c|c|c|c|}
\hline TeachPract & $\mathrm{N}$ & Mean & Std. Dev. & Std. Error Mean \\
\hline DSTE A Internship & 13 & 4.36 & .508 & .14082 \\
\hline PSIE 4 Non-Internship & 9 & 4.44 & .335 & .11160 \\
\hline
\end{tabular}

Table 12

Independent samples t-test of difference in internship and non-internship students' means

\begin{tabular}{cccccc}
\hline & $\mathrm{F}$ & $\mathrm{Sig}$ & $\mathrm{T}$ & $\mathrm{Df}$ & Sig.(2-tailed) \\
\hline PSTE 4 Equal variances assumed & 1.926 & .180 & -.431 & 20 & .671 \\
Equal variances not assumed & & & -.465 & 19.983 & .647 \\
\hline
\end{tabular}

The calculated $t$-value of the independent samples $t$-test is -.431, $\mathrm{p}>.05$.

Therefore, we fail to reject the null hypothesis. That is, there is no significant difference 
between the means of the post-course preservice teachers in their fourth week of teaching (4.36) and the mean of the preservice teachers not yet on teaching internship (4.44).

\section{Discussion of Quantitative Results}

Pearson correlation analysis comparing the growth means in PSTE and STOE showed the two variables to be highly correlated $(\mathrm{r}=1.00, \mathrm{p}<.05)$ — confirming STOE as a sufficiently similar variable to be co-measured during the study to gauge possible effects of maturation. The mean growth of the preservice teachers' PSTE over the course of the study (.274) was significantly higher than their mean growth in STOE (.189). Therefore, this suggests that the statistically significant growth observed in their PSTE as a result of their experience in the methods course was unlikely due to effects of maturation alone. The largest growth in personal STEB (.460) was observed over the first 7 weeks of the course. This could likely have been because most of the fundamentals of science teaching were taught during the first half of the course. Additionally, according to the qualitative findings, two of the learning experiences that many of the preservice teachers perceived as most influential in their PSTE development-the modelings and microteachings—also occurred within the first seven weeks. A high degree of variability among preservice teachers PSTE at each measure was reflected in the statistically significant findings of the between-subjects test. The results of this test supports the qualitative assertion from the qualitative findings that the various aspects of the learning experiences during the methods course influenced individual preservice teachers’ PSTE differently.

The slight decrease in the post-course measure of PSTE is commonly observed in the last wave of data collected on educational interventions. Many researchers have 
attributed this phenomena to the "fade-away" effect (Averch et al., 1972; Cascio \& Staiger, 2012; Currie \& Duncan, 1995), which naturally occurs in the aftermath when the intervention is not reinforced. However, the decline observed in this study was shown to be statistically insignificant, which suggested that the preservice teachers continued to maintain high levels of PSTE beliefs even up to 7 weeks beyond the methods course. This finding is also particular significance because thirteen of the twenty-one preservice teachers who completed the post-course measure, were by this time approximately four weeks into their final teaching internships in local schools. A paired samples $t$-test showed no significant difference between students who were in their final internship and those who were not—supporting conclusions by Yilmaz \& Huyuguzel Cavas (2008) that teaching internship does not have a significant effect on preservice teachers' STEB. Therefore, during methods courses may indeed be the best time to influence preservice teachers’ personal science teaching efficacy beliefs.

The slight decline in PSTE effects observed may also be analogous to what Cantrell, Young, and Moore (2003) identified as the influence of adverse effects of prolonged engagement with the realities of school climate and other challenging inschool factors which may influence their efficacy beliefs. This is supported by the fact that the qualitative results show that during their field experiences the preservice teachers had significant challenges managing classroom and institutional constraints. Additionally, failing to reject the null hypothesis that there is no statistically significant difference in PSTE of preservice teachers on teaching internship and those who are not suggested that a cognitive apprenticeship-based methods course has the potential to produce PSTE that is robust. Moreover, it may produce the kind of PSTE that not only prepares elementary 
preservice teachers for their final teaching internship, but that may also serve as impetus for lasting science teaching effectiveness in the field.

Limitations. Several important limitations must be considered when interpreting

and applying the quantitative results of this study. First, the original validity measures of the STEBI-B were not made readily available. However, the original instrument is said to have good content validity as determined by a panel of science educators, and good construct validity (Enoch \& Riggs, 1990). Second, a relatively small sample size was used due to the small student population, limiting access to the number of eligible participants. This small population also diminished the possibility of having a control group for comparison, though there may be ethical considerations which warrant due consideration in determining suitable control interventions. Third, more waves of data collection may be useful during and after the intervention to better measure the history effect and to more adequately measure the sustainability of the intervention results over time. Finally, the results may also have been influenced by positionality factors (Merriam, 2002) as the course instructor was also the researcher, which may have introduced some level of data collection bias.

\section{Qualitative Results and Discussion}

Research Question \#2: From their perspectives, how do Bahamian preservice elementary teachers describe their experiences in a methods course delivered using cognitive apprenticeship-based instructional coaching and the effects of the cognitive apprenticeship-based instructional coaching methods on their science teaching efficacy beliefs? 
According to Merriam (2002), in basic interpretative qualitative research “findings are a mix of... recurring patterns supported by data from which they were derived.” Focused coding during the second coding cycle resulted in five relevant recurring categories/themes: two relating to the preservice teachers' experiences during the methods course (Table 13) and three which spoke to the influence of the learning experiences on their personal science teaching efficacy beliefs (Table 14). In the following section, qualitative data are presented to illustrate the findings in each category, and they are interpreted and discussed.

\section{Experience during the Methods Course}

The quantitative results showed a statistically significant linear increase in the personal science teaching efficacy beliefs of the preservice teachers as a result of their experience in the methods course. Two of the five categories derived from the qualitative data referenced their experiences and may help to explain this phenomenon observed. The two categories comprised of references to their: (i) changes in their attitude/feelings and (ii) perceptions of growth in personal science teaching efficacy beliefs (PSTE). The largest number of references were made to “changing attitudes/feelings,” representing most (68\%) of the coded data about how they perceived their experience during the methods course.

Table 13

Categories/themes regarding preservice teachers' experiences

\section{Categories}

1. Changes in Attitudes/Feelings

2. Perception of Growth in PSTE

\section{Number of References} 38

18 
Changes in Attitudes/Feelings. When discussing their experience during the methods course, preservice teachers referred to changes in their attitudes/feelings about their science teaching abilities and towards students' science learning in the majority of the coded references. Several preservice teachers reported beginning the course with initial feelings of fear and anxiety primarily due to having low confidence in their abilities to teach science effectively. However, as they engaged in the learning activities in the course their anxiety levels declined. The following cases are illustrative:

When the course first began I was shy and uncertain of how to teach science lessons effectively but through learning in class and actively working on assignments I believe that I can now teach science lessons effectively. (Portfolio Reflection)

I went from not having the faith that I could teach science at all, let alone effectively for students to learn and gain something from it, to teaching science in a meaningful way and providing an environment for all my students to succeed at science. (Portfolio Reflection)

The contents in this course led to the diminishing of that fear present at the beginning and provided me with a step by step guide to go into the classroom feeling comfortable enough to deliver an effective science lesson where learning takes place. (Portfolio Reflection) 
These findings reveal preservice teachers' struggles with their personal science teaching efficacy beliefs at the beginning of the course as evidenced by references to being uncertain and not having faith. In two of the cases above, the word "fear" was used to describe their feelings towards teaching science. This is most likely because, as Yilmaz and Huyuguzel Cavas (2008) noted, preservice teachers often view science as difficult and feel inadequately prepared to teach it. However, the preservice teachers held that their attitudes and feelings began to change as they learned the content and engaged in the learning experiences in the course. Their use of the terms "actively working” and "step-by-step guide" to describe the learning experiences suggested that the course promoted a high degree of engagement, modeling, and guided practice, which are characteristic of cognitive apprenticeship learning (Collin, Brown, \& Newman, 1989). Additionally, the findings in this category also suggested that not only were their personal science teaching efficacy beliefs influenced, but their outcome expectancies were as well—the other dimension of science teaching efficacy belief (Enochs \& Riggs, 1990). This excerpt from a preservice teachers' portfolio reflection is illustrative,

At the beginning of the semester, the class took a survey and I answered that the way a teacher teaches has no direct correlation between the students grasping the content. I said this because there are so many other factors that contribute to a child not learning, like absenteeism and ability. I now realize that the methods and strategies a teacher uses can mean the different between a pass and a fail for a student. 
This preservice teacher's reference to the role of children's ability to learn science suggested an initial subscription to the notion that some students are predisposed to succeed in science and that teaching therefore would have little influence on some students' science achievement. If this is so, then it may also provide an explanation for the feelings of anxiety/fear some preservice teachers may have about teaching in a reformed-based environment where "all" students are expected to be proficient in science. Given that this interview took place after the course had ended, it is very likely that the field experience aspect of the intervention influenced changes in belief about students' learning observed in this preservice teacher's comment above. Therefore, providing opportunities for preservice teachers to explore the effectiveness of the methods and strategies they have learned and see the results may also cause them to confront misconceptions about how students learn science—and to see that their teaching does in fact play a significant role in students' achievement in science.

Perceptions of Growth in PSTE. In the remaining 32\% of the references about their experience in the methods course, several preservice teachers attempted to describe their perceptions of their growth in personal science teaching efficacy during the course. These are depicted in the following comments:

The time that I was in the course, I think it was a continuous growth because it was always pertinent information given, and you know, implementing the things you were taught. (Personal Interview) 
I never stopped learning and there was always something new and meaningful something that I can actually use in the future and not just something text book centered, everything was always powerful and useful. (Personal Interview)

The preservice teacher in the first instance made reference to "continuous" growth throughout the methods course—as did several of the others. Deeper analysis of the codes reflected that the preservice teachers were specifically referring to growth in selfconfidence (4 references), teaching abilities (4 references), love for teaching science (1 reference), and reflective practice in science teaching (1 reference). The remaining 8 references spoke to their perceptions of growth in general. The findings suggested that this growth was not attributed solely to the fact that they were learning new information as they would have in any traditional methods course- -but more so because they themselves deemed the information as "pertinent," "meaningful," and always coupled with opportunities to "implement the things" they were learning. Therefore, it seems as though this model which allowed the needs of the preservice teachers to drive the design and implementation of the scaffolding activities (SAK lectures/Activities) may have been central in keeping their learning experiences relevant (i.e. pertinent/meaningful). Additionally, situating the knowledge through modeling and on-going guided practice using the local curriculum as a framework is likely to have contributed to the preservice teachers' assessment of their learning in the previous quotes as being "useful" and "not just textbook centered” (i.e. meaningful). Finally, the sequencing of the key learning experiences in the course—unit/lesson planning workshops at the beginning, microteaching at mid-course, and the field experience at the end—is most likely to have 
allowed for the continuous application (i.e. implementing) of the knowledge and skills learned throughout the course noted in the first preservice teacher's comment above.

\section{Influence of Course Aspects on PSTE Development}

The results of the quantitative findings also demonstrated how the overall influence of the methods course was not uniformed throughout. The growth means individual preservice teachers at each measure were different, and the between-subjects test showed statistically significant variations in the degree of influence different aspects of the intervention had on individual preservice teachers. The remaining three categories (Table 13) consisted of codes wherein the preservice teachers discussed the various aspects of the methods course, and may provide insight into the variations of influences on their personal science teaching efficacy observed in each of the quantitative measures. The preservice teachers' perceptions of how the CAIC methods course influenced their PSTE development accounted for the largest category of references (34) here. On the other hand, references to the unique aspects of the methods course made-up the second largest category (25). In the smallest category of references, preservice teachers reflected on their overall perception of the methods course's influence on their PSTE.

Table 14

Categories/themes regarding aspects of methods course Categories 1. Influence of CAIC methods on PSTE Development

2. Unique Aspects of The Methods Course Number of References

3. Post-Course Views on PSTE 34 


\section{Influence of Specific Aspects in PSTE Development}

The elementary preservice teachers explained how the CAIC methods used during the course influenced the development of their beliefs about their ability to teach science effectively. References to the influence of all of the CAIC methods used in the course were observed in the data. However, the findings in this section will show that respective preservice teachers appeared to value the significance of each method differently, as it relates to the methods' influence on the development of their personal science teaching efficacy beliefs.

Modeling. The instructor-coach modeled unit and lesson plan development using the backwards design (Wiggins \& Mc Tighe, 1998), and modeled lessons to demonstrate using the 5E Learning Cycle (Settlage \& Southerland, 2012). Preservice teachers who perceived the modeling as influential in the development of their PSTE described it as follows:

One of the most significant experiences of this semester that has influenced my beliefs about my ability to teach science effectively is when [the instructor-coach] modeled a science lesson for the class. This was a simple yet extraordinary experience because I had never seen it done that way. Throughout college life most teachers just usually tell students what they want or expect from them but [the instructor-coach] took the time and effort to demonstrate for us exactly what he wanted to see in our teaching and science lessons. This brought it home for me because it made me realize that I was capable of teaching science and teaching it effectively if I planned for it. (Portfolio Reflection) 
So by you modeling it, I could actually see the flow so that when I got into the classroom, I took whatever you did, you know and then I just memorize it and incorporate it into my classroom activities. (Personal Interview)

Well, seeing it visually you will never forget it so it will always be there in your head and you got to match up, because if you were planning and you had a question like well I don't remember how to do this. Then you can always go back to your model and correct it and make it the right way, so I thought that was beneficial too. (Personal Interview)

These sample quotes represent the diversity of the preservice teachers' perspectives on the influence of the modeling on their PSTE as referenced in the data. In the first case the preservice teacher noted that she gained confidence in her own ability to effectively execute a science lesson through observing the instructor-coach's modeling. In addition to being fascinated to see a professor actually model lesson for the first time, she noted that it "brought it home" for her. That is, the modeling appears to have confirmed within her that with effective planning she too could use the strategies learned to successfully execute a science lesson. In the other two cases, the modeling appears to have provided the preservice teachers with a visual pattern to follow as well as a tool for self-correction, because they both talked about improving their science teaching effectiveness and practices through committing the models to memory. In each case, the preservice teachers are being influenced by the modeling as a vicarious learning experience (Bandura, 1986). 
That is, they appeared to have generated ideas and beliefs about their own competence and abilities from observing the instructor-coach execute tasks.

Coaching. In addition to on-going informal coaching provided throughout the methods course as preservice teachers engaged in learning tasks, individual coaching sessions with the instructor-coach were also facilitated as needed. Mandatory coaching sessions were held with each preservice teacher following their microteaching lessons and any field lesson observations. The coaching involved providing corrective feedback and encouragement to the preservice teachers, while also facilitating articulation of their ideas and beliefs—and reflection on their strengths, weaknesses, challenges, and personal development. The following quotes capture the essence of the preservice teachers' perceptions of the influence of coaching on their PSTE:

The one-on-one with [the instructor-coach] was one of the most beneficial aspects of the course. Getting feedback on my microteaching and hearing my strengths, weaknesses and how to improve. Sharing my evaluation of the lesson and talking it over with someone who has a lot of experience teaching science helped me to differentiate the strategies that I used. (Portfolio Reflection)

Many of the preservice teachers deemed the feedback and encouragement from the coach as most beneficial. The quote above suggested that these preservice teachers placed significant value on receiving the instructor-coach’s constructive criticism, affirmation and validation of their practice. Also, as reflected in this quote, the data suggest that students equally appreciate being able to share their own ideas about their performance. 
They seemed to value the opportunity to discuss them in the context of the expert-novice relationship inherent in the coaching to reinforce their own instructional decision-making abilities, metacognition and development as a reflective practitioner. Another preservice teacher shared how the coaching session helped her rebound from a decline in PSTE after a challenging microteaching exercise. She noted,

Learning and reading about the various skills is totally different from actually having to execute it. At times I can get a little nervous and during the microteaching activity I became discouraged somewhat in my abilities to teach science. I sat down with the lecturer and got some tips as to how I can improve. I applied those tips during my field experience and found them to be successful. (Personal Reflection)

This preservice teacher was confident and motivated about delivering an effective science lesson prior to microteaching. However, she experienced several challenges attributed to nervousness and anxiety which hindered the success of her lesson and led to discouragement relative to her science teaching abilities. This is not uncommon. According to Bandura (1986), individuals can experience setbacks in self-efficacy beliefs when they are not successful at mastery tasks they undertake. However, in this case, the coaching session with the instructor-coach after microteaching allowed for articulation, reflection, feedback, and support of the preservice teacher's emotional well-being (Bandura 1986), which seemed to have helped to salvage the loss in PSTE which resulted from that potentially devastating experience. 
Scaffolding. Several learning experiences were purposefully designed as scaffolds to support the preservice teachers STEB development during the course. Scaffolding was facilitated by the instructor-coach through the SAK presentations with cooperative learning activities and microteaching. This preservice teacher captured the essence of the sentiments expressed about the influence of the SAK presentations/activities in her interview. She noted, They actually helped me because especially when I went into the field and then I came back to class, you would actually 'hit the spot' that I needed extra practice on. So when you lecture on, "this is what you do and how you do it," it was really effective for me and I grasp the information that I need to know on how to deal with certain aspects that happened in my class prior to that class. (Personal Interview)

In this excerpt, the preservice teacher deemed the SAK presentation, referred to as lectures, to be relevant and meaningful, as evidenced by the statement that they "hit the spot" where assistance was needed. This sentiment was most likely expressed because the SAK presentations/activities were in fact designed by the instructor-coach based on needs observed either during the lessons, the microteaching, or field experience. In essence, the scaffolds were in essence narrowly-tailored to support PSTE development in relevant areas of need. The cooperative learning activities which followed each presentation were meant to influence PSTE by providing guided master learning experiences (Bandura, 1986). 
Speaking specifically to the perceived effects of the cooperative learning aspect of the SAK presentations, another preservice teacher noted:

The group work was another aspect of the course that was beneficial to me. Sharing ideas and planning with other members in the class who were also learning to teach science effectively also helped me to learn. (Portfolio Reflection)

This preservice teachers' excerpt also reflected the view of others, that sharing and planning collaboratively during the cooperative learning aspects of the SAK presentations was very beneficial in developing of their confidence in their abilities to teach science effectively. This is most likely because the nature of the collaboration in group work allows for vicarious learning experiences which is one of the source of self-efficacy development (Bandura, 1986). It is likely also that the cooperative groupings created a social learning environment where preservice teachers could also support each other's physical and emotional well-being — which Bandura (1986) also identified as an important source of self-efficacy development.

All of the preservice teachers cited that they believed the microteaching had a significant influence in their development as future teachers of science. Generally, they viewed it as an opportunity to practice, implement what they had learned and to learn from watching each other. The following excerpt is illustrative: 
The microteaching was also beneficial and allowed me to attempt a science lesson before actually teaching in the classroom. It allowed me to observe myself and also my other colleagues; observing what strategies work and what strategies may not be best for certain activities. During the microteaching I was also able to get a feel of the backward design lesson to see how each stage should flow, strange at first but worked fine in the end. (Portfolio Reflection)

The preservice teacher in this portfolio reflection recounted the benefit of the microteaching in providing an opportunity to "get a feel” for implementing science lessons using the new instructional strategies. Granted they had already seen it modeled by the instructor-coach prior to the microteaching, it seemed that experiencing it themselves gave them a greater degree of confidence. This is commensurate with Bandura's (1986) notion that mastery experiences have the greatest influence on an individual's self-efficacy development. In many of the references in this category, several of the preservice teachers mentioned the microteaching as the most beneficial aspect of the course in the development of their science teaching confidence. In the aforementioned quote, the preservice teacher also expressed how she learned "how" and "when" to use specific strategies from observing others microteach. Therefore, the microteaching also apparently acted as an opportunity for preservice teachers observing their peers to engage reflectively and metacognitively about their own future practice.

Exploration with Mentoring. The 4-week field experience was the exploration element of the methods course. Preservice teachers engaged in authentic practice in local schools. The following excerpts are illustrative of their perceptions of the exploration: 
The field experience itself was good and I'm glad for the opportunity it provided for me to practice which will eventually make perfect. It bought me into contact with real situations that will occur in the classroom and left me to use this experience to foster my growth as I continue to work on becoming an effective teacher of science. (Portfolio Reflection)

I would say that was my biggest growing point, because it showed me that I understood what I was taught. (Personal Interview)

The aforementioned quotes suggested that the preservice teachers viewed the field experience as another opportunity to gain mastery experiences (Bandura, 1986). However, unlike the microteaching, the preservice teachers appreciated the ability to experience and practice in the "real" classroom context. In the first case, the field experience seemed to have set a foundation for continual growth in science teaching effectiveness. In the second case, this preservice teacher identified the field experience as the "biggest growing point," which supported its intention to provide a mastery learning task which has the greatest influence on self-efficacy development (Bandura, 1977). Also, the comment seems to suggest that some degree of uncertainty may continue to linger in preservice teachers even after the modeling and microteaching that only authentic learning experiences could abate. This is inferred from her comment that "it proved” that she now understood what "he taught," referring to the instructor-coach.

At this stage, for many of the preservice teachers, the previous coaching for corrective feedback evolved into coaching as mentorship. The relationship became more 
focused on assisting them with learning to manage issues of classroom context. For example, classroom management and managing group dynamics emerged as major issues for many preservice teachers while on their field experience. This preservice teacher described how the instructor-coach aided her with this challenge:

There were times I was not consistent with my rules and consequences and I wasn't being as firm as I should be. However, I've gotten good advice from the lecturer and general view on how the lesson he observed went. With my third lesson, I was then able to manage the students well because I made sure to lay out the rules and consequences before the lesson and I stayed consistent with it. (Portfolio Reflection)

This preservice teacher experienced significant classroom management issues at the beginning of her field experience which hindered the effectiveness of her teaching. This is another example of how learners can experience challenges during mastery tasks which could adversely affect their PSTE. However, the instructor coach's observation and expert mentoring feedback supported her learning to manage dynamics of the classroom environment without adversely affecting her PSTE.

Uniqueness of the Learning Experience. The second largest category comprised of references to the aspects of the methods course the preservice teachers considered to be unique when compared to other methods courses they had taken. The following excerpt succinctly and unequivocally captured the essence of the coded references in this category: 
It was very different because you not only broke down things for us, you showed us a new design. You modeled things for us and showed us what you expected of us and also you provided feedbacks for us whether it was good or bad no matter what we were doing. Whether it was the microteaching, the presentation, for our unit plan, our lesson plan, you provided feedback for us. Most teachers don't do that. We just see our final grade at the end of the semester. But you let us know where we stood so that was very good and that made it different from other methods courses. (Personal Interview)

This comment suggested that the activities of the instructor-coach went beyond mere explanation or "breaking down" of content, and that the new evidence-based tools (5E Learning Cycle and Backwards Design), were novel approaches to instructional delivery. As aforementioned, the modelling was consistently cited as something they had not experienced previously in any of their other methods courses. The excerpt also suggested that the preservice teachers valued the amount of on-going formative feedback and encouragement as other unique aspects. It seems as though the feedback in other methods courses were primarily summative. However, the significant amount of formative feedback inherent in the CAIC allows for the kind of self-monitoring and self-reflection preservice teachers need to develop as self-regulated professional learners and continue enhancing their PSTE. More specifically, the elementary preservice teachers identified the coaching through corrective feedback (five sources, eight references), modeling by instructor-coach (five sources, eight references), scaffolding activities (four sources, five references), and learning the new unit plan format and new teaching strategies (five 
sources, six references) as the unique aspects of their learning experience in the methods course.

\section{Post-Course Views on PSTE}

Overall, the preservice teachers perceived that the learning experiences were very influential in the development of their PSTE. This is reflected in the following sample excerpts from three of their final portfolios:

This course has completely turned my perspective, my view and my belief around when it comes to my ability to teach science effectively. (Portfolio Reflection)

This course has had a powerful influence on my beliefs about my ability to teach science effectively. (Portfolio Reflection)

My self-esteem and confidence level has been boosted and therefore I look forward to teaching science and imparting the knowledge and skills onto my students. (Portfolio Reflection)

The preservice teachers used strong adjectives such as “completely” and "powerful” to explain the effect of the CAIC methods course on their science teaching confidence. The first adjective implies perception of a complete transformation as a result of the learning experiences, whereas the latter appears to speak to the meaningfulness of the learning experiences. Further data analysis revealed that the perspectives and "views" in the first quote referred to preservice teachers' initial negative perceptions about science teaching and learning — whereas "beliefs" referred to their beliefs about their personal abilities to teach science effectively prior to participating in the course. Therefore, as evident in the 
second quote, the preservice teachers generally felt that their PSTE (self-esteem and confidence level) had been "boosted" as a result of their learning experiences in the course. Also, the latter part of the last comment suggested optimism about teaching science effectively and also a belief that effective teaching can lead to improved student learning outcomes.

\section{Conclusion}

The overall results of this study suggested that the cognitive apprenticeship-based instructional coaching (CAIC) methods course may provide an effective reform-based model for developing and sustaining the science teaching efficacy beliefs (STEB) of preservice elementary teachers. The quantitative findings in this study further illustrated that the results obtained by adopting the CAIC approach designing and implementing of science methods courses can be significantly positive for preservice teachers.

Additionally, perceptions of the preservice teachers about the influence of the CAIC methods course presented in the qualitative data suggested that this model may also be worth exploring for its ability to influence preservice teachers who come to methods course with various learning needs and with different levels of STEB. Embracing the coaching role that utilizes the tools of cognitive apprenticeship (Collins, Brown, \& Newman, 1989) may equip science methods instructors with a framework to design and implement methods courses that engage students as apprentices in meaningful learning opportunities that are narrowly-tailored to foster Bandura’s (1986) four aspects of self-

efficacy development, as they learn to teach science effectively through authentic social engagement within the local and functional context of instruction. 


\section{References}

Allinder, R. M. (1994). The relationship between efficacy and the instructional practices of special education teachers and consultants. Teacher Education and Special Education, 17, 86-95.

Averch, H. A., Rand Corporation., \& United States. (1972). How effective is schooling? A critical review and synthesis of research findings. Santa Monica, CA: Rand Corp.

Aydin, S. \& Boz, Y. (2010). Pre-Service elementary science teachers’ science teaching efficacy beliefs and their sources. Elementary Education Online, 9(2), 694-704.

Bandura, A. (1986). Social foundations of thought and action: A social cognitive theory. Englewood Cliffs, NJ: Prentice- Hall.

Bandura, A. (1977) Self-efficacy: Toward a unifying theory of behavioral change. Psychological Review, 84, 191-215.

Bybee, R. W. (1997). Achieving scientific literacy: From purposes to practices. Portsmouth, NH: Heinemann.

Bleicher, R. E., \& Lindgren, J. (2005). Success in science learning and preservice science teaching self-efficacy. Journal of Science Teacher Education, 16, 205- 225.

Borman, J., \& Feger, S. (2006). Instructional coaching: Key themes from the literature. Providence, RI: The Education. Alliance at Brown University.

Brown, J. S., Collins, A., \& Duguid, P. (1989). Situated cognition and the culture of learning. Educational Researcher, 18(1), 32-42. Reprinted in H. McLellan (Ed.) Situated learning perspectives. Englewood Cliffs NJ: Educational Technology Publications, 1996, 19-44.

Campbell, D. T., \& Stanley, J. C. (1963). Experimental and quasi-experimental designs for research on teaching. In N. L. Gage (Ed.), Handbook of research on teaching (pp. 171-246). Chicago, IL: Rand McNally.

Cantrell, P., Young, S., \& Moore, A. (2003). Factors affecting science teaching efficacy of preservice elementary teachers. Journal of Science Teacher Education, 14(3), 177-192.

Cascio, E., \& Staiger, D. (2012). Knowledge, Tests, and Fadeout in Educational Interventions. NBER working Paper Number 18038. Retrieved on March 18, 2015 from: http://www.nber.org/papers/w18038.pdf 
Collins, A. (2006). Cognitive apprenticeship. In R. K. Sawyer (Ed.) Cambridge Handbook of the Learning Sciences (pp. 47-60).Cambridge UK: Cambridge University Press.

Collins, A., Brown, J. S., \& Newman, S. E. (1989). Cognitive apprenticeship: Teaching the crafts of reading, writing, and mathematics. In L. B. Resnick (Ed.), Knowing, learning, and instruction: Essays in honor of Robert Glaser (pp. 453-494). Hillsdale, NJ: Lawrence Erlbaum Associates.

Currie, J., \& Duncan T. (1995). “Does Head Start Make A Difference?” The American Economic Review. 85(3): 341-64.

Darling-Hammond, L. (2000). Teacher quality and student achievement: A review of state policy evidence. Education Policy Analysis Archives, 8(1), 50.

Denton, C. A., \& Hasbrouck, J. (2009). A description of instructional coaching and its relationship to consultation. Journal of Educational and Psychological Consultation, 19(2), 150-175.

Enoch, L. G., \& Riggs, I. M. (1990). Further development of an elementary science teaching efficacy belief instrument: A preservice elementary scale. School Science and Mathematics, 90(8), 694-706.

Haycock, K. (1998). Good teaching matters: How well-qualified researchers can close the gap. Thinking K-16, 3(2), 1-14.

Holzberger, D., Phillip, A., \& Hunter, M. (2013). How teachers' self-efficacy is related to instructional quality: A longitudinal analysis. Journal of Educational Psychology, 105(3), 774-786.

Karplus, R., \& Thier, H. (1967). A new look at elementary school science. Chicago: Rand-McNally.

Knight, J.(2009). Coaching: Approaches and perspectives. Thousand Oaks, CA: Corwin Press.

Lakshmanan, A., Heath, B. P., Perlmutter, A. and Elder, M. (2011). The impact of science content and professional learning communities on science teaching efficacy and standards-based instruction. Journal of Research in Science Teaching, 48, 534-551.

Merriam, S. B. (2002). Qualitative research in practice: Examples for discussion and analysis. San Francisco, CA: Jossey-Bass. 
Saldaña, J. (2013). The coding manual for qualitative researchers (2nd ed.). Thousand Oaks, CA: Sage.

Scharmann, L. C., \& Hampton, C. M. (1995). Cooperative learning and preservice elementary teacher science self efficacy. Journal of Science Teacher Education, 6(3), 125-133.

Settlage, J., \& Southerland, S. A. (2012). Teaching science to every child: Using culture as a starting point, $2^{\text {nd }}$ edition. New York, NY: Routledge, Taylor, \& Francis Group.

Shadish, W. R., Cook, T. D., \& Campbell, D. T. (2002). Experimental and quasiexperimental designs for generalized causal inference. Boston, MA: Houghton Mifflin.

Stock, J. (1999). Introduction to single subjects design. Retrieved on November 2, 1014 from: https://www.msu.edu/user/sw/ssd/issd02.htm.

Tashakkori, A., \& Teddlie, C. (Eds.). (2003). Handbook of mixed methods in social and behavioral research. Thousand Oaks, CA: Sage.

Wiggins, G., \& McTighe, J. (1998). Understanding by design. Alexandria, VA: Association for Supervision and Curriculum Development.

Wright, S. P., Horn, S. P., \& Sanders, W. L. (1997). Teacher and classroom context effects on student achievement: Implications for teacher evaluation. Journal of Personnel Evaluation in Education, 11(3), 57-67.

Yilmaz, H., \& Huyuguzel Cavas, P. (2008). The effects of the teaching practice on preservice elementary teachers' science teaching efficacy and classroom management beliefs. Eurasia Journal of Mathematics, Science \& Technology Education, 4 (1), 45-54. 


\title{
CHAPTER III
}

\section{STUDY \#2, PARTICIPATORY ACTION RESEARCH CASE STUDY-THE UTILITY OF COGNITIVE APPRENTICESHIP-BASED INSTRUCTIONAL COACHING FOR IMPROVING SCIENCE TEACHING EFFICACY BELIEFS AND COMPETENCY IN IMPLEMENTING AN INQUIRY-BASED CURRICULUM AMONG BAHAMIAN ELEMENTARY TEACHERS}

\author{
Abstract \\ Inservice teacher professional development is a critical focus of science education \\ reform movements globally. This participatory action research case study explored the \\ utility of a cognitive apprenticeship-based instructional coaching (CAIC) professional \\ development program for improving science teaching efficacy beliefs (STEB) of \\ Bahamian elementary teachers and their competency in effectively implementing inquiry- \\ based curricula. Five inservice teachers participated in the 10-week professional \\ development program. Individual and focus group interviews were undertaken before, \\ during, and after the program to determine the teachers' perspectives of the effectiveness \\ of the CAIC program and its utility for addressing local professional development needs \\ in elementary science education. The findings suggested that while the teachers perceived \\ that all of the CAIC methods were beneficial, scaffolding and coaching appeared to have \\ had the greatest influence on improving their STEB. This outcome supported the growing \\ body of literature emphasizing the importance of relationships in effective instructional \\ coaching programs. The findings further suggested that the CAIC professional \\ development program may also have been an effective means of enhancing teachers’ \\ competency in implementing inquiry-based curricula.
}




\section{Introduction}

Science education reform has become a critical focus for educators and policymakers globally in recent decades. Advancements in technology, medicine, and other science-related fields all served as impetuses to increase human capacity in science by improving science education in schools as a fundamental step towards this goal. In the U.S., according to Pea and Collins (2008), the present reform movement is focused on a “systemic” approach to improving science education. This involves a concentration on the aggregate of variables influencing K-12 science education simultaneously. That is, it is focused on coordinating curriculum design, learning activities, learning tools, assessments, and teacher professional development (Pea \& Collins, 2008). Concurrent with moves in the U.S., science education reform has also become a national priority in The Bahamas in recent years. In 2010, a committee was convened by the Bahamas Environment Science and Technology Commission and they developed a document entitled, Bahamas Roadmap for Science and Technology (Curling et al., 2010). This landmark document emphasized the dire need for greater research capacity in science and science education in the country. The document also highlighted the need to "expand opportunities for teacher up-grading, with greater emphasis being placed on current trends in S \& T [science and technology] education. This should include preservice and inservice training” (Curling et al., 2010, p. 24). Further, in 2012, the Prime Minister of

The Bahamas developed the Ministry of Education, Science, and Technology (“Cabinet Appointments,” 2012) which further demonstrated commitment to advancing science education as a national priority. 
A common thread between the science education reform efforts undertaken in both the U.S. and The Bahamas is that classroom teachers and their instructional practices are the central focus. Substantial emphasis is being placed on preservice teacher learning and inservice teacher professional development as fundamental steps towards improving teacher quality and ultimately student achievement outcomes in science.

“Teacher quality" had been found to be the in-school variable most highly correlated with student achievement outcomes (Darling-Hammond, 2000; Haycock, 1998; Wright, Horn, \& Sanders, 1997). According to Colbert, Brown, Choi, and Thomas (2008), "professional development is a common and necessary approach in improving teacher quality” (p. 135). However, traditional models of professional development, which are still widely used in both the U.S. and The Bahamas, have been found to be largely ineffective at changing teachers' classroom practices. These archaic workshop and seminar formats were shown to have low rates of transferability beyond the actual training sessions and very little influence on teachers' long-term instructional practice. Subsequently, the U.S. National Staff Development Council in the Standards for Staff Development (2001) called for a departure from traditional approaches to teacher professional development to embrace more effective, non-traditional, and evidence-based models.

The call for reform in teacher professional development approaches led many researchers to revisit the seminal findings of Joyce and Showers (1980), who had long before suggested that the existent approaches to professional development were ineffective. Joyce and Showers (1980) found that traditional teacher learning workshops and seminars alone yielded a menial average of about $10 \%$ transferability into classroom practice. However, they discovered that upwards to "90\% of learners will transfer a new 
skill into their practice as a result of theory, demonstration, practice, and corrective feedback during the training when it is followed up with job-embedded coaching” (UC Davis, 2013). Subsequently, many job-embedded professional development programs for inservice teachers began to emerge in recent years as part of professional development reform initiatives in the U.S. Instructional coaching is one such approach to providing job-embedded professional development for teachers that emerged.

According to Knight (2009), "an instructional coach partners with teachers to help them incorporate research-based instructional practices into their teaching which help students learn more effectively" (p. 30). In 2008 Cornett and Knight noted that "there are currently more than 2,100 full-time coaches in Florida alone” (p. 2). Some preliminary research on instructional coaching indicated many benefits, including its potential to provide a link between teachers and administrators (Baker, 2010), improve teacher selfefficacy (Scurry, 2010), enhance teacher reflection (Reed, 2006), increase teachers’ emotional intelligence (Avant, 2012), and foster effective collaboration in communities of practice (Wicker, 2006). In other studies, however, instructional coaching programs were found to have fallen short of their intended goals due to apparent failure to first ground the instructional coaching in strong theoretical models. According to Denton and Hasbrouck (2009), “unfortunately, the rush to implement coaching before strong theoretical models, or even well-defined job descriptions, were in place has caused a good deal of confusion related to the role and focus of coaching” (p. 155). To this end, more robust empirical studies are needed to identify strong theoretical coaching models which can provide more effective frameworks for designing and delivering inservice teacher professional development programs in critical needs areas such as science. 


\section{Research Purpose and Question}

The purpose of this study was to investigate the utility of a cognitive apprenticeship-based (Collins, Brown, \& Newman, 1989) instructional coaching professional development program for improving science teaching efficacy beliefs (STEB) and competency in implementing inquiry-based science curricula among Bahamian inservice elementary teachers. The intervention focused on developing teacher efficacy beliefs because they were identified as the variable most significantly correlated with teacher quality (Henson, 2001).

The concept of STEB is derived from Bandura's (1986) concept of self-efficacy beliefs and refers to a teacher's self-perceived ability to teach science effectively. Improving teacher quality begins with increasing their efficacy beliefs because their ideas about teaching and learning in a given content area greatly influence their attitude and commitment towards professional development initiatives in that area. This is significant because the degree to which teachers embrace professional development programs is highly correlated with the rate at which the information gained is transferred into their actual classroom practice.

The guiding research question which formulates the parameters of this paper is:

1. From the perspectives of Bahamian inservice elementary teachers, how did participating in a cognitive apprenticeship-based instructional coaching program influence the development of their science teaching efficacy beliefs and ability to implement inquiry-based curricula? 


\section{The Bahamian Case}

The literature is scarce about challenges facing Bahamian inservice elementary teachers of science. Hence, as a groundbreaking study, data were collected and analyzed from individual interviews with five inservice teachers (Pseudonyms: Mae, Melinda, Faith, Zajah, and Lillian) to ascertain their perspectives of the key challenges facing elementary science education in The Bahamas. The interview data were analyzed inductively using “challenges facing elementary science education in The Bahamas” as an a priori code in the first coding cycle. Finally, focused coding was used in a second coding cycle to organize the data into categories (Saldana, 2013). Memoing was then used to keep an audit trail and to summarize the findings in each category. Three major challenges regarding elementary science teaching in The Bahamas emerged.

\section{(i) Shortcomings in preservice training}

Preservice teachers learn the fundamentals of science teaching and learning in their undergraduate science methods course(s) and their STEB are developed simultaneously. However, three of the five inservice teachers interviewed felt their preservice teacher training in science was inadequate. Faith’s comment here is illustrative, as she recalled not learning "how" to teach science:

Even though it's teaching, they never really teach you how to teach. It's like they give you material, and content, that type of thing. As far as, this is how you actually do it in the classroom, I don't think that was there. (Personal Interview) 


\section{(ii) Shortcomings in professional development and lack of instructional support}

General Issues. Teacher professional development (PD) is essential for providing instructional support to classroom teachers in implementing new innovations in schools. Traditional school-based workshops are the primary form of PD for Bahamian inservice teachers and are usually facilitated an average of 2-5 days per year. Mae explained: At [my] school, it's actually when we have our midterm break in February, it's two days. Then when you come back from summer vacation a week earlier than students, so there is actually like two to three days PD. So, all together we got like five days school-based per year. (Personal Interview)

Teachers feel these sessions yield little transfer of knowledge and skills into classroom practice because often there is no follow-up as Faith describes in this vignette:

We went to professional development, but a lot of times what we did, we don't really use in the classroom... Some days you might, but for the most part, you just got it and don't utilize it...They just give it [information] to you there, but then there's no follow up to make sure that you're doing it and to guide you as to what you should do. It is useful but you don't have persons on staff to go through it with you, and making sure that it's being implemented in the classrooms. (Personal Interview)

In addition to the school-based PDs, according to Lillian, "sometimes Ministry [of Education] will organize workshops for teachers for developmental purposes” (Personal Interview). However, many teachers do not find them useful and have also developed a great deal of apathy towards PDs offered by the Ministry of Education. Mae elaborated on the disdain they have developed towards the ministry's PDs in this excerpt: 
People only go because they get a half day off from school. They give you half day from school to attend these sessions. Sometimes you may have to go to another school too. So, many teachers just sign their names, put their bags near the door or in another classroom, and then say they're going to the washroom. Instead, they leave to go home. (Personal Interview)

Issues in Science. Bahamian elementary school teachers reportedly receive very little PD and instructional support in science. The few seminars/workshops offered in science were thought to be somewhat beneficial but for the most part they are optional. Hence, only a comparatively small numbers of teachers ever attend. Speaking about this, Mae recalled:

[In the] summer, you can choose to go to the science professional development [sessions]. It's actually your choice... you choose which session you go to. The sessions run two days. The science professional development session is normally the second day. I feel that most of them are beneficial because they are more hands-on and they're teaching you how to teach. (Personal Interview) PD in science, therefore, can be described as self-directed in this context. Thus, Bahamian elementary teachers' involvement in science-related PDs range from none since university (reported by Melinda) to multiple annually (reported by Mae).

\section{(iii) Challenges in effectively implementing the new inquiry-based curricula}

Curriculum implementation is the primary responsibility of inservice teachers in the classroom. However, most reform-based elementary science curricula, including the revised Bahamas Primary Science Curriculum, are now inquiry-based. Many Bahamian 
inservice teachers are experiencing challenges with implementing the new curriculum effectively. Many of them simply do not understand it because they were never formally trained to use it. This first comment here is illustrative: "it is not clearly defined... you have to really spend time going into it and trying to understand what they are saying” (Faith, Personal Interview). Zajah, an elementary science specialist, shared her experience with assisting teachers at her school to understand the new curriculum in the following excerpt:

Some of them they have weaknesses in certain areas. They'll come to me for assistance. Or, I'll just go to their classes and teach the lessons for them if they don't feel comfortable or confident enough to teach a particular topic that is on their curriculum. (Personal Interview)

These key issues outlined in this case summary reflect the insurmountable challenges presently experienced in advancing elementary, and inevitably every other level of science education in The Bahamas.

\section{Theoretical and Conceptual Frameworks}

Bandura's (1986) theory of self-efficacy provides the theoretical underpinnings for this study. Cognitive apprenticeship theory (Collins, Brown, \& Newman, 1989) formed the basis for the conceptual design and implementation of the instructional coaching intervention.

Bandura developed the concept of self-efficacy beliefs as part of his Social Cognitive Theory (Bandura, 1977). Self-efficacy beliefs refers to “one’s belief in one’s own ability to successfully perform a specific task” (Lakshmanan, Heath, Perlmutter, \& 
Elder, 2011). Therefore, the degree to which individuals are willing to engage in specific tasks is significantly influenced by their beliefs about their ability to be successful. The construct, science teaching efficacy beliefs (STEB), came from Bandura's self-efficacy concept. It refers to teachers' self-perception of their abilities to teach science successfully. Bandura (1986) posited that the four factors which contribute most significantly to the development of self-efficacy (and as such, STEB as well) are mastery experiences, vicarious experiences, social and verbal persuasion, and physical and emotional well-being. He determined, however, that mastery experiences were the most influential. The learning tasks and cognitive apprenticeship-based instructional coaching model used in this study were designed to target each of these four sources of selfefficacy development (Table 15).

According to Collins, Brown, and Newman (1989), “cognitive apprenticeship refers to the focus on learning-through-guided-experience, on cognitive and metacognitive, rather than physical skills and processes” (p. 457). Cognitive Apprenticeship is designed to teach the pertinent thinking and problem-solving skills for mastery in a given field. The methods used in cognitive apprenticeship are scaffolding, modeling, coaching, articulation, reflection and exploration. Collins (2006) defines the methods of cognitive apprenticeship as follows:

Modeling involves an expert performing a task so that the students can observe and build a conceptual model of the processes that are required to accomplish it. Coaching consists of observing students while they carry out a task and offering hints, challenges, scaffolding, feedback, modeling, reminders, and new tasks aimed at bringing their performance closer to expert performance. Scaffolding 
refers to support the teacher provides to help students carry out tasks. Articulation includes any method of getting students to explicitly state their knowledge, reasoning, or problem-solving processes in a domain. Reflection involves enabling students to compare their own problem solving processes with those of an expert, another student, and ultimately, an internal cognitive model of expertise. Exploration involves guiding students to a mode of problem solving on their own. (pp. 50-1)

According to Borman and Feger (2006), "the focus of the expert/novice interaction in a cognitive apprenticeship is on developing cognitive skills of reflection through discourse and application of knowledge” (p. 3). Therefore, a CAIC professional development program involves engaging inservice teachers in mastery learning experiences through guided practice with corrective feedback within a local context of instruction. The methods of cognitive apprenticeship were employed in facilitating the learning experiences of the inservice teachers.

\section{Review of Literature}

\section{Inservice Teacher Professional Development}

Professional development is necessary for improving teaching quality and effectiveness (Colbert, Brown, Choi, \& Thomas, 2008). On-going opportunities for professional development are particularly important for teachers of science given the ever-changing nature of the fields of science and science education. According to Posnanski (2002), 
effective teachers of sciences need continuous skill development throughout their careers. As contemporary ideas of both science teaching and learning change, so too must teachers have opportunities to study and engage in the theories and research that drive these reformative changes. (p. 189)

Thus, the quality of the professional development is equally as important as providing these opportunities if they are to significantly influence teacher quality. Colbert, Brown, Choi, \& Thomas (2008) affirmed that "improving teacher quality depends on improving professional development and improving professional development depends on creating meaningful learning experiences for teachers” (p. 138).

Reflection and collaboration are two important elements frequently cited in the literature as critical components of effective professional development programs. Posnanski (2002) noted that "effective in-service professional development programs should attempt to have teachers identify, discuss, and reflect on various pedagogical issues as well as their own beliefs about effective teaching behaviors” (p. 191). This approach facilitates teachers' development of the metacognitive skills necessary for continued instructional effectiveness in a reform-based educational environment. Colbert et al. (2008) also suggested that collaborative engagement through professional learning communities has also been identified in an increasing number of studies as being a key characteristic of effective professional development. A professional learning community in this context refers to a group of educators working together to support and enhance each other in their professional growth. These learning communities allow for support through prolonged engagement, which encourages optimal and sustained transferability 
of the new innovations into teachers’ classroom instructional practice (Lakshmanan, Heath, Perlmutter, \& Elder, 2011).

\section{Science Teaching Efficacy Beliefs}

Reflective and collaborative professional development programs may not only positively influence teacher behavior but also enhance science teacher efficacy (Lakshmanan, et al., 2011). This is particularly noteworthy as teacher efficacy has been found to be significantly correlated with key variables in effective instructional practices such as teacher persistence (Bandura, 1997) and commitment to teaching content effectively and thoroughly (Gibson \& Dembo, 1984). Lakshmanan et al. (2011) concluded "that adding experience, such as professional learning communities, to professional development programs can enhance science teaching efficacy” (p. 547). According to Bandura (1997), "teacher efficacy in science education is of particular concern, given the increasing importance of scientific literacy and competency in the technological transformations occurring in society” (p. 242).

Lakshmanan et al. (2011) cited Ballone and Czerniak’s (2001) argument "that a focus on the role of teacher beliefs is essential for successful science education reform” (pp. 534-5). This means that teachers' STEB have significant implications for the success of science education reform goals and subsequently future scientific advancements. Therefore, developing teaching efficacy beliefs should be an important goal of teacher professional development (Lakshmanan et al., 2011). Further, Guskey (1988) suggests that teachers with higher STEB are the most likely to implement reform innovations. 


\section{Instructional Coaching and Science Teaching Efficacy Beliefs}

Instructional coaches provide support for teachers in schools as they attempt to integrate new curriculum innovations into their instructional practices. Studies supporting the potential of instructional coaching to improve teacher quality and efficacy beliefs through collaborative professional development are increasing in the literature.

According to Colbert et al. (2008), traditional models "such as workshops, seminars, and so on should be supplanted by new models such as mentoring, peer observation and coaching, networking and collaborative work” (p. 137). Shidler (2008) noted that “coaching for increased teaching efficacy (both institutional and self) has been an essential component to various educational reforms such as No Child Left Behind” (p. 453). She went on to explain that to build teaching efficacy beliefs, "coaches need to focus on specific content, model techniques and instructional practices, and dedicate consultative hours to working with teachers when children are not present in order to better facilitate reflection” (p. 459). Coaching had not only been reported as useful for teachers with low levels of teaching efficacy beliefs, but also beneficial for continuously developing the efficacy beliefs of teachers at all levels. Ross (1992) "found that all teachers, regardless of their efficacy, were more effective with increased contact with their coaches” (p. 62).

\section{Inquiry-based Curricula and Teacher Change}

Recent studies by Roehrig, Kruse, and Kern (2007) revealed that “despite the central role of science as inquiry in science education reform documents, there is little evidence that teaching in K-12 classrooms is, in fact, centered around inquiry (p. 884). At 
the elementary levels, some studies reported that "even when using inquiry-based science curriculum materials, elementary teachers may not always effectively engage students in science as inquiry” (Forbes \& Davis, 2010, p. 820). In many cases, this is because teachers at this level struggle with understanding inquiry and inquiry-based curricula and as such depend heavily on science curriculum materials/programs to guide their practice. Parke and Coble (1997) confirmed teachers’ reports “that their primary guides for their classroom is the district-adopted textbook" (p. 774). Another reason for scientific inquiry having slow transferability into these teachers' instructional practices is that teacher change takes time. Therefore, professional development introducing curricular change needs to be systematic and on-going. According to Davis (2002), "those advocating change should acknowledge that teacher learning is a gradual process-which we know learning is_-instead of the learning on the spot, which seems to be the picture of an allat-once comprehensive curriculum change” (p. 23). Intensive one-on-one professional development over an extended period of time may be necessary for some teachers to confront their beliefs and embrace new reform-based curriculum being introduced (Roehrig et al., 2007).

\section{Description of Intervention}

For this study, five Bahamian elementary inservice teachers participated in a cognitive apprenticeship-based instructional coaching professional development program where they received mentorship by the researcher as the instructional coach for ten weeks. The instructional coach and teachers collaborated in a professional learning community meeting together for one hour bi-weekly. The program included several key 
elements designed to enhance the STEB of the inservice teachers and their competency in implementing the new inquiry-based curriculum. The major aspects were as follows:

(i) The inservice teachers were engaged in a number of problem-based cooperative learning tasks designed to address deficiencies in scientific skills, attitudes, and knowledge called SAK Activities, as determined to be necessary by the instructional coach. For example, in one task they were presented with scenarios requiring different types of cooperative learning strategies, and had to work together to decide when, where, and how the strategy would be most effective.

(ii) The participating teachers were also required to plan and execute a 30-minute microteaching lesson within the professional learning community for guided practice as they developed mastery of the contents learned during the program. A time for self-reflection on their lessons as well as a group feedback session was facilitated after every microteaching lesson.

(iii) Through modeling, the instructional coach also taught the teachers to use Backwards Design (Wiggins \& McTighe, 1998) and the 5E Learning Cycle teaching model (Bybee, 1997) as research-based tools for implementing inquiry science curricula. Backwards design is an evidence-based process of instructional planning which begins with the established learning goals of the curriculum and proceeds backwards with selecting appropriate assessments before electing relevant learning activities to meet those goals. The 5E Learning Cycle, a modification of Karplus and Thier’s (1967) learning cycle, was developed by Rodger W. Bybee of the Biological Sciences Curriculum 
Study (BSCS) project (1997). It is a systematic experiential model for delivering inquiry-based lessons in a series of five phases: engage, explore, explain, extend, and evaluate. They used these tools to construct a 3-lesson individual unit plan. In addition to modeling the use of these new approaches, the instructional coach employed modeling to demonstrate mini lessons using the same-while simultaneously making expert thinking and instructional decision-making visible to them. These model lessons were followed by a reflective discussion on each lesson.

(iv) The instructional coach also facilitated one-on-one coaching sessions with individual teachers after their microteaching lessons. Additional individual coaching and debriefing sessions were scheduled throughout the 10 weeks as needed, initiated by either the instructional coach or the teachers themselves.

(v) As their culminating learning task, participating inservice teachers were required to execute their individual 3-lesson inquiry-based unit plan developed during the PD within their respective classrooms. One of these lessons was observed by the instructional coach, and individual coaching sessions were held after each lesson observation.

The conceptual relationship between the aspects of the program, the methods of cognitive apprenticeship (Collins, Brown, \& Newman, 1989), and the specific sources of selfefficacy development they targeted are outlined in Table 15 below. 
Table 15

Conceptual relationship between aspects of the methods course and theories employed

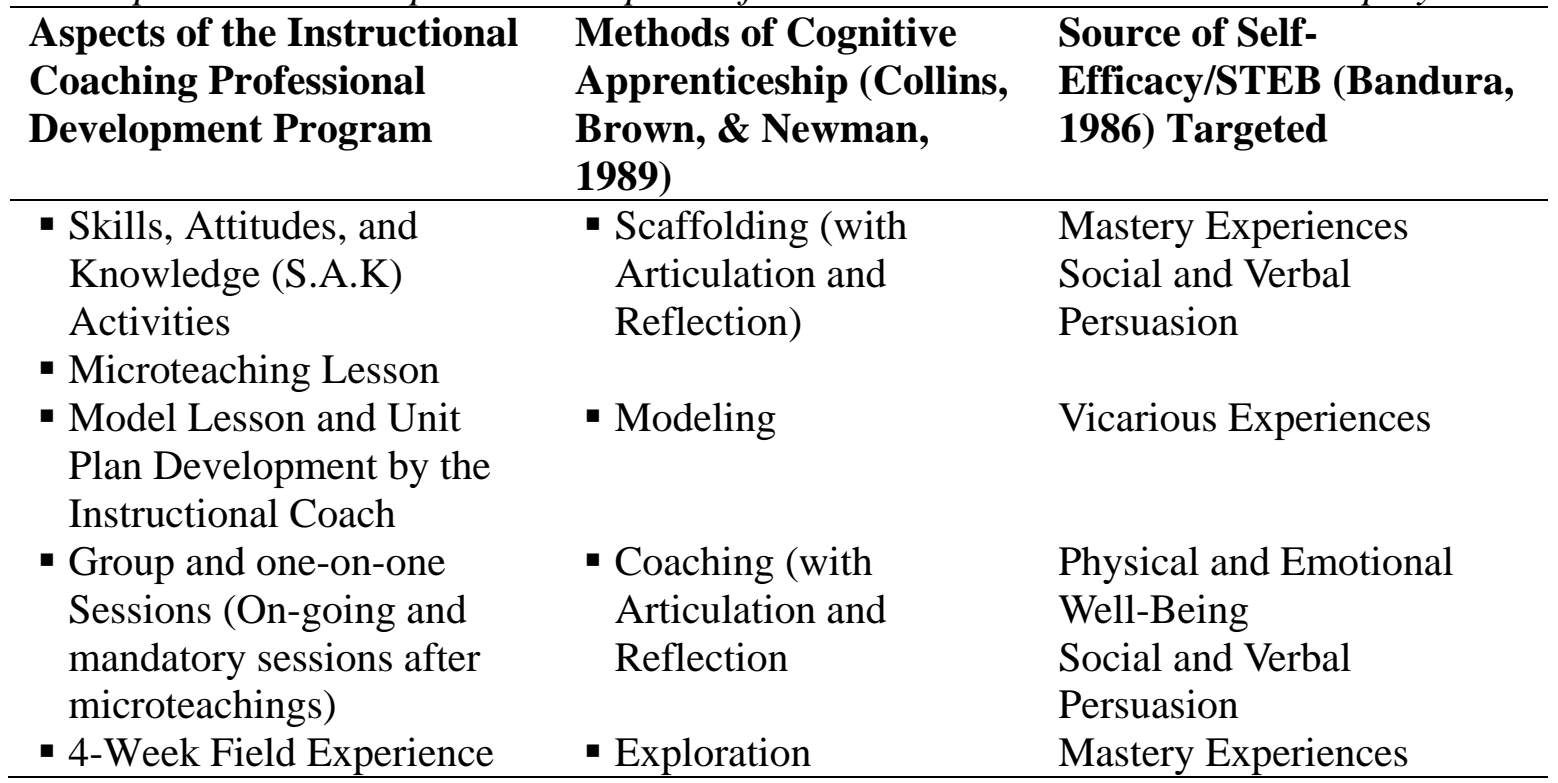

\section{Methodology}

This qualitative study employed a participatory action research (PAR) case study research design. According to Merriam (2002), PAR “focuses upon the political empowerment of people through group participation in the search for and acquisition of knowledge and subsequent action to change the status quo" (p. 10). It involves "solving a problem or obtaining information in order to inform local practice” (Fraenkel \& Wallen, 2008, p. 390), and is therefore very limited in generalizability. Nevertheless, the global need for stronger professional development models which are based on sound theoretical models makes this study potentially beneficial beyond the local context. While the results are limited in generalizability, the theoretical and conceptual frameworks used in this study are universal and the intervention can be modified to suit other contexts of instruction. 
Participatory action research involves various levels of participation. According to Fraenkel and Wallen (2008),

Higher levels of involvement may include helping in instrument development, data collection, and data analysis, participating in the data interpretation; making recommendations for further research; actively participating in designing the study; formulating the problem of concern; even initiating the research effort.” p. 592

The extent of the inservice teachers' involvement in this study was in formulating the problem (as outlined in the case above) and participating in the individual and focus group interviews. As participants in the study, they were also involved in data collection and in data interpretation through member checking of the findings. The data from the final focus group interview were also used to help determine the implications of the study's outcomes for local practice. Case study research design also helped to form the parameters of this study as it involved "an intensive description and analysis of a phenomena or social unit such as an individual, group, institution, or community (Merriam, 2002, p. 8). In this instance, the bounded unit under study is a group of Bahamian elementary inservice teachers.

\section{Participants}

Five inservice elementary teachers (all female) and the instructional coach (male) were the participants in the study. Participants ranged in age from early 20s to early 50s. The researcher and instructional coach is a university professor in elementary science education. He taught elementary and middle school science and technology for several 
years prior to returning to university to pursue a doctorate degree in science education. The group of inservice teachers was comprised of one early childhood and four first through fifth grade teachers. Their teaching experience spanned a range of four to twenty seven years. Three of the teachers taught in the Bahamian public school system, while the others taught at private schools. One of the participants was the elementary science specialist teacher at her school, another the science coordinator at her school, and the remaining three teachers were generalist teachers. A science specialist teacher in The Bahamas is an elementary teacher who teaches all science classes to students in grades 46 in their assigned school, whereas a science coordinator is a general education teacher with the responsibility of overseeing the teaching and learning of science as part of an interdisciplinary curriculum for students in grades K-3. All participants were teacher trained with baccalaureate degrees in elementary education, with the exception of the science specialist, who held a bachelor of education degree in secondary biology education.

\section{Data Collection}

The data sources in this study were triangulated (Patton, 1990) with individual and focus group interviews. Two 30-45 minute interviews were conducted with each inservice teacher within a week before and after the study. One focus group interview was facilitated at week 10 and the other approximately one week after the final field teaching experience. The first set of individual interviews focused on obtaining background information about the participants and their beliefs about science teaching and learning prior to participating in the study. The second interview focused on their 
prior experience with inservice professional development and how their participation in this type of professional development influenced their science teaching efficacy beliefs (STEB) and curriculum implementation. During the first focus group interview, participants focused on how the coaching program influenced their STEB and competency in implementing the inquiry-based curriculum. In the second focus group interview, participants concentrated on the role that instructional coaching played in helping to manage challenges in the field. Additionally, based on their experiences, the group also explored how a CAIC program in schools might enhance the STEB of Bahamian elementary in-service elementary teachers and competency in implementing inquiry-based curricula effectively. All data sources were recorded electronically and transcribed.

\section{Data Analysis}

The qualitative data were stored, managed, and coded manually using NVivo 10 software. Five coding methods were selected based on the nature of the research question, which "suggest the exploration of personal, interpretive meanings found within the data” (Saldana, 2013, p. 61). Therefore, first cycle coding methods employed were: in vivo coding to find the participants' voices within the data; process coding to reveal participants' actions and interactions; emotion coding to "label the emotions recalled and/or experienced by the participants, or inferred by the researcher about the participant” (Saldana, 2013, p. 105); and values coding to label participants’ attitudes, values, and beliefs about the intervention and science teaching and learning. During the second coding cycle, focused coding was employed to reassemble the data which resulted 
from the first coding cycle by organizing the now segmented data into meaningful categories. Finally, the data in each category were coded using the six methods of cognitive apprenticeship and "curriculum implementation" as a priori codes. Memoing was used at this stage to analyze each category inductively to ascertain the narratives embedded in them. In addition to triangulating (Patton, 1990), the data source, member checking, and a peer review process were also engaged to strengthen the trustworthiness of the findings. Member checking was executed at two levels, once after the memos for each category were written, and then the final write-up was sent out to participants for feedback on accuracy of the representation and interpretation. Data were revised in lieu of feedback received. The peer reviewer was a science teacher educator who holds a doctorate degree in science education. She helped to enhance the quality of the study by cross-checking the data and resulting narratives for accuracy of the inferences drawn from them and also reviewing the final write-up of the findings for accuracy of representation and possible biases imposed. All of the feedback was discussed and decisions were mutually agreed upon as to whether it was necessary to revisit the data set and how to move forward. Also, as this study was part of a larger doctoral dissertation project, an additional level of peer-review was built-in through feedback and guidance received from the members of my dissertation committee.

\section{Findings}

In the following sections, the findings from the a priori coding cycle are reported. They represent five Bahamian elementary inservice teachers’ perceptions of: (i) how the methods of the cognitive apprenticeship-based instructional coaching (CAIC) program 
influenced the development of their science teaching efficacy beliefs (STEB) (Table 16) and (ii) how the CAIC program influenced their competency in effectively implementing the new inquiry-based Bahamian elementary science curriculum (Table 17).

\section{Influence of CAIC Program on Science Teaching Efficacy Beliefs}

The methods of CAIC were used as a priori codes to determine inservice teachers' perceptions of the CAIC program on their STEB and the findings are summarized in Table 16.

Table 16

Findings on influence of CAIC methods on science teaching efficacy beliefs.

\begin{tabular}{|c|c|c|c|}
\hline $\begin{array}{l}\text { A Priori Codes } \\
\text { (References, } \\
\text { Percentage) }\end{array}$ & $\begin{array}{l}\text { Themes/Nodes - Perceptions of Influence } \\
\text { on STEB Development. }\end{array}$ & $\begin{array}{l}\text { Number } \\
\text { of } \\
\text { Teachers }\end{array}$ & $\begin{array}{l}\text { Number of } \\
\text { References }\end{array}$ \\
\hline \multirow{6}{*}{$\begin{array}{l}\text { Scaffolding (with } \\
\text { Articulation \& } \\
\text { Reflection) } \\
(18 / 55,32.7 \%)\end{array}$} & Supported Development through Guided & & \\
\hline & Practice (Microteaching) & \multirow[t]{2}{*}{$4 / 5$} & \multirow[t]{2}{*}{ 9/18 } \\
\hline & Enhanced Confidence through Corrective & & \\
\hline & Feedback (Peer-Review Sessions) & \multirow[t]{2}{*}{$5 / 5$} & \multirow[t]{2}{*}{$6 / 18$} \\
\hline & Supported Development through & & \\
\hline & Collaboration (SAK Activities) & $3 / 5$ & $3 / 18$ \\
\hline \multirow{4}{*}{$\begin{array}{l}\text { Coaching (with } \\
\text { Articulation \& } \\
\text { Reflection) } \\
(17 / 55,30.9 \%)\end{array}$} & Corrected Misconceptions and Remediated & $4 / 5$ & $5 / 17$ \\
\hline & Deficiencies & \multirow[t]{2}{*}{$1 / 5$} & \multirow{2}{*}{$2 / 17$} \\
\hline & Challenged Stagnation & & \\
\hline & $\begin{array}{l}\text { Facilitated Learning and Confidence through } \\
\text { Coaching Feedback }\end{array}$ & $5 / 5$ & $10 / 17$ \\
\hline \multirow{2}{*}{$\begin{array}{l}\text { Modeling (14/55, } \\
\text { 25.5\%) }\end{array}$} & $\begin{array}{l}\text { Enhanced Confidence from Visual Patterns } \\
\text { Fostered Self-Improvement via Self- }\end{array}$ & $5 / 5$ & $11 / 14$ \\
\hline & Reflection and Clarified Misconceptions & $3 / 5$ & $3 / 14$ \\
\hline $\begin{array}{l}\text { Exploration } \\
(6 / 55,10.9 \%)\end{array}$ & $\begin{array}{l}\text { Supported in Implementation and Proved } \\
\text { Effectiveness of New Strategies }\end{array}$ & $5 / 5$ & $6 / 6$ \\
\hline
\end{tabular}

Quotes about the influence of these methods accounted for more than three quarters (55/70, 78.6\%) of the references that resulted from the a priori coding cycle. The 
vast difference in the number of references to each CAIC method suggested that the degree of influence they had on respective teachers' STEB also varied. Member checking with the participants during the focus group interview validated this inference as correct. In the following sections, the teachers' perceptions of the influence of each CAIC method on their STEB is reported.

Scaffolding. Teachers' perceptions of the scaffolding accounted for the largest number of references to the influence of the CAIC program on their STEB (18/55, 32.7\%). The SAK Activities were essential cooperative group learning activities/tasks engaged in throughout the program to support the inservice teachers as they developed mastery in expert instructional decision-making and practices in science teaching. Additionally, microteaching was the main scaffold designed to support their synthesis of everything they had learned during the program before implementing them in the field. Inservice teachers (4/5) discussed the influence of the microteaching scaffold on their STEB development in more than half of the scaffolding-related references (9/18). They perceived it is beneficial because it provided a unique opportunity for guided practice. These excerpts are illustrative of their perspectives:

I think that the microteaching was most important... even after the modeling, when you actually have to go and teach yourself, there are still some things that were a bit off. Being able to get a dry run or trial run with your lesson, you are able to fix those things before you actually reached to the class and taught it to the students. (Mae, Focus Group Interview 2) 
That [the microteaching] was good because it allows you now to perform and see and hear results so that when you go back into your classroom, you're more confident. (Lillian, Interview 2)

Within the first inservice teacher's quote is a suggestion that even after the essential skills and concepts of the new strategies were taught, uncertainties and misconceptions may have still lingered. Lillian's comment further proposed that on a deeper level, some skepticism may also exist about the results they could truly obtain using the new strategies. These may have been reservations about potential student achievement outcomes or measurable improvements in their own instructional practice outcomes. Nevertheless, they both held that because of the guided practice, they were able to remedy their uncertainties or misconceptions before going into the field, which gave them greater confidence to effectively integrate their new knowledge into their classroom practice.

The peer-review sessions facilitated after each microteaching lesson provided an opportunity for the teachers to articulate their ideas and to openly reflect on their lessons. In six of the remaining nine scaffolding-related references, all of the teachers discussed the value of these sessions. Their narratives suggested that the corrective feedback they received afterwards played an important role in enhancing confidence in their readiness for science teaching in the field, as reflected below:

The demo teaching, after getting the feedback I was now able to go back and to enhance the lesson: take things out, add things in, tweak the lesson. So when it was time for me to teach, I was much more confident because I now knew where 
my weaknesses were. Now, I was able to improve on that and to make the lesson better. (Zajah, Interview 2)

Somebody else is there saying, "Okay, you could've done this better," and even encourage[ing] you from those little constructive criticisms. It encourages you as well as gives you confidence, "I can do better in my next lesson." (Melinda, Focus Group Interview 1)

In both cases above, teachers deemed the collaborative discussion of their lessons with peers and the instructional coach beneficial. The feedback was likely well received because by this time (week 8), the group had become a full-functioning community of practice (Wenger, 1998) and had learned to trust and value each other's expertise. Additionally, Mae noted that, "in providing feedback to them with their lesson, [she] was able to then take their lessons and make it my own using the feedback that was given from [her]self and the others” (Interview 2). This showed that vicarious learning (Bandura, 1986) of knowledge and strategies also took place simultaneously, and improved their own pedagogies through exchanging ideas during these peer review sessions.

Finally, the teachers (3/5) discussed the influence of the SAK Activities in the remaining three scaffolding-related references. They suggested the cooperative learning was the most beneficial aspect of these learning experiences. This particular case is illustrative:

I worked with a primary generalist and the experience was rewarding because those areas that she was weak in, I was able to break things down for her, and to 
make it more simplified. That to me, was very rewarding being able to help someone; seeing that I'm the one with the science degree, being able to empower a fellow teacher, or fellow colleague to make them more confident in their science area was rewarding for me. (Zajah, Interview 2)

As demonstrated above, these cooperative learning experiences allowed this teacher to share her strengths while simultaneously supporting another's weakness. This partnership between an elementary science specialist with stronger content knowledge and skills and an elementary general education teacher appeared to have been mutually beneficial. The specialist gained positive reinforcement through intrinsic gratification, while the generalist teacher's confidence was undoubtedly boosted as she became more adept at scientific knowledge and skills.

Coaching. The inservice teachers' perceptions of the influence of the coaching method accounted for the second largest number of references about the influence of the CAIC program on their STEB (17/55, 30.9\%). The coaching involved observing teachers as they engaged in tasks and providing goal-oriented, one-on-one corrective feedback and encouragement as they developed proficiency in knowledge and skills. These formal and informal coaching sessions were facilitated throughout the program as needed. Four of five inservice teachers reported the coaching as influential in the development of their STEB because the corrective feedback and encouragements helped them to correct misconceptions, and remediate their deficiencies. The following two excerpts are illustrative: 
I've learned a lot through that feedback again, clear misconceptions, things that I wasn't too sure about, because I was still having thoughts, “am I doing this right?” But with the one-on-one I was able to get more confident in what I was doing and still learn; "well okay, this is what you are supposed to be doing, you are on the right track." And of course you were encouraging with the lots of encouragement with the one-on-one feedback. (Melinda, Interview 2)

That [one-on-one coaching] was beneficial and it was good. Because I'm not a science teacher, per se, because I'm a General Ed teacher, there are quite a few things that I'm not quite aware of, because I'm not "in-depth" into the science like that. You were able to help me and walk me along, walk me through certain things. (Faith, Interview 2)

Both of these teachers reported that the coaching sessions helped clarify uncertainties. In the first case, the coaching also provided continuous feedback and reinforcement through encouragement. The teacher in the second instance acknowledged shortcomings in her science content knowledge and skills. However, she received the necessary feedback through the expert-novice relationship between her and the instructional coach.

The findings also suggested that the coaching may have fostered continual growth in STEB by helping to avoid stagnation (i.e. fixation at one level of expertise/development). For example, one of the teachers in the study spoke to how the prompting and probing of the instructional coach enabled her to move beyond her personal limitation. She said, 
It helped you too because sometimes you think you have it, like okay, yeah, this is a wonderful idea. And then here comes [the coach], well what about this? It helped you. It pushed you to expand on a deeper level as well. (Focus Group Interview 1)

As illustrated in the statement above, at times when she thought she'd optimized her potential, the coach's prompting challenged her to "expand" to the next level. This suggests that CAIC can serve as motivation for teachers who may at times become comfortable at specific levels of competency or development. In addition, some inservice teachers (3/5) attributed the opportunities for articulation and reflection during the oneon-one coaching as making a significant contribution to their STEB development. According to Zajah, Having the one-on-one, you're more confident in terms of sharing your weaknesses. Because like I said, before this professional development, I really thought I knew how to write a lesson plan; but after getting the positive feedback and you being patient and not condemning or laughing or criticizing in the negative way, I felt that, that was very, very helpful. (Zajah, Interview 2)

In this case, the coaching sessions seemed to provide a safe place wherein this teacher was comfortable openly sharing her challenges and weaknesses. Hence, the affective attributes of the coaching (i.e., patience, supportive, non-judgmental) relationship appeared to have been very instrumental in maximizing the impact of these reflective dialogues on their STEB. 
Modeling. The inservice teachers recounted their perceptions of the influence of the modeling on their STEB development in approximately 25.5\% (14/55) of the total references to the CAIC methods. The modeling involved systematic demonstrations of inquiry-based lesson planning using the Backwards Design (Wiggins \& McTighe, 1998) and of model lessons by the instructional coach using the 5E Learning Cycle (Settlage \& Southerland, 2012). Several inservice teachers (4/5) suggested that the modeling enhanced their confidence by providing visual patterns to follow. Consider, for example, the following excerpts:

I like the fact that with the program itself, it actually modeled. It's not the fact that you just go to your teaching lesson, but you actually have someone model it for you. I felt more confident when it came with teaching my own lessons because I knew step-by-step what I had to do. (Faith, Focus Group Interview 2)

The modeling was very beneficial, because I'm a visual learner. You could tell me something, but if you show it to me, I can mimic it, I could make it better, it's my time to do it. By being able to see you model the lesson first, empowered me to say, "Now, if [the coach] could do it, I could do it too." It was like, it will kind of boost to your little self-esteem to go then to know what to do. (Zajah, Interview 2) In both instances above, the inservice teachers perceived they gained confidence and skills through observing the instructional coach model what they were learning. Faith apparently valued that she was not expected to implement the new strategies blindly into her classroom practice without the benefit of seeing them modeled first. As indicated, the 
models as visual patterns left them less room for errors or uncertainties about their abilities to "do it too."

In other instances the findings suggested that the inservice teachers (3/5) also utilized the modeling for self-improvement through self-reflection, and as a tool for clarifying lingering misconceptions. The following comments are illustrative, You (instructional coach) modeling to me showed me where I can improve on, and things that I could do differently. (Faith, Interview 2)

It takes away any doubt or any misunderstandings, you know, you are able to get a clearer idea of what is expected of you. Any misconceptions, they were cleared up too. (Melinda, Interview 2)

The previous quotes reveal a great deal of self-reflection on the part of these inservice teachers. The quotes suggest that they did not merely passively spectate during the instructional coach’s modeling but were also vicariously engaged (Bandura, 1986) in the model demonstration. During the modeling, Faith evaluated the effectiveness of her own classroom practice, whereas Melinda embraced the opportunity to clarify lingering misconceptions about what they had been learning.

Exploration. Finally, the inservice teachers discussed the influence of the exploration in the smallest category $(6 / 55,10.7 \%)$ discussing the influence of the CAIC methods on their STEB development. Exploration in this context referred to situated practice with the new strategies within their local classroom contexts of instruction. The findings suggested that the CAIC support offered during the exploration helped the teachers problem-solve to work out the nuances of implementing their new knowledge 
and validating its effectiveness in the "real" classroom. For example, commenting on how the CAIC helped Faith adapt the strategies to accommodate special needs in her classroom; she noted, "with the scaffolding and the feedback that I got, I now know that these kids are not all on the same level. I need to differentiate in my activities” (Focus Group Interview 1). The following excerpts show other ways that the CAIC supported the teachers' STEB development during exploration:

After you explained, I wanted to go back to the explore because you showed us that it's really not discouraging them, it's about letting them bring their own ideas that they bring to the table, and then letting them prove their ideas either right or wrong. (Mae, Interview 2)

One challenge that I faced was time. My fourth grade only has thirty minutes of science per week. As opposed to trying to cover three objectives, I find that with the design I could only cover one because of time. (Zajah, Focus Group Interview 2)

In the first instance, the instructional coach had observed a lesson during which a teacher did not effectively execute the explore phase of the 5E Learning Cycle. After discussing the lesson with the instructional coach, who reemphasized the importance of that phase and provided suggestions for improvement, the teacher developed confidence and a greater appreciation for the strategy. In the other case, this inservice teacher struggled with too much planning given the time allocated to teach science. The instructional coach helped her refine objectives and strategies to manage time while maintaining the integrity of the 5E Learning Cycle. 
It appears that many teachers also received positive reinforcement from discovering the effectiveness of the new strategies during the exploration. Lillian noted, for example,

I sure did enjoy that and I knew my children enjoy that and it worked out really well because I could have come back days after and asked questions pertaining to that same thing and get the same positive, correct answer so I know that it works. (Focus Group Interview 1)

References such as this one suggested that teachers may have been wondering how effective the new strategies would be in the "real” classroom context. It can be inferred from the quote above that finding the innovations to be effective during exploration, as Lillian did, can potentially have a positive influence on teachers STEB.

\section{Implementing Inquiry-Based Curricula}

The main goal of the CAIC program was to teach Bahamian inservice teachers to use the Backwards Design (Wiggins \& McTighe, 1998) and the 5E Learning Cycle (Bybee, 1997) as tools to implement the new inquiry-based elementary science curriculum. Whereas the teachers described their perceptions of the influence of the CAIC methods on their STEB in 78.6\% (55/70) of the total references from the a priori coding cycle, they discussed the CAIC's influence on their competency in implementing the new inquiry-based curriculum in the remaining 21.4\% (15/70) of references (Table 17). 
Table 17

Findings on influence of CAIC on inquiry-based curriculum implementation.

\begin{tabular}{llll}
\hline A Priori Code & Themes/Nodes & $\begin{array}{l}\text { Number of } \\
\text { Teachers }\end{array}$ & $\begin{array}{l}\text { Number of } \\
\text { References }\end{array}$ \\
\hline $\begin{array}{l}\text { Inquiry-based } \\
\text { Curriculum }\end{array}$ & $\begin{array}{l}\text { Improving Instructional Effectiveness } \\
\text { Changing Perceptions Influence of }\end{array}$ & $5 / 5$ & $8 / 15$ \\
15/70, (21.4\%) & $\begin{array}{l}\text { Teaching on Learning } \\
\text { Improving Curriculum Understanding }\end{array}$ & $3 / 5$ & $5 / 15$ \\
& & $2 / 5$ & $2 / 15$ \\
\hline
\end{tabular}

The inservice teachers reported minimally using the curriculum prior to participating in the program and many recounted that their lessons lacked the meaningful student engagement inherent in true inquiry-based lessons. In slightly more than half of these references, all of the teachers expressed that they believed that they could be more effective in science teaching as a result of the CAIC program. Two of the teachers spoke about the coaching's influence on their instructional effectiveness in the following excerpts:

After the coaching, you were able to do more. You could've gone back to your students and explored different areas in teaching and different methods as well. You focused more on having your students involved in what you are doing, and it isn't that I will be standing in front of the class and doing everything. I involve my students more, having them using a method of inquiry and experimenting and interacting with whatever materials and even modeling what was taught, what we learned from the session. (Lillian, Focused Group 1)

With the coaching and everything that you would have learned it makes you think, "I want to go beyond just basically looking at the curriculum" and say, "I can't just go and stand in front of the class." If you want to go beyond, you're actually 
interacting with your material and getting your students to interact with it as well.” (Melinda, Focus Group Interview 1)

These teachers' comments cited above suggested that the coaching and instructional tools empowered them to "do more” and try new things. This apparent confidence likely resulted from knowing they had access to expert guidance and assistance through the instructional coach, making them comfortable enough to venture beyond the parameters of mundane teaching. This is evidenced by the fact that in both comments they attributed their behaviors to the instructional coaching (i.e., "with the coaching," "after the coaching”). The coaching also seemed to have helped them embrace more studentcentered approaches to teaching and learning, which is more indicative of true inquiry lessons.

In the five of the fifteen references to competency in curriculum implementation, the inservice teachers described how they believed the CAIC influenced their perceptions of their teaching on students' science learning. These two cases are explanative,

Sitting in the class when we're looking at you teaching us and we're learning that we should be modeling when teaching to our children, not just saying, "This is what I want. This is how you should be doing this. These are the steps that you have to follow." (Melinda, Focus Group Interview 1)

Even though I might have been slow with getting some stuff, he didn't rush. That's what I've learned because in my class I have some slow learners. I've learned these kids are all capable, but the same time this person might not be able to get as quick as the other person. Now, I have to be patient with this one. If the other 
student is more advanced, give them something that they can do on their own. On the other hand, I can work with this person to bring them up to the level where they need to be. (Faith, Focus Group Interview 1)

In the first case, the teacher mentioned how the instructional coach's modeling allowed her to see the importance of also modeling for students as they learn science.

Traditionally, she may have been accustomed to giving instructions without modeling how to execute them. In the second instance, this teacher reported that through the coaching she learned the importance of being patient with students as they learned science and of differentiating instruction to meet the needs of diverse learners in the classroom. This likely influenced her in this way because she recognized that within the program were teachers at different levels of proficiency. She was slower at picking up certain things at times, yet the coach showed patience with her.

In the remaining references, two teachers (2/5) expressed how participating in the CAIC program helped them to understand the new inquiry-based curriculum and how to use it effectively. Zajah and Mae's comments here are expressive,

Well, for me, the coaching enabled me to effectively dissect the curriculum because before, you just go in and look at the scheme and say, "Okay, this is the objective for the day, we're going to cover it." For me, it enabled me to effectively dissect the curriculum in which I was able to look at each objective in its own entity and to teach it more effectively, I guess with more enthusiasm. (Zajah, Focus Group Interview 2) 
After coaching, it has helped me to be able to dissect the curriculum rather than just going to the curriculum to get the topic, because that's about it that I got from the curriculum was the topic that I needed to teach. It has really helped me to be able to more accurately dissect the curriculum and use it in the way that it should be used. (Mae, Focus Group Interview 2)

The above comments supported the case that the inservice teachers did not use the new inquiry-based curriculum beyond looking at topics and learning outcomes, because they lacked the training to interpret them. However, through coaching, they learned the elements of the curriculum and how to integrate each component to develop lessons focused on building conceptual understanding through inquiry.

\section{Discussion}

The findings of this study showed that the methods used in the cognitive apprenticeship-based instructional coaching (CAIC) program had varying degrees of influence on the inservice teachers' science teaching efficacy beliefs (STEB). Fundamentally, proficiency in teaching is inherently different among educators mainly due to their training and experiences. Therefore, the teachers came to the program with a diversity of needs which inevitably influenced what they individually valued as beneficial. This strengthens the support for the CAIC approach, which utilizes different methods to meet the diversity of needs that teachers supported by an instructional coach may have.

Coaching and Scaffolding. The inservice teachers discussed the coaching and scaffolding in most of the references about the influence of the program on their STEB. 
There are a number of likely reasons for this. First, these two methods are heavily relationship-focused. Therefore, this expert-novice relationship seemed to have created a suitable and safe space for addressing the inservice teachers' individual needs—-be they correcting misconceptions, remediating deficiencies, or challenging them to advance to the next level. The guided practice and collaboration in the scaffolding also allowed teachers to relate with their colleagues and the instructional coach for individual support and encouragement as they developed mastery of the learning tasks. Thus, this finding adds to the growing body of literature supporting collaborative engagement through professional learning communities as a characteristic of effective professional development (Colbert, et al., 2008). It also supports many conclusions of the literature that cite relationships as the most important factor in instructional coaching success (Knight, 2008). In addition, these two methods both incorporated numerous formal and informal opportunities for articulation and reflection. Through the individual coaching and group feedback sessions, they were able to receive corrective feedback from the instructional coach and their colleagues. That all of the teachers found these sessions beneficial supports the conclusions of Posnanski (2002), that effective professional developments should allow for discussion and reflection of pedagogical issues and teachers' own beliefs. Further, collaborative discussion and reflection also allows for social and verbal persuasion through encouragement, for example, which also supported the teachers' physical and emotional well-being (Bandura, 1986). Hence, the findings in this section support the statement by Lakshmanan, Heath, Perlmutter, and Elder (2010) that reflective and collaborative professional developments may indeed have a significant positive influence on science teaching efficacy. 
Modeling and Exploration. The inservice teachers determined that modeling and exploration had a great impact on the development of their STEB. Their portrayal of the modeling as providing a visual pattern which gave them confidence in their own abilities supported Bandura’s (1986) claims that vicarious experiences can have a powerful impact on an individual's efficacy beliefs. Therefore, it is imperative that modeling during instruction is explicit, because "it is useful to the learner only to the extent that it can be interpreted" (Lyon, 2003, p. 17). The inservice teachers also reported that the modeling also became an impetus for self-improvement through self-reflection as they compared their own practices to that of expert practice modeled by the instructional coach. This level of metacognition demonstrated by the inservice teachers underscores a very important benefit of cognitive apprenticeship learning (Collins, Brown, \& Newman, 1989)—developing teachers' ability to continuously improve through self-correction resulting from reflective practice. Their perception also supported Shidler's (2008) conclusion that coaches' modeling of techniques and instructional practices is an essential component of building teaching efficacy beliefs.

During the exploration, the inservice teachers were primarily concerned with reconciling their new knowledge and skills gained from the PD with the nuances of "real" classroom context, such as accommodating diverse learners and time management. It facilitated "situated learning” (Collins, 2006) and offered an opportunity to gain mastery experience (Bandura, 1986) — the most influential source of self-efficacy development. According to Bandura (1986), individuals' lack of success in mastery learning tasks can be deleterious to their efficacy beliefs. Therefore, as the findings support, the presence of the instructional coach during exploration was critical in supporting teachers as they 
problem-solved to integrate their new knowledge and skills through these nuances. It helped to avert adverse influences on the success in the field experience and on their personal STEB.

Implementing Inquiry-based Curricula. As Knight (2009) noted, the main responsibility of an instructional coach is to help teachers integrate evidence-based reforms and practices into their teaching. Inquiry-based teaching is a departure from the traditional modes of teaching and learning science, which can be an overwhelming transition for teachers without support. This is likely why the long-term and systematic support from the instructional coach was beneficial and empowered the teachers as they improved their instructional effectiveness. It can also be inferred that instructional coaching may be a mechanism to decrease teacher resistance often experienced when new reforms are introduced (Guskey, 1988). The finding which suggested that the instructional coach's practices influenced the teachers' perceptions about teaching and learning is very significant because they were vicariously learning (Bandura, 1986) to use the CAIC methods to enhance working with their own students.

Finally, the mastery learning experiences (Bandura, 1986) of "dissecting” the curriculum for understanding seemed to have successfully improved their competence in implementing the new inquiry-based curriculum. The inservice teachers' reasons for not using the new curriculum supported the conclusion of Roehrig, Kruse, and Kern (2007), that even though many science curriculum documents are meant to be inquiry-based, the same does not translate into practice because teachers lack understanding about inquiry and inquiry-based curricula. Therefore, the perceived positive influence of the CAIC on 
the teachers' abilities echoed critical sentiments by Davis (2002), that curriculum change should be gradual and systematic if it is to truly influence teachers' classroom practice.

\section{Implications}

\section{Implications for the Bahamian Context}

The results of this study hold important implications for science teacher professional development in The Bahamas. The experiences of the participants demonstrated several ways in which an efficient model of cognitive apprenticeship-based instructional coaching (CAIC) may support elementary teachers' development of science teaching efficacy beliefs (STEB) and enhance their ability to implement inquiry-based science curricula.

First, it may improve the quality of inservice teacher professional development in science by providing immediate expert corrective feedback (i.e. coaching) for novice and experienced teachers. As Mae noted, "a coach is there to give you immediate feedback. After you've done the lesson, within that day, you'll have feedback to say this is what you could have done better” (Focus Group Interview 2). Additionally, reflecting on how

CAIC may have benefitted her in her first year, Faith explained,

If I had this in my first year in the classroom, I would have felt so much more valuable to those students. We go to college, they teach us basics, they don't teach us how to teach really. They give us content and all that kind of stuff, but had you had something like this when you go into that classroom you could be so much more effective. (Focus Group Interview 2) 
Second, a CAIC program may also provide much-needed support for the weaknesses of many Bahamian elementary teachers in science content knowledge and instructional practices. Zajah’s comment is supportive,

I think that in our society in The Bahamas, we definitely need science coaches. I have teachers at my school right now who don't teach science. Because they don't know it, they don't teach it.” (Focus Group Interview 2)

Similarly, Faith explained that, “a lot of the times when we don't do stuff, it's not because we don't want to, it's because we don't know how to. Having this, it would be very beneficial”. (Focus Group Interview 2)

Third, a CAIC program can provide the appropriate level of support and followup to ensure that reform-based curricula and practices are implemented with fidelity and sustained over the long-term. Speaking to this point, Mae stated,

I think that follow-up is really important because dealing with the Ministry, sometimes they just throw stuff on teachers and they say look here, this is what we're going to do, this needs to be changed. Then the follow-up comes two, three years later and they didn't start teaching yet. If you have that constant follow-up, you have those coaches there, you can ensure what it is that you want done is being done. Not waiting until five, six years down the line, you realize that certain schools haven't even started it yet (Focus Group Interview 2).

This is a major challenge with effectively implementing new initiatives in schools which instructional coaching can readily address because of their prolonged engagement in the local context of instruction. Zajah’s comment here supports this: 
The long term is definitely better because it gives you time to grow and to walk; take it in strides. Because not everything you are going to catch in one day so having the time, the different sessions, I found that I was able to grow in every area. (Focus Interview Group 2)

Finally, the results of this study hold significant implications for helping to overcome teacher frustration associated with ineffective science teaching, which will inevitably lead to low STEB. Faith’s comment here underscores this point, I think a lot of times we get frustrated because we don't feel like we are getting through to the children. We are frustrated because we are teaching and no one is paying us no attention. It's all because we have been really doing an in depth study of the lesson. We don't really know when it's time to be a teacher. With having the coaches, they're able to better help us prepare ourselves to go before these kids and teach them. (Focus Group Interview 2)

Teacher frustration is a persistent problem in content areas that elementary teachers feel inadequately prepared to teach, like science (Yilmaz \& Huyuguzel Cavas, 2008). However, in a CAIC supported environment, "the coaches will be there to assist the teacher, ease that frustration, and give them that immediate feedback after the lesson so they'll know what to do for the next time” (Zajah, Focus Group Interview 2). Though no one innovation can serve as a panacea for all the challenges faced by the elementary science education in The Bahamas, CAIC can be a positive step in the right direction for much-needed science professional development reform. 


\section{Implications for Theory and Research}

Though the findings of this qualitative study cannot be generalized beyond the local context of implementation, they hold important implications for theory development and continued research. First, given the scarcity of strong instructional coaching models, the outcomes of this study suggested that the cognitive apprenticeship-based instructional coaching (CAIC) approach may be a viable means of improving the science teaching efficacy beliefs (STEB) among elementary teachers. This implication is noteworthy because as the specifics of learning tasks (ex. SAK Activities, length of field experience, and microteaching) may vary depending on the contexts, this model puts greater emphasis on using the methods of cognitive apprenticeship (Collins, Brown, \& Newman, 1989), which are highly transferrable between contexts. The CAIC approach is not a cookie-cutter approach, but rather serves as a strong framework in which to provide effective instructional coaching.

The findings also suggested that the CAIC approach may potentially be effective for retooling teachers and facilitating their learning of reform-based innovations with fidelity and consistency. None of the participants in this study had prior experience with instructional coaching, using Backwards Design or the 5E Learning Cycle. Nevertheless, they perceived that they had developed mastery over the duration of the study. They deemed the coaching to be extremely beneficial to their STEB development and committed to integrating the new innovations into their classroom instructional practices. The findings of this study may also hold implications for providing quality instructional coaching in an efficient and cost-effective manner. Though there are benefits to having resident instructional coaches in schools, the findings suggest they may not be required 
for the CAIC model to be effective. In this case, the instructional coach was not resident in their schools, but he effectively worked with five teachers from different schools, with permission from their principals. In a time where K-12 budgets are being cut in the U.S., the CAIC approach may support continuing to provide this essential service as opposed to dismantling programs all together. Finally, the finding of this study suggested that the CAIC model used may provide a viable alternative to traditional formats of professional development which were shown to have minimal effect on teachers' actual classroom practice. Further studies are needed to validate these implications. 


\section{References}

Avant, R. C. (2012). Instructional coaching and emotional intelligence (Doctoral Dissertation). Available from ProQuest Dissertations and Theses database. (UMI No. AAT 3509025)

Baker, G. W. (2010). Instructional coaching in U.S. urban school districts: The principal perspective on how coaches are supervised (Doctoral Dissertation). Available from ProQuest Dissertations and Theses database. (UMI No. 857923369)

Ballone, L.M., \& Czerniak, C.M. (2001). Teachers’ beliefs about accommodating students' learning styles in science classes. Electronic Journal of Science Education, 6(2), 4-29.

Bandura, A. (1977). Self-efficacy: Toward a unifying theory of behavioral change. Psychological Review, 84(2), 191-215.

Bandura, A. (1986). Social foundations of thought and action: A social cognitive theory. Englewood Cliffs, NJ: Prentice- Hall, Inc.

Bandura, A. (1997). Self-efficacy: The exercise of control. New York, NY: Freeman.

Bencze, L. \& Hodson, D. (1999). Changing practice by changing practice: Toward more authentic science and science curriculum development. Journal of Research in Science Teaching, 36, 521-539.

Borman, J., \& Feger, S. (2006). Instructional coaching: Key themes from the literature. Providence, RI: The Education. Alliance at Brown University. Retrieved August 14, 2008, from http://www.centerforcsri.org/files/CenterIssueBriefSept07Coaching.pdf

Bybee, R. W. (1997). Achieving scientific literacy: From purposes to practices. Portsmouth, NH: Heinemann.

Cabinet appointments announced. (2012, May 10). The Nassau Guardian. Retrieved from http://www.thenassauguardian.com/index.php?option=com_content\&view=article \&id=30840: cabinet-appointments-announced-\&catid=3:news\&Itemid=27

Colbert, J., Brown, R.S., Choi, S., \& Thomas, S. (2008). An investigation of the impacts of teacher-driven professional development on pedagogy and student learning. Teacher Education Quarterly, 35(2), 135-154.

Collins, A. (2006). Cognitive apprenticeship. In R. K. Sawyer (Ed.) Cambridge handbook of the learning sciences (pp. 47-60).Cambridge UK: Cambridge University Press. 
Collins, A., Brown, J. S., \& Newman, S. E. (1989). Cognitive apprenticeship: Teaching the crafts of reading, writing, and mathematics. In L. B. Resnick (Ed.), Knowing, learning, and instruction: Essays in honor of Robert Glaser (pp. 453-494). Hillsdale, NJ: Lawrence Erlbaum Associates.

Cornett, J., \& Knight, J. (2008). Research on coaching. In J. Knight (Ed.) Coaching: Approaches and perspectives. Thousand Oaks, CA: Corwin.

Curling, L., St. Cyr. K., Moss, S., Moultrie, S., Vanderpool, J., \& Wilchcombe, N. (2010). Bahamas roadmap for science and technology. Bahamas Environment, Science, and Technology Commission. Retrieved from: http://www.best.bs/Documents/Road_Map_new_10.01.06.pdf

Darling-Hammond, L. (2000). Teacher quality and student achievement: A review of state policy evidence. Education Policy Analysis Archives, 8(1), 50.

Davis, K. S. (2002). "Change is hard.” What science teachers are telling us about reform and teacher learning of innovative practices. Science Education, 87, 3-30.

Denton, C. A., \& Hasbrouck, J. (2009). A description of instructional coaching and its relationship to consultation. Journal of Educational and Psychological Consultation, 19(2), 150-175.

Forbes, C. T., \& Davis, E. A. (2010). Curriculum design for inquiry: Preservice elementary teachers' mobilization and adaptation of science curriculum materials. Journal of Research in Science Teaching, 47, 820-839.

Fraenkel, R. J. \& Wallen, N. E. (2008). How to design and evaluate research in education ( $7^{\text {th }}$ ed.). New York, NY: Mc-Graw-Hill.

Gibson, S., \& Dembo, M. (1984). Teacher efficacy: A construct validation. Journal of Educational Psychology, 76, 569-582.

Guskey, T. (1988). Teacher efficacy, self-concept, and attitudes toward the implementation of instructional innovation. Teaching and Teacher Education: An International Journal of Research and Studies. 4(1), 63-69.

Henson, R. K. (2001, January). Teacher self-efficacy: Substantive implications and measurement dilemmas. Presented at the annual meeting of the Educational Research Exchange, Texas A \& M University.

Joyce, B., \& Showers B. (1980). Improving inservice training: The messages of research. Educational Leadership, 37(5), 379-385. 
Karplus, R., \& Thier, H. (1967). A new look at elementary school science. Chicago: Rand-McNally.

Knight, J. (2009). Coaching: Approaches and perspectives. Thousand Oaks, CA: Corwin Press.

Lakshmanan, A., Heath, B. P., Perlmutter, A., \& Elder, M. (2011). The impact of science content and professional learning communities on science teaching efficacy and standards-based instruction. Journal of Research in Science Teaching, 48, 534551.

Lyon, G. E. (2003). Development of science teacher identity in pre-service teachers as situated cognition: defining self as teacher in a school based context. University of Georgia-Athens). Retrieved on June 1, 2013 from http://athenaeum.libs.uga.edu/bitstream/handle/10724/6746/lyon_grace_e_200308 _phd.pdf?sequence $=1$

Merriam, S. B. (2002). Qualitative research in practice. San Francisco, CA: Jossey-Bass.

National Staff Development Council. (2001). Standards for staff development (Revised). Oxford, OH: NSDC.

Parke, H. M. and Coble, C. R. (1997). Teachers designing curriculum as professional development: A model for transformational science teaching. Journal of Research in Science Teaching, 34, 773-789.

Patton, M. Q. (1990). Qualitative evaluation and research methods ( $2^{\text {nd }}$ ed.). Newbury Park, CA: Sage.

Pea, R. D. \& Collins, A. (2008). Learning how to do science education: Four waves of reform. In Y. Kali, M. Linn, \& E. Roseman (Eds.). Designing coherent science education: Implications for curriculum, instruction, and policy (pp. 3-12). New York: Teachers College Press.

Posnanski, T. J. (2002). Professional development programs for elementary science teachers: An analysis of teacher self-efficacy beliefs and a professional development model. Journal of Science Teacher Education, 13, 189-220.

Reed, L. A. (2006). Case study of the implementation of cognitive coaching by an instructional coach in a title I elementary school (Doctoral Dissertation). Available from ProQuest Dissertations and Theses database. (UMI No. 304932087) 
Roehrig, G. H., Kruse, R. A. and Kern, A. (2007). Teacher and school characteristics and their influence on curriculum implementation. Journal of Research in Science Teaching, 44, 883-907.

Ross, J. A. (1992). Teacher efficacy and the effect of coaching on student achievement. Canadian Journal of Education, 17(1), 51-65.

Saldaña, J. (2013). The coding manual for qualitative researchers (2nd ed.). Thousand Oaks, CA: Sage.

Scurry, S. N. (2010). Perceptions of instructional coaches in the elementary school setting and their impact on teacher self efficacy (Doctoral Dissertation). Available from ProQuest Dissertations and Theses database. (UMI No. 829500183)

Settlage, J., \& Southerland, S. A. (2012). Teaching science to every child: Using culture as a starting point, $2^{\text {nd }}$ edition. New York: Routledge, Taylor, \& Francis Group.

Shidler, L. (2008). The impact of time spent coaching for teacher efficacy on student achievement. Early Childhood Educational Journal, 36(5), 453-460.

UC Davis Children's Hospital. (2013, February 11). Instructional coaching: An effective way to train. Retrieved October 13, 2013 from: http://pcit.ucdavis.edu/coachingblog

Wenger, E. (1998). Communities of practice: learning, meaning, and identity. Cambridge University Press.

Wicker, R. K. (2006). Do science coaches promote inquiry-based instruction in the elementary science classroom? (Doctoral Dissertation). Available from ProQuest Dissertations and Theses database. (UMI No. 305358649)

Wiggins, G., \& McTighe, J. (1998). Understanding by design. Alexandria, VA: Association for Supervision and Curriculum Development.

Yilmaz, H., \& Huyuguzel Cavas, P. (2008). The effects of the teaching practice on preservice elementary teachers' science teaching efficacy and classroom management beliefs. Eurasia Journal of Mathematics, Science \& Technology Education, 4(1), 45-54. 


\section{CHAPTER IV:}

\section{TOWARDS AN EFFECTIVE MODEL FOR IMPROVING SCIENCE TEACHING EFFICACY BELIEFS THROUGH COGNITIVE APPRENTICESHIP-BASED INSTRUCTIONAL COACHING (CAIC)}

Increasing advancements in science and technology have placed a greater demand

on education systems globally to produce more scientists, technicians, and engineers. The call in the U.S. for increased human capacity in the aforementioned areas resounded as early as the 1950s, after the launch of the Soviet satellite, Sputnik. In the decades that followed, K-12 science education reform gained prominence on the agenda of policymakers and educators at all levels. According to Pea and Collins (2008), the present K-12 science education reform wave has espoused a "systemic” approach, which involves a focus on the aggregate of all variables influencing science education including curriculum development, standards-based education, research-based instructional practices, and teacher professional development. Hence, systemic science education reform movement has placed classroom teachers of science and their instructional practices as the primary focus.

A similar trend has been observed with the increasing importance of science education in The Bahamas. Over the past decade in particular, the Bahamian government invested substantial revenue into revising science curricula and implementing many new initiatives to reform science education locally. The large numbers of foreign direct investments in industrial chemical and biological industries, have also served as catalysts to increase capacity in science and technology as the country becomes more global. In 2002, for example, “net private foreign direct investment rose to \$316.7 million from 
\$164.7 million in 2001” (The Bahamas Guide, 2013). Additionally, the newly created Ministry of Education, Science, and Technology by the current Bahamian government also emphasized their strong commitment to the development of science education. Further, in the 2011-2013 budget year, The Bahamas Ministry of Education increased the annual budget allocation for inservice teacher professional development as a move to improve teacher quality in critical subject areas such as science and mathematics.

\section{Teacher Quality and Instructional Coaching}

Teacher quality has consistently shown to be the "within school” variable most highly correlated with student achievement outcomes (Darling-Hammond, 2000; Haycock, 1998; Wright, Horn, \& Sanders, 1997). Subsequently, renewed interest is being placed on improving the quality of preservice teacher learning and inservice teacher professional development in science emphasis in both the U.S. and The Bahamas. Several new approaches to preservice teacher learning and inservice teacher professional development have been explored in recent years. Instructional coaching is one such approach that emerged in the U.S. in an effort to provide job-embedded professional development for inservice teachers. According to Knight (2009), an instructional coach "partners with teachers to help them incorporate research-based instructional practices

into their teaching” (p. 30). Though peer coaching is not a new phenomenon, the development of the instructional coach role in schools is novel.

In this collected papers dissertation, the concept of instructional coaching was extended beyond inservice teacher professional development, and its utility was explored for supporting preservice teacher learning as well. The findings of these two studies 
suggested that a strong theoretical model of instructional coaching can serve as a highlyeffective mechanism of supporting both preservice and inservice elementary teachers as they learn to incorporate evidence-based instructional practices into their science teaching.

\section{Science Teaching Efficacy Beliefs and CAIC}

The purpose of these "collected papers" was to examine the utility of cognitive apprenticeship (Collins, Brown, \& Newman, 1989) as a theoretical model to provide instructional coaching towards improving the science teaching efficacy beliefs of preservice and inservice elementary teachers in The Bahamas. The construct, science teaching efficacy beliefs (STEB), is derived from Bandura's concept of self-efficacy beliefs (Bandura, 1977). Whereas self-efficacy belief refers to an individual's perception of their personal ability to be successful at a given task, science teaching efficacy belief refers to teachers' self-perceived ability to teach science effectively (Enoch \& Riggs, 1990).

The development of science teaching efficacy beliefs became the focus of numerous studies in the literature because it has been identified as the greatest predictor of science teaching efficacy. That is, teachers who have greater confidence in their abilities to effectively teach science are the most likely to be effective in their classroom practice. They are also the most likely to embrace reformed-based innovations (Allinder, 1994), persist in the face of challenges (Cantrell, Young, \& Moore, 2003), and have higher levels of motivation (Aydin \& Boz, 2010; Yilmaz \& Huyuguzel Cavas, 2008). According to Bandura (1977), science teaching efficacy belief development, as with self- 
efficacy beliefs, can most significantly be influenced by mastery experiences, vicarious experiences, social and verbal persuasion, and the individual's physical and emotional well-being. Therefore, a strong theoretical model for science instructional coaching designed to improve preservice and inservice teachers' science teaching efficacy beliefs should provide opportunities for meaningful engagement in learning experiences that target these four areas specifically.

Cognitive apprenticeship-based instructional coaching (CAIC) provides a model for learning the thinking and problem solving skills involved in effective science instruction through guided practice within the relevant context of instruction. CAIC is germane to both preservice teacher learning and inservice teacher professional development because teachers are members of what Davenport (2005) refers to as a knowledge profession. They think for a living. Therefore, through reformed science methods courses and professional development initiatives, elementary teachers can learn the thinking and problem solving skills involved in effectively incorporating evidencebased instructional practices into their teaching. The learning experience also imbues the tenets of social cognition (Bandura, 1977) because the learning takes place within a social context with peers, facilitated by an expert. The consistent expert-novice interaction and dialogue inherent in CAIC also adds to the value of this novel approach. The findings in this collected papers dissertation suggested that CAIC may provide a strong model to positively influence both science teaching efficacy beliefs as well as enhance teachers' competency in implementing inquiry-based curricula. 


\section{Influence of the Cognitive Apprenticeship-Based Instructional Coaching}

The studies within this collected papers dissertation empirically showed the viability of a cognitive apprenticeship-based instructional coaching approach for effective use in preservice teacher training and inservice teacher professional development. The quantitative finding in the first study revealed a statistically significant positive increase in the personal science teaching efficacy (PSTE) of the preservice teachers as a result of participating in the reformed methods course. Given the limited availability of participants and small sample size, the science teaching outcome expectancy (STOE) variable was measured to assess the effects of maturation and possible results which likely could have otherwise been achieved in a traditional methods course. The rate of increase in PSTE was significantly larger than the rate of increase in STOE, suggesting that the increases observed were unlikely due to the effects of maturation alone. The qualitative findings in the second study suggested that the inservice teachers perceived that the professional development program had a profound impact on their science teaching efficacy beliefs, as well as their perceptions of their abilities to implement the new inquiry-based curriculum. In the following sections, the overall findings relative to the effects of the cognitive apprenticeship-based instructional coaching methods on the preservice and inservice are juxtaposed.

\section{Modeling}

Modeling was an essential method in the effectiveness of cognitive apprenticeship-based instructional coaching interventions. It "involves an expert performing a task so that the students can observe and build a conceptual model of the 
processes that are required to accomplish it” (Collins, 2006, p. 50). The instructor/instructional coach in these studies modeled science lessons using the $5 \mathrm{E}$ Learning Cycle (Settlage \& Southerland, 2012), and modeled unit and lesson plan development using the Backwards Design (Wiggins \& McTighe, 1998). The findings suggested that the preservice and inservice teachers perceived that the modeling played a significant role in the development of their science teaching efficacy beliefs because it provided vicarious learning experiences (Bandura, 1977). In both instances, they reported gaining confidence in their own abilities as a result of vicariously engaging in this learning experience. However, the purpose of their engagements seemed to have been different. Whereas, the preservice teachers, many of whom had never seen a professor model lessons, appeared to focus on developing a visual pattern to follow. The inservice teachers seemed to have placed greater emphasis on using the modeling to evaluate and improve their own classroom practice. This observed difference is very likely because most of the preservice teachers had never taught or taught science before and subsequently did not have an existing schema (Piaget \& Cook, 1952) of science teaching to compare or modify. On the other hand, the inservice teachers, as a result of their years of experience in the classroom were able to make immediate application of the modeling to their individual classroom practice.

\section{Scaffolding}

Scaffolding was another critical method used in implementing the cognitive apprenticeship-based instructional coaching interventions. In a broad sense, "scaffolding refers to any support the teacher provides to help students carry out tasks” (Collins, 2006, 
p. 51). In these studies, scaffoldings were provided through a series of needs-based presentations with cooperative learning activities called SAK activities, and microteaching lessons designed to bridge the theory and practice divide. The participants in both studies placed significant value on the relevance of the scaffolds to their unique needs and revered the opportunities they provided for collaborative engagement. The findings suggested that preservice teachers seemed to focus often during these times on brainstorming (i.e. sharing ideas and planning), while the inservice teachers appeared to be more keenly focused on affirming each other's strengths and supporting each other's weaknesses. The fact that the preservice teachers share similar backgrounds relating to science knowledge, skills, experience and teacher training most likely explains this observation, compared with the vast diversity among the inservice teachers. Therefore, the natures of the scaffolding needs were different and consequently the kinds of support and problem solving needed to complete the cooperative learning tasks also differed. "Working together” likely fostered STEB development by facilitating social and verbal persuasion, an important source of self-efficacy development (Bandura, 1977). The participants in both reported that the "guided practice" inherent in the microteaching scaffold was pivotal to their STEB development. It was most likely highly regarded by participants in both studies because it provided mastery learning experiences, which Bandura (1977) noted is the most effective way of influencing efficacy belief. Additionally, observing their peers/colleagues during microteaching became a means to engage them in vicarious learning (Bandura 1977), another significant source of STEB development. 


\section{Coaching}

Coaching was a third essential method used to successfully deliver the cognitive apprenticeship-based instructional coaching interventions. "Coaching consist of observing students while they carry out a task and offering hints, challenges, scaffolding, feedback, modeling, reminders, and new tasks aimed at bringing their performance closer to expert performance” (Collins, 2006, p. 51). In addition to providing on-going corrective feedback throughout, mandatory individual coaching sessions were also facilitated after each microteaching for participants in both studies. The findings suggested that the participants in both studies perceived the coaching as being diagnostic in that it helped them to correct personal misconceptions and shortcomings within the confines of a safe and supportive relationship. This expert-novice relationship appeared to have contributed significantly to the preservice and inservice teachers’ physical and emotional well-being (Bandura, 1977). The qualitative data in the first study suggested that the preservice teachers looked to the coaching relationship more affectively—for affirmation and validation—as they developed mastery in science teaching. On the other hand, the qualitative data in the second study suggested that this relationship for the inservice teachers became more psychomotor. They were focused on partnering with the instructional coach to help them improve their classroom instructional practice in science.

\section{Articulation and Reflection}

The opportunities for articulation and reflection during the studies were indispensable components of the cognitive apprenticeship-based instructional coaching approach. According to Collins (2006), 
Articulation includes any method of getting students to explicitly state their knowledge, reasoning, or problem-solving processes in a domain. Reflection involves enabling student to compare their own problem solving processes with those of an expert, other students, and ultimately, an internal cognitive model of expertise. p. 51

These were vital because CAIC in a knowledge profession (Davenport, 2005), such as teaching, is all about learning how to think, solve problems, and advance as a reflective practitioner. During these studies, opportunities for articulation and reflection came through formal and informal one-on-one dialogues with the instructor/instructional coach or reflective group sessions with their peers/colleagues. The data suggested that these sessions likely promoted their STEB development by also supporting their physical and emotional well-being (Bandura, 1977) enabling them to share their weaknesses and challenges in a non-threatening environment. It can be further inferred that these opportunities also facilitated social and verbal persuasion (Bandura, 1977) through constructive peer/collegial exchanges within their professional learning community (preservice teachers) and community of practice (inservice teachers). The qualitative data seemed to suggest that both the preservice and inservice teachers were learning how to think about and through instructional planning issues in an expert manner through these expert-novice dialogues with the instructional coach. 


\section{Exploration}

The final of the cognitive apprenticeship-based instructional coaching methods utilized in both studies is exploration. "Exploration involves guiding students to a mode of problem solving on their own” (Collins, 2006, p. 51). In the studies in this dissertation, these were a 3-week and a 4 -week field teaching experience for the inservice and preservice teachers respectively. During this time, they were expected to implement all they had learned while doing this practicum in a local school. The findings suggested that participants in each study were concerned about how effective the new strategy would be in the "real" context of instruction and perceived this as an opportunity to see for themselves. Thus, the role of the instructor/instructional coach took on a more collegial approach towards guiding the preservice and inservice teachers as they problem solve during their field experience. Some of the preservice teachers reported using the exploration to continue refining their understanding and clarify lingering misconceptions about the strategies they learned, but for the majority, the instructional coaching was focused on helping them work out technical issues of classroom context such as time and classroom management. The instructional coaching for the inservice teachers, on the other hand, remained focused primarily on working out the nuances of integrating the new strategies into their existing instructional practices. They seemed to have been more focused on issues such as adapting the strategies to the diverse learning needs in their classrooms and achieving results. The exploration was likely to have influenced the STEB of the preservice and inservice teachers because it provided yet another opportunity for mastery learning experiences (Bandura, 1977). 


\section{General Implications}

\section{General Implications for Practice}

The findings of this collected papers dissertation have significant implications for positively influencing elementary science education. Foremost, they provide a practical and potentially highly-transferrable approach to directly influence science teaching efficacy beliefs among inservice and preservice teachers. Though the nuances of employing CAIC cannot be divorced from the local contexts of implementation, the methods (modeling, coaching, scaffolding, articulation, reflection, exploration) can be applied universally. Additionally, as a novel application of instructional coaching practices to preservice teacher training, the CAIC model warrants further exploration as a potentially viable reform-based alternative to the traditional elementary science methods courses. This new approach causes science teacher educators to view students as apprentices (Collins, Brown, \& Newman, 1989), which can ultimately change the way preservice teacher training and learning is perceived.

CAIC may also change the way professional development as support for inservice teachers is perceived and presented. If further investigations support the efficacy of this model, then a strong instructional coaching alternative can emerge to the traditional models of delivering job-embedded professional development for teachers. Further, in The Bahamas, given time and resources, full-time instructional coaches in schools using this model may prove a more effective approach to developing local elementary teachers’ STEB. Thus, it may eliminate the need for the coordinators and specialists and empower generalist teachers to develop their STEB and mastery of implementing the new inquiry- 
based curriculum. On the other hand, the model can be explored for its potential to provide a strong theoretical model to strengthen the hundreds of instructional coaching programs across the U.S., thereby improving the success of reformed-based curricula implementation and teaching innovations in schools.

\section{General Implications for Theory and Further Research}

Given that cognitive apprenticeship-based instructional coaching has shown to be a potentially effective means of positively influencing science teaching efficacy beliefs, two important general implications for theory and research can be derived from the findings in these collected papers:

Implication \#1: Cognitive apprenticeship-based instructional coaching may have the potential to positively influence preservice and inservice elementary teachers with different levels of science teaching efficacy beliefs.

The baseline measure of personal science teaching efficacy (PSTE) of the preservice teachers in the first study showed that they all entered the methods course with different levels of PSTE. Though a positive linear increase in the PSTE of all participants was observed throughout the course, the between-subjects test of the repeated measure analysis of variance further revealed that the growth means also varied significantly between the preservice teachers at each measurement. This suggested, therefore, that the influence of the various methods of the cognitive apprenticeship-based instructional coaching (coaching, modeling, scaffolding, etc.) on individual preservice teachers' PSTE were likely not uniform or linear. The qualitative findings further supported this, as the 
preservice teachers attributed various levels of significance to how much they perceived that respective CAIC methods influenced their STEB development. For example, some identified the modeling as being most beneficial to building their confidence, others said the scaffolding, while some did not express great confidence until their field experience as reflected in one of the preservice teacher's comment cited in chapter two.

Similarly, in the second study, the qualitative findings concluded unequivocally that the inservice teachers too valued each of the CAIC methods differently, as reflected in the outcomes in Table 16. This is a particularly important implication because of the fact that preservice and inservice teachers inherently present to a learning situation with different levels of STEB, which demands approaches that can adequately address the diversity of needs and abilities within a general learning environment, such as a methods course or a professional development program.

Implication \#2: Cognitive apprenticeship-based instructional coaching may potentially provide a means of expeditiously achieving positive results in preservice and inservice elementary teachers' science teaching efficacy belief outcomes.

Paucity of time is a commonly cited challenge in designing and delivering effective preservice teacher training and professional development programs in science. The cognitive apprenticeship-based instructional coaching employed with the two studies in this dissertation show how positive results in science teaching efficacy beliefs might be achieved within a limited timeframe. The preservice and inservice teacher interventions were engaged over a short 14 and 10 weeks period respectively. However, the 
quantitative result in the first study showed a statistically significant positive influence on the preservice teachers' science teaching efficacy beliefs within the first seven weeks. In fact, the greatest increase in PSTE was observed during this period. While some of this growth may have been the result of maturation effects, it was shown that the observed difference between the growth in STOE (measured for maturation effect) and PSTE measured throughout the study were unlikely due to effects of maturation alone. Similarly, the qualitative findings in the second study showed that most of the references cited about the influence of the program were about the significance of the scaffolding, coaching, and modeling respectively. The scaffolding, modeling, and the majority of the coaching were done within the first seven weeks of the professional development program. The remaining three weeks were dedicated to guided exploration in the field. Therefore, the findings in both studies supported CAIC as a potentially viable means of producing significantly positive results in PSTE over a relatively short time.

Unfortunately, post-intervention measures of PSTE were only ascertained in the first study, which showed that there was no significant decrease in the PSTE growth observed as a result of participating in the reformed methods course upwards to seven weeks after. Therefore, further studies will be needed to determine the extent to which these results might be sustained over time. However, given the limited time normally allocated for teacher learning and professional development in science, the results of these collected papers may hold promise as a feasible step in the right direction towards achieving the goals of the current science education reform movement. 


\section{References}

Allinder, R. M. (1994). The relationship between efficacy and the instructional practices of special education teachers and consultants. Teacher Education and Special Education, 17, 86-95.

Aydin, S. \& Boz, Y. (2010). Pre-Service elementary science teachers’ science teaching efficacy beliefs and their sources. Elementary Education Online, 9(2), 694-704.

Bandura, A. (1986). Social foundations of thought and action: A social cognitive theory. Englewood Cliffs, NJ: Prentice- Hall.

Bandura, A. (1977). Self-efficacy: Toward a unifying theory of behavioral change. Psychological Review, 84(2), 191-215.

Cantrell, P., Young, S., \& Moore, A. (2003). Factors affecting science teaching efficacy of preservice elementary teachers. Journal of Science Teacher Education, 14(3), 177-192

Collins, A. (2006). Cognitive apprenticeship. In R. K. Sawyer (Ed.) Cambridge Handbook of the Learning Sciences (pp. 47-60). Cambridge UK: Cambridge University Press.

Collins, A., Brown, J. S., \& Newman, S. E. (1989). Cognitive apprenticeship: Teaching the crafts of reading, writing, and mathematics. In L. B. Resnick (Ed.), Knowing, learning, and instruction: Essays in honor of Robert Glaser (pp. 453-494). Hillsdale, NJ: Lawrence Erlbaum Associates.

Darling-Hammond, L. (2000). Teacher quality and student achievement: A review of state policy evidence. Education Policy Analysis Archives, 8(1), 50.

Davenport, T. H. (2005). Thinking for a living: How to get better performance and results from knowledge workers. Boston, MA: Harvard Business School Press.

Denton, C. A., \& Hasbrouck, J. (2009). A description of instructional coaching and its relationship to consultation. Journal of Educational and Psychological Consultation, 19(2), 150-175.

Enoch, L. G., \& Riggs, I. M. (1990). Further development of an elementary science teaching efficacy belief instrument: A preservice elementary scale. School Science and Mathematics, 90(8), 694-706.

Knight, J. (2009). Coaching: Approaches and perspectives. Thousand Oaks, CA: Corwin Press. 
Pea, R. D. \& Collins, A. (2008). Learning how to do science education: Four waves of reform. In Y. Kali, M. Linn, \& E. Roseman (Eds.) Designing coherent science education: Implications for curriculum, instruction, and policy (pp. 3-12). New York: Teachers College Press.

Piaget, J., \& Cook, M. T. (1952). The origins of intelligence in children. New York: I nternational Universities Press.

The Bahamas Guide. (2013). Foreign Investment in The Bahamas. Retrieved on February 10, 2015 from: http://thebahamasguide.com/business-investment/foreigninvestment

Wiggins, G., \& McTighe, J. (1998). Understanding by design. Alexandria, VA: Association for Supervision and Curriculum Development.

Yilmaz, H., \& Huyuguzel Cavas, P. (2008). The effects of the teaching practice on preservice elementary teachers' science teaching efficacy and classroom management beliefs. Eurasia Journal of Mathematics, Science \& Technology Education, 4(1), 45-54. 
VITA

\section{TEO O.H.COOPER}

Born, Nassau, The Bahamas

2002-2007

Bachelor of Education (B.Ed.)

Biology/Combined Science

The College of The Bahamas

Nassau, Bahamas

2007-2008

Master of Science (M.S.)

Higher Education Administration

Florida International University

Miami, Florida

2008-2011

Science Teacher

Miami-Dade County Public Schools

Miami, Florida

2011-2015

Doctor of Education (Ed.D.)

Curriculum \& Instruction: Science Education

Florida International University

Miami, Florida

2013-2014

Lecturer, Science Education

The College of The Bahamas

Oakes Field Campus

Nassau, Bahamas

2015-Present

Lecturer, Science Education

The College of The Bahamas

Northern Bahamas Campus

Freeport, Grand Bahama, Bahamas

\section{PUBLICATIONS AND PRESENTATIONS}

Cooper, T. (October, 2014). Promoting Gender Equity through Classroom Instructional Practices. Presented at the Anglican Board of Education Faculty Symposium, Nassau, Bahamas.

Cooper, T. (October, 2014). Access and Choice in Bahamian Higher Education. Presented at The College of The Bahamas School of Education Conference, Nassau, Bahamas. 
Cooper, T. (September, 2013). Practice, Professionalism, \& Patriotism in Bahamian Science Education. Presented at the first meeting of the Bahamas Association of Science Educators, Nassau, Bahamas.

Cooper, T., and Almodovar, J. (2008). Student Leadership Development in Higher Education: An Annotated Bibliography (Master’s Capstone). 